\title{
Development of Demographic Models to Analyze Populations with Multi-Year Data-Using Agassiz's Desert Tortoise (Gopherus agassizii) as a Case Study
}

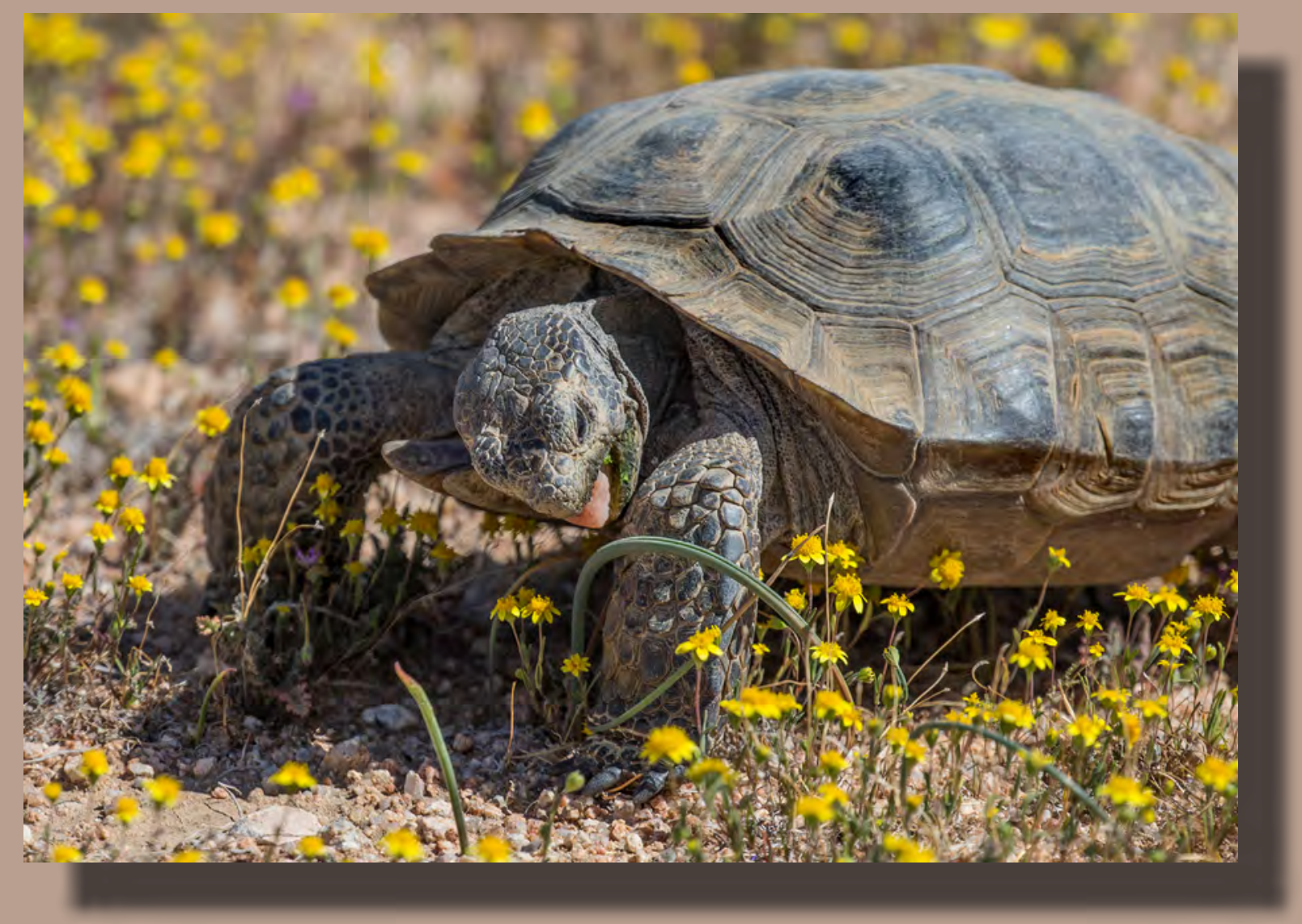

Open-File Report 2018-1094 
Cover: Desert Tortoise eating along an interpretive trail at the Desert Tortoise Research Natural Area interpretive center, eastern Kern County, California. Photograph taken by Freya Reder, independent contractor, April 2011, used with permission. 


\section{Development of Demographic Models to Analyze Populations with Multi-Year Data-Using Agassiz's Desert Tortoise (Gopherus agassizii) as a Case Study}

By Kristin H. Berry and Julie L. Yee

Open-File Report 2018-1094 


\section{U.S. Geological Survey, Reston, Virginia: 2021}

For more information on the USGS - the Federal source for science about the Earth, its natural and living resources, natural hazards, and the environment—visit https://www.usgs.gov or call 1-888-ASK-USGS.

For an overview of USGS information products, including maps, imagery, and publications, visit https://store.usgs.gov/.

Any use of trade, firm, or product names is for descriptive purposes only and does not imply endorsement by the U.S. Government.

Although this information product, for the most part, is in the public domain, it also may contain copyrighted materials as noted in the text. Permission to reproduce copyrighted items must be secured from the copyright owner.

Suggested citation:

Berry, K.H., and Yee, J.L., 2021, Development of demographic models to analyze populations with multi-year data-Using Agassiz's Desert Tortoise (Gopherus agassizii) as a case study: U.S. Geological Survey Open-File Report 2018-1094, 55 p., https://doi.org/10.3133/ofr20181094.

ISSN 2331-1258 (online) 


\section{Acknowledgments}

We thank Jonathan Rose, Diane Elam, and an anonymous person for reviews. We acknowledge the cooperation and contributions of the Bureau of Land Management, California Department of Fish and Wildlife (Game), and Desert Tortoise Preserve Committee, Inc. 



\section{Contents}

Acknowledgments …...........................................................................................................................

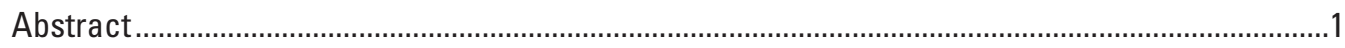

Introduction

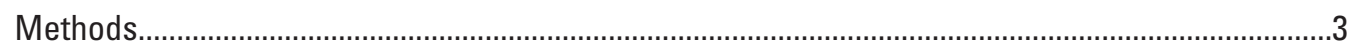

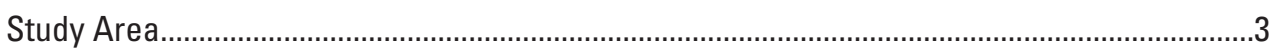

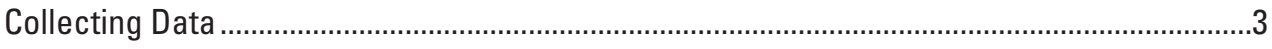

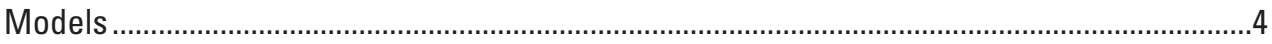

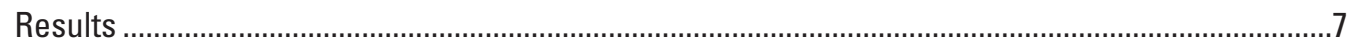

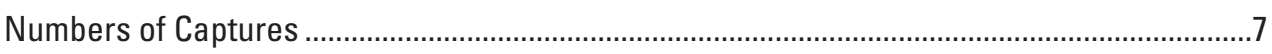

Convergence

Probability of Tortoises Growing from One Size/Age State to a Larger Size ............................8

Probability of Desert Tortoises Changing Location .....................................................................

Survival of Tortoises by Size/Age State ......................................................................................

Detection of Desert Tortoises between Censuses at the Annual Level .....................................9

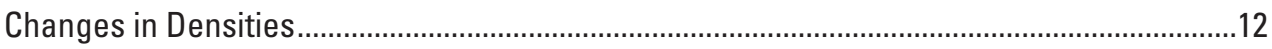

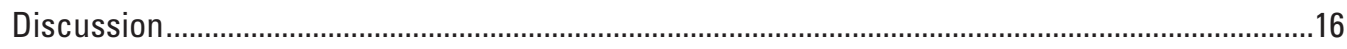

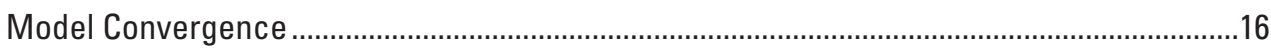

Strengths and Weaknesses of Models .......................................................................... 16

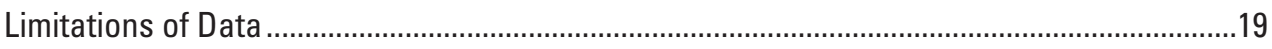

Low Detectability ..............................................................................................................

Population Trends and Changes Over Time....................................................................19

Low Survival and High Mortality Rates ...........................................................................2

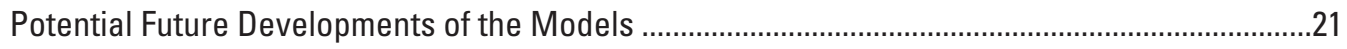

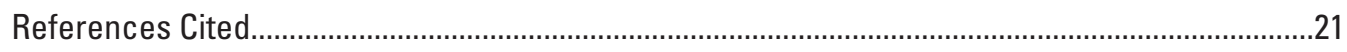

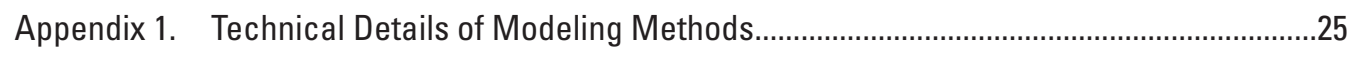

Appendix 2. Technical Details of Modeling Results ..................................................................38

Appendix 3. JAGS Code for Multistate JS Model...................................................................... 48

\section{Figures}

1. Path diagram illustrating hierarchical relationships between state variables, location, and survival, and state transitions .................................................................

2. Scatterplot of tortoise recapture ratio in relationship to winter precipitation..................7

3. Graph showing estimated probabilities of a desert tortoise growing to a larger size based on intervals between years for the 34-year study at the Desert Tortoise Research Natural Area, western Mojave Desert, California....

4. Graphs showing estimated median probabilities with 90-percent credible intervals of annual survival by sex and size-age class state for desert tortoises developed from mark-recapture data collected over a 34-year period at the Desert Tortoise Research Natural Area, western Mojave Desert, California

5. Graphs showing estimated median probabilities with 90-percent credible intervals of desert tortoises surviving $>5$ years by sex and size-age at the Desert Tortoise Research Natural Area, western Mojave Desert, California 
6. Graphs showing median probabilities with 90-percent credible intervals of detecting desert tortoises at the census level, when a tortoise is available to be detected at the Desert Tortoise Research Natural Area, western Mojave Desert, California

7. Graph showing density estimates of all sizes of desert tortoises per square kilometer for the 14 censuses conducted between 1979 and 2012 at the Desert Tortoise Research Natural Area, western Mojave Desert, California

8. Graphs showing density estimates of all sizes of desert tortoises per square kilometer occurring inside the fence and outside the fence by census at the Desert Tortoise Research Natural Area, western Mojave Desert, California, 1979-2012

9. Graphs showing density estimates of desert tortoises per square kilometer by survey census, sex, size-age class, and location with regard to the fence at the Desert Tortoise Research Natural Area, western Mojave Desert, California.....

\section{Tables}

1. Precipitation falling between 0 ctober 1 and March 31 during the time periods associated with each of the seven survey years at the Desert Tortoise Research Natural Area, western Mojave Desert, California ...

2. Probability of desert tortoises moving from inside to outside the fence or from outside to inside the fence between consecutive surveys by sex and size-age class at the Desert Tortoise Research Natural Area, western Mojave Desert, California, during the 1979-2012 study period

3. Comparison of assumptions on population closure, and assumptions or abilities in the analysis of detection probability, movements, demographic processes, population estimation and other issues for the Stratified Lincoln Index developed by Overton (1981) and Jolly-Seber

4. Comparison of density estimates at the Desert Tortoise Research Natural Area for 1979 and 1985 using the Stratified Lincoln Index method and the Jolly Seber model.

\section{Conversion Factors}

International System of Units to U.S. customary units

\begin{tabular}{lcl}
\hline \multicolumn{1}{c}{ Multiply } & By & \multicolumn{1}{c}{ To obtain } \\
\hline & Length & \\
\hline millimeter $(\mathrm{mm})$ & 0.03937 & inch (in.) \\
centimeter $(\mathrm{cm})$ & 0.3937 & inch (in.) \\
meter $(\mathrm{m})$ & 3.281 & foot (ft) \\
\hline & Area & \\
\hline square kilometer $\left(\mathrm{km}^{2}\right)$ & 0.3861 & square mile $\left(\mathrm{mi}^{2}\right)$ \\
square kilometer $\left(\mathrm{km}^{2}\right)$ & 247.1 & acre \\
\hline
\end{tabular}




\title{
Development of Demographic Models to Analyze Populations with Multi-Year Data-Using Agassiz's Desert Tortoise (Gopherus agassizii) as a Case Study
}

\author{
By Kristin H. Berry and Julie L. Yee
}

\section{Abstract}

We developed a model for analyzing multi-year demographic data for long-lived animals and used data from a population of Agassiz's desert tortoise (Gopherus agassizii) at the Desert Tortoise Research Natural Area in the western Mojave Desert of California as a case study. The study area was 7.77 square kilometers and included two locations: inside and outside the fenced boundary. The wildlife-permeable, protective fence was designed to prevent entry from vehicle users and sheep grazing. We collected mark-recapture data from 1,123 tortoises during seven annual surveys consisting of two censuses each over a 34-year period. Additional data were collected when marked tortoises were recovered dead and removed between survey years. We used a Bayesian modeling framework to develop a multistate Jolly-Seber model because of its ability to handle unobserved (latent) states and modified this model to incorporate the additional data from non-survey years. Three size-age states (juvenile, immature, adult), sex (female, male), two location states (inside and outside the fenced boundary), and three survival states (not-yet-entered, entered/alive, and dead/removed) were incorporated into the model. We calculated population densities and estimated probabilities of growth of the tortoises from one size-age state to a larger size-age state, survival after 1 year and 5 years, and detection. Our results show a declining population with low estimates for survival after 1 year and 5 years. The probability for tortoises to move from outside to inside the boundary fence was greater than for tortoises to move from inside the fence to outside. The probability for detecting tortoises differed by size-age state and was lowest for the smallest tortoises and highest for the adult tortoises. The framework for the model can be used to analyze other animal populations where vital rates are expected to vary depending on multiple individual states.

\section{Introduction}

Development of demographic models and calculations of vital rates are desirable for learning more about the potential for population growth, recovery, and survival of species in general and can be especially valuable for providing guidance on recovery efforts for threatened and endangered species (Beissinger and Westphal, 1998; Hellgren and others, 2000; Norris and McCulloch, 2003). Mark-recapture techniques and multistate models were used to develop a demographic model for the loggerhead sea turtle (Caretta caretta; Monk and others, 2011), and matrix models were used to evaluate headstarting as a management tool for other long-lived turtles, specifically the yellow mud turtle (Kinosternon flavescens) and Kemp's ridley sea turtle (Lepidochelys kempi; Heppell and others, 1996). Preparation of demographic models is also important as baseline, before a population or species becomes imperiled (for example, the alligator snapping turtle, Macrochelys temminckii; Folt and others, 2016]), and demographic models, when coupled with ecological and spatial models, can provide a basis for estimating risk from climate change for vulnerable species (Pearson and others, 2014). 
Agassiz's desert tortoise (Gopherus agassizii, hereinafter "desert tortoise" or "tortoise") is one of six species of North American tortoises; all have populations that are threatened, endangered, or in peril (Murphy and others, 2011; Berry and Aresco, 2014; Edwards and others, 2016). The desert tortoise was listed as a threatened species by the State of California in 1989 and by the Federal government in 1990 (U.S. Fish and Wildlife Service, 1990; California Department of Fish and Wildlife, 2016). A few years before the desert tortoise was listed as threatened, Turner and others (1987) developed the first life table for desert tortoises, drawing on mark-recapture data from 1977 through 1986 (primarily 1983-86). The life table included estimates of survival and fecundity for a population in the eastern Mojave Desert. The authors estimated that the population had the potential to increase at a rate of 2 percent per year. However, they noted that local extinctions could occur if tortoise habitat deteriorated irreversibly through human activities. Doak and others (1994) developed stage-based demographic models for the desert tortoise, using mark-recapture data from eight study areas in the western Mojave Desert. According to Doak and others (1994), the models predicted population declines, and the populations were at risk of extinction within decades. Wisdom and others (2000) followed with an analysis of vital rates and population growth, and Reed and others (2009) conducted a vital rate sensitivity analysis for females only. Authors of the latter three studies emphasized the relative importance of adult survival compared with survival of the smaller, younger size classes in recovering tortoise populations (Doak and others, 1994; Wisdom and others, 2000; Reed and others, 2009). However, Hellgren and others (2000, p. 1297), in a study on the demography of the related Texas tortoise (Gopherus berlandieri), emphasized that high survival of early life stages (hatchlings) was "necessary for population persistence."

To demonstrate new methods for modeling demographic attributes, we used data from a long-term study of desert tortoise populations at the Desert Tortoise Research Natural Area (Natural Area) as a case study. In 1979, Berry and others (1986) established a 7.77-square kilometers $\left(\mathrm{km}^{2}\right)$ study area centered on an interpretive kiosk at the Natural Area in the western Mojave Desert. The study area was divided into two portions, 58 percent inside the protective fenced boundary and 42 percent outside the fence, where land received considerable use from human activities (recreational vehicle use, camping, and sheep grazing). The boundary fence was made of hog wire, raised off the ground, and wildlife-permeable. The long-term objectives were to track changes in population attributes inside and outside the fence over time and to determine the effects of visitor use on the tortoise population. The authors used the stratified Lincoln Index (Overton, 1981) to assess densities between the first annual survey in 1979 and the second annual survey in 1985. They reported declines in populations both inside and outside the fence in the 6-year period and also noted other demographic attributes (size-age class structure, sex ratios, mortality, and causes of death).

Our objectives were to develop demographic models using modern mark-recapture modeling techniques (Williams and others, 2002; Royle and Dorazio, 2008, 2012; Link and Barker, 2010; Kéry and Schaub, 2012; among others). To apply the models, we used some datasets from the mark-recapture surveys of tortoises at the Natural Area. Specifically, we estimated:

- Probabilities of a tortoise transitioning from a smaller to a larger size-age state;

- Probabilities that a tortoise changes its location with respect to the protective fence (inside-to-outside the fence versus outside-to-inside the fence);

- Probabilities of annual and 5-year survival by sex, location (inside or outside the fence), and size-age state;

- Probabilities of detecting a tortoise, given it was in the study area, by sex, location (inside or outside the fence), and size-age state, and, as a secondary objective, the potential influence of precipitation on the detectability of tortoises; and

- Total population sizes among the sexes, size-age states, and locations (inside and outside the fence) for each sampling year.

In this Open-File Report, we report a model for analyzing multi-year demographic data for long-lived animals and use selected datasets from a population of Agassiz's desert tortoise at the Desert Tortoise Research Natural Area in the western Mojave Desert of California as a case study to describe the model. We then used the model and datasets along with several other datasets on vegetation, clinical signs of disease and trauma on the tortoises, causes of death and annualized mortality rates, predators, and anthropogenic impacts for a journal article (Berry and others, 2020). 


\section{Methods}

\section{Study Area}

The $7.77-\mathrm{km}^{2}$ study area was located at the southeastern corner of the Desert Tortoise Research Natural Area in eastern Kern County, California, at elevations of 740-790 meters (m). The study area was divided by the Natural Area boundary fence into inside $\left(4.53 \mathrm{~km}^{2}\right)$ and outside $\left(3.24 \mathrm{~km}^{2}\right)$ portions. The fence was made of hog wire and was raised about 25 centimeters $(\mathrm{cm})$ off the ground to allow passage of wildlife and to protect tortoises and habitat inside the fence from sheep grazing and uncontrolled recreational vehicle use, which occurred outside the fence (details in Berry and others, 1986). Perennial vegetation was composed of several associations of creosote bush scrub (California Department of Fish and Game, 2010). Three of the more common and dominant species of shrubs included creosote bush (Larrea tridentata), white bur-sage (Ambrosia dumosa), and rayless goldenhead (Acamptopappus sphaerocephalus). Most precipitation, typical of the western Mojave Desert, occurs in late fall and winter (Rowlands, 1995). Twenty-year annual norms for the hydrologic water year (October 1-September 30) were 141.1 millimeters $(\mathrm{mm})$ and fall-winter norms were $112.5 \mathrm{~mm}$ (PRISM, www.prism.oregonstate.edu/).

\section{Collecting Data}

We conducted censuses of the tortoise population in 7 survey years $(1979,1985,1989,1993,1997,2002,2012)$ spanning 34 years and at intervals ranging from 4 to 10 years. In each survey year, two back-to-back censuses occurred in spring between late March and the first week of June at the height of tortoise activity (Zimmerman and others, 1994). A total of 14 censuses occurred. The field team sought tortoises by walking transects less than or equal to $10 \mathrm{~m}$ apart, covering the entire plot with north-south transects followed by east-west transects or vice versa. When a tortoise was found for the first time, it was assigned a unique identification number and notched in a pattern conveying the unique number on one or more marginal scutes. Throughout this report, unless otherwise noted, we used the term "capture" to refer to the first-time capture of an unmarked tortoise or recapture of a marked tortoise. We also use the term "detection" to refer to the capture of a tortoise or recovery of a dead tortoise.
Subsequent to the first capture and as tortoises were observed, data were recorded on identification numbers, locations and standard metrics: straight-line carapace length at the midline (MCL, in millimeters) and weight (in grams) for all tortoises and sex for tortoises $\geq 180 \mathrm{~mm}$ MCL (see Berry and Christopher [2001] and Jacobson [2014] for examples of data sheets that we used). During the surveys, field workers also collected and photographed shell-skeletal remains and recorded the locations of the remains. The remains were later reassembled (if necessary) and analyzed in the laboratory to determine size, sex, and if it was a marked tortoise (Berry and Woodman, 1984; Berry and Christopher, 2001).

In addition to data collected on the 14 censuses, tortoises were sometimes found during non-census periods, either opportunistically or during other research activities in the study area. These encounters occurred before the first annual survey (before 1979), between the seven annual surveys, and after the last annual survey (after 2012), and provided supplemental information for our demographic model. Three types of non-census encounters were potentially useful - dead encounters of marked individuals, live encounters when a tortoise was first captured, and live encounters when a tortoise was last recaptured. Marked tortoises encountered dead were removed from the study area and, therefore, were unavailable for future recapture. Failure to account for these removals would lead to underestimates of detection probability. Occasionally a tortoise was captured live before being recaptured during a census year. We considered including these opportunistic captures because they represented a more accurate start year of when that tortoise was known to be in the population and available for detection than we would have by relying only on encounters during the survey years. Sixty-six tortoises were captured live opportunistically (that is, not on a survey) and 34 of the 66 tortoises were recaptured during a census year. However, there were relatively few of them ( 3 percent; 34 of 1,123 modeled tortoises) and they generally occurred shortly before a census recapture. Ultimately, we did not include them in the model because the opportunistic captures would provide relatively little additional information. The same was true for tortoises recaptured live during non-survey years and then not seen again. We also considered including these opportunistic recaptures; however, there were relatively few of them $(<3$ percent; 29 of 1,123 modeled tortoises) too, and they generally occurred shortly after a census observation. Including them in the model would have provided relatively little information. 


\section{Models}

We used mark-recapture data from 1,123 tortoises to develop a multistate Jolly-Seber (JS) model to describe size-age, locations relative to the boundary fence, and survival (states) of marked and recaptured tortoises, and to estimate densities in each state category as well as by sex (Jolly, 1965; Seber, 1965; Schwarz and Arnason, 1996; Link and Barker, 2010; Kéry and Schaub, 2012; Royle and Dorazio, 2012). Jolly-Seber models are applied to marked animal data by expressing the encounter pattern of each individual in terms of a likelihood function for the given individual's probability of survival and recapture. For example, frequent redetections over an extended range of time support the likelihood of a high survival probability and a high recapture rate, whereas inconsistent redetections over an extended range of time support the likelihood of a high survival probability and low recapture rate, and a sequence of frequent redetections followed by no further redetections can indicate a likelihood of mortality. By producing estimates of capture probabilities, JS models can be used to jointly estimate the number of uncaptured individuals - hence, total population size or population density.

We hypothesized that size-age and sex could potentially affect the locations (inside fence versus outside fence) of tortoises, and that size-age, sex, and locations of tortoises could potentially affect their survival and detection rates. These states were subject to change (that is, state transitions) for individual tortoises in consecutive censuses as they grew from smaller to larger size-age, moved locations between inside and outside the fence, and in some cases died. When a marked tortoise was not redetected, then its status was unknown (or latent) and we lacked direct information on its size-age, location, and survival, and thus its inclusion in the population. Our encounter histories for desert tortoises included many unobserved (latent) states. We chose a Bayesian modeling framework to develop our multistate JS model because of its ability to handle unobserved (latent) states (Kéry and Schaub, 2012).

We summarized observed states of size-age, location, and survival status of tortoises into three categorical variables:

1. Size-age. We assigned each tortoise to one of three size-age classes based on carapace length (MCL):

(a) about 45-139 $\mathrm{mm}$, juvenile and small immature tortoises (hereinafter, "JV"); (b) $\geq 140-179 \mathrm{~mm}$, large immature tortoises (hereinafter, "IM"); and (c) $\geq 180 \mathrm{~mm}$, subadult (small) and moderate to large-sized adult tortoises (hereinafter, “AD”).

2. Location. We categorized the location of capture, recapture, or recovery of each tortoise as either inside or outside the fenced boundary of the Desert Tortoise Research Natural Area.
3. Live-dead status. We categorized the survival status of each tortoise at each of their detections as either live or dead; in cases when a tortoise was alive but moribund, we categorized it as dead.

Sex was assigned to adult tortoises based on secondary sex characteristics of the male (that is, longer and often upturned gular horn, concave posterior plastron in the male, longer tail, and larger size; Woodbury and Hardy, 1948). We defined sex only for AD tortoises. Sex of JV and IM tortoises was a latent variable, except for tortoises later recaptured or recovered as adults when their sexes could be determined.

We applied biological assumptions when constructing hierarchical mathematical models (see section "Mathematical Models" in appendix 1) for the probability of a state transition between consecutive censuses in terms of the time since the last census and other state variables, either observed or latent. For example, tortoises in our model were allowed to transition from smaller to larger size-age states according to a probability function based on the time between censuses, whereas we assumed zero probability of transitioning from larger to smaller size-ages. During periods of drought, it was possible for the MCL of tortoises to shrink and potentially be placed into a smaller size-age than an earlier census. However backward growth never occurred between our three size-age state categories and we assumed it to have zero probability in our models. We use a path diagram to illustrate the hierarchy of relationships among state variables and other covariates, and their effects on state transition and detection processes (fig. 1).

Tortoises in our model were also allowed to move locations freely between inside and outside the fence, and we modeled two probability functions - one for the probability of changing from an inside location to an outside location, and another for the probability of changing from an outside location to an inside location. We allowed location transition probabilities to vary as a function of sex and size-age class, in accordance with differences in home range sizes between these demographic classes. In general, adult males have larger home ranges than adult females and the smaller, younger tortoises have smaller home ranges (Harless and others, 2009; Hazard and others, 2015). We reasoned that individuals with larger home ranges would have larger rates of location changes and may travel outside the study area on a short- or long-term basis.

Because surveys were conducted at irregular time intervals, sometimes as short as 1 month and other times as long as 1 decade, we modeled the probability of surviving from one survey to the next survey as the annual survival probability raised to a power equal to the number of years since the previous survey (that is, interval survival $=$ [annual survival] $\wedge$ [time since last census]). We modeled annual survival probability as a function of sex, size-age class, and location. 


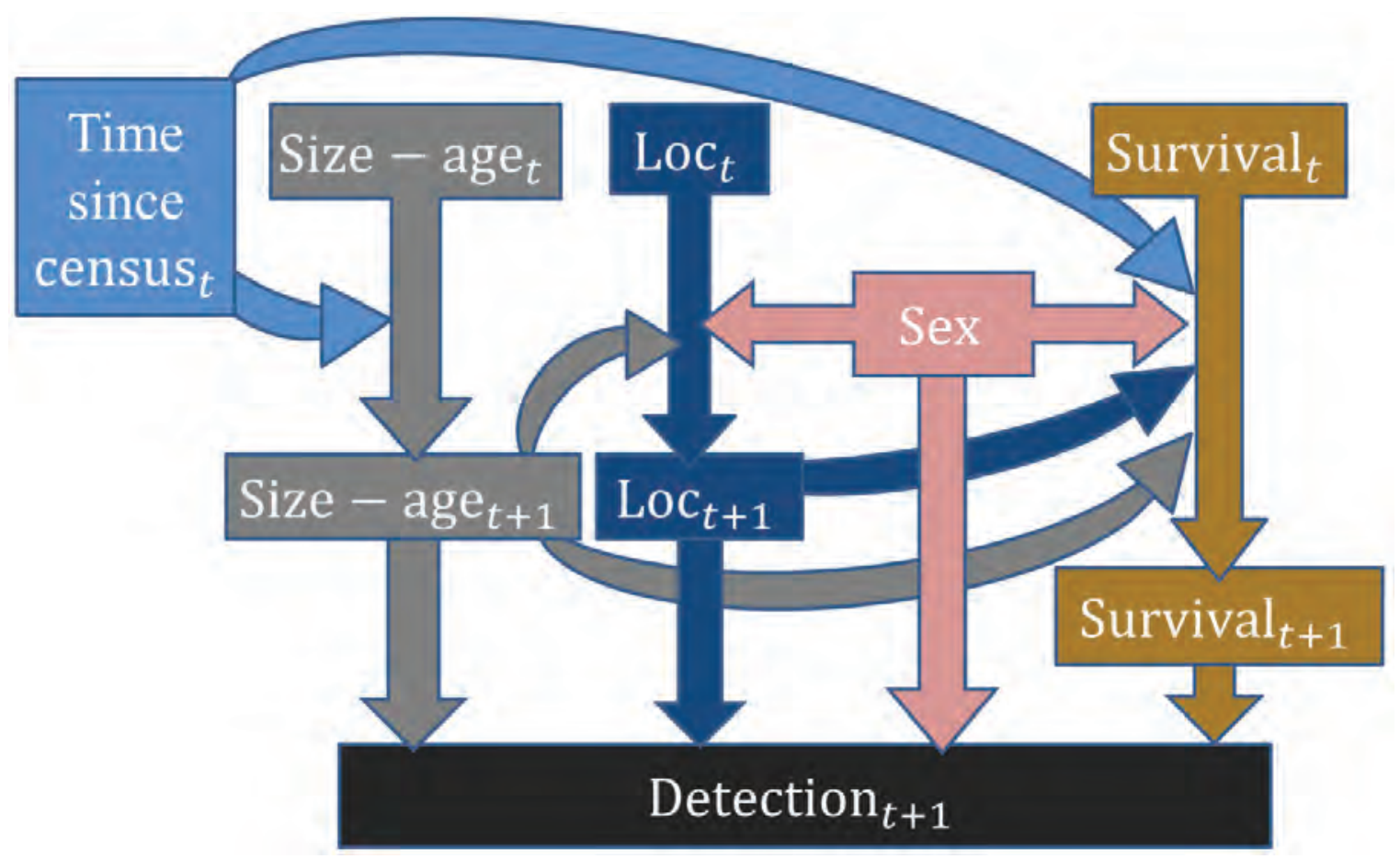

Figure 1. Hierarchical relationships between state variables (size-age [gray boxes], location [dark-blue boxes], and survival [mustard boxes]) and state transitions (vertical arrows between state variables going from time $t$ to time $t+1$ ). Other covariates include time since last census (years since time $t$, light-blue box) and sex (pink box). Arrows pointing to arrows represent the effects of covariates and state variables on the probabilities of other state transition processes. Arrows pointing to detection represent the effects of sex and state variables on the probability of detection of a given tortoise.

In the final component of our hierarchical model, we modeled the process of capturing and recapturing tortoises by allowing detectability (that is, the probability of capture or recapturing a tortoise given it is there to capture) to vary as a function of sex, size-age class, and location. Sex differences could occur because males have greater movement activity and are more likely to spend time above ground where they are easier to find. Size-age differences could occur because large mature tortoises are easier to detect than small young tortoises. We expected tortoises outside the fence to be easier to detect than tortoises inside the fence because substantial parts of the area outside the fence gradually became denuded and the ground compacted due to off-road vehicle activity and sheep grazing. Therefore, our models assume that detectability outside the fence was equal to or greater than detectability inside the fence.

We used a Bayesian implementation of a multistate JS model as outlined by Kéry and Schaub (2012), using a 14-interval model, with several key modifications:

1. Censuses were conducted at unequal intervals ranging from 1 month (between consecutive censuses in the same year) to 10 years (from 2002 through 2012); therefore, we allowed the probability of growth and survival between intervals to depend on the length of time of the preceding interval.
2. We expanded the state-space in our multistate model to accommodate not just multiple states of a variable but also multiple state-space variables (size-age states JV, IM, and AD; location states Inside and Outside; and entry/survival states Not-yet-entered, Alive and present, and Dead or removed or permanently emigrated; see appendix 1). Following the assumptions illustrated in fig. 1, we modeled the state space hierarchically, for example, allowing the probability of entry/survival to depend on location and size-age states, and location states to depend on size-age (see section "Mathematical Models" in appendix 1 for details).

3. The standard multistate JS model assumes that dead animals are not observable, whereas in our study the carcasses of marked tortoises were often found during and between censuses and then removed. We incorporated death information into our model whenever available to account for these deaths and to better estimate survival probability (see section "Death Records" in appendix 1).

4. We modified the JS model in a manner that could accommodate data from non-census detections occurring at variable times midway during intervals (see section "Non-Census Data Modeling" in appendix 1). 
5. Age transitions in our model were one-way (for example, juveniles could become adults, but adults could not become juveniles); therefore, we non-randomly initialized the Markov chains for the Bayesian model simulations to avoid conflicts between randomized initial age and realized age after later intervals in the data. To ensure that chains were not converging to solutions that could be biased by their initial values, we applied highly contrasting rules when initializing different chains (see section "Initializing Markov Chains" in appendix 1). We considered the Bayesian simulations to converge when these chains converged to similar distributions.

We drew on monthly PRISM records for rainfall data for each of the fall-winter periods (October 1-March 31) preceding the annual surveys (table 1 ). We initially included precipitation in the detectability component of preliminary models as a continuous covariate. Timing and amounts of rainfall have a profound influence on above-ground activity for tortoises (Henen and others, 1998; Duda and others, 1999; Christopher and others, 2003). We reasoned that years with greater fall-winter precipitation had greater annual vegetation (forage) in spring, resulting in increased time that tortoises spent above ground during censuses, thus increasing their detectability. However, dense annual vegetation during such a spring could also obscure tortoises, especially the smaller ones, thereby reducing detection. As the vegetation dries, detection is likely to improve. In drought years, fewer tortoises are active above ground, potentially reducing detection (Henen and others, 1998; Duda and others, 1999). In cases where rain occurs in April or May during a drought year, tortoises may emerge to drink, thus potentially increasing detectability

Table 1. Precipitation falling between 0 ctober 1 and March 31 (winter rain) during the time periods associated with each of the seven survey years (1979, 1985, 1989, 1993, 1997, 2002, and 2012) at the Desert Tortoise Research Natural Area, western Mojave Desert, California.

[The precipitation figures are from PRISM records (www.prism.oregonstate.edu/) and were used in the preliminary model. Recapture ratio is a raw index of detectability calculated as the number of recapture events in a given year divided by the number of unique tortoises captured or recaptured that year]

\begin{tabular}{cccc}
\hline $\begin{array}{c}\text { Winter } \\
\text { years }\end{array}$ & $\begin{array}{c}\text { Spring } \\
\text { years }\end{array}$ & $\begin{array}{c}\text { Winter rain } \\
\text { (millimeters) }\end{array}$ & $\begin{array}{c}\text { Recapture } \\
\text { ratio }\end{array}$ \\
\hline $1978-79$ & 1979 & 172.32 & 0.9275 \\
$1984-85$ & 1985 & 117.51 & 2.112 \\
$1988-89$ & 1989 & 46.89 & 1.064 \\
$1992-93$ & 1993 & 316.81 & 0.713 \\
$1996-97$ & 1997 & 82.02 & 1.050 \\
$2001-02$ & 2002 & 41.73 & 1.240 \\
$2011-12$ & 2012 & 97.31 & 1.556 \\
\hline
\end{tabular}

in the census with the precipitation event. (Such an event occurred in May of the 14th census, resulting in emergence of several tortoises).

The initial results from the preliminary models suggested a potentially non-significant or negative correlation between precipitation and detectability. Therefore, we re-evaluated the potential for meaningful precipitation effects and ultimately decided to exclude precipitation from our final models. In that evaluation, we defined, for each year, a raw index of detectability based on the ratio of recaptures (number of times a tortoise was recaptured in that year, ignoring any history from previous years) divided by first-time captures (the time a tortoise was captured for the first time that year, ignoring previous years). In table 1, we show the recapture ratio and annual precipitation across years. The relationship between recapture ratio and winter precipitation is unclear, due to the sparseness of years and the large leverage of an unusually high precipitation $(317 \mathrm{~mm})$ in the 1993 spring year combined with a relatively low recapture rate. The relatively low recapture ratio may be associated with the high mortality from the epidemic of an infectious upper respiratory tract disease caused by species of Mycoplasma (Jacobson and others, 1991; Brown and others, 1999). The analysis with this year suggests a potentially negative relationship, whereas in the absence of this year, the relationship appears potentially positive (fig. 2). In either case, the pattern is highly variable and not statistically compelling. We decided that the data were too sparse and too variable to be meaningful, and we excluded precipitation from further modeling.

We used Markov Chain Monte Carlo (MCMC) simulations to fit and evaluate our JS model. We used the 'jagsUI package in R software as an interface for using Just Another Gibbs Sampler (JAGS) software to conduct these MCMC simulations (Plummer, 2003, 2016; Kellner, 2016; R Core Team, 2016). We initialized three Markov chains differently based on biologically contrasting assumptions about population demographics, and we examined trace plots and potential scale reduction factors to assess the chains for convergence (Gelman and others, 1997). These chains reflected the posterior distributions (that is, distributions of credible values for population demographic parameters) from which we derived our estimates of densities per square kilometer and state transition probabilities (that is, probabilities of growth, movement, and survival). We estimated population densities and probabilities by taking the median (50-percent quantile) of posterior distributions and 90-percent credible intervals (CI) by taking the 5-percent and 95-percent quantiles of the posterior distribution. To avoid cumbersome reporting, we present the median estimates, followed by the 90 -percent $\mathrm{CI}$ in parentheses. We considered differences in variables to be significant at $P \leq 0.1$, or if the 90-percent CIs did not overlap. We report all figures from our resulting models to two significant digits. 


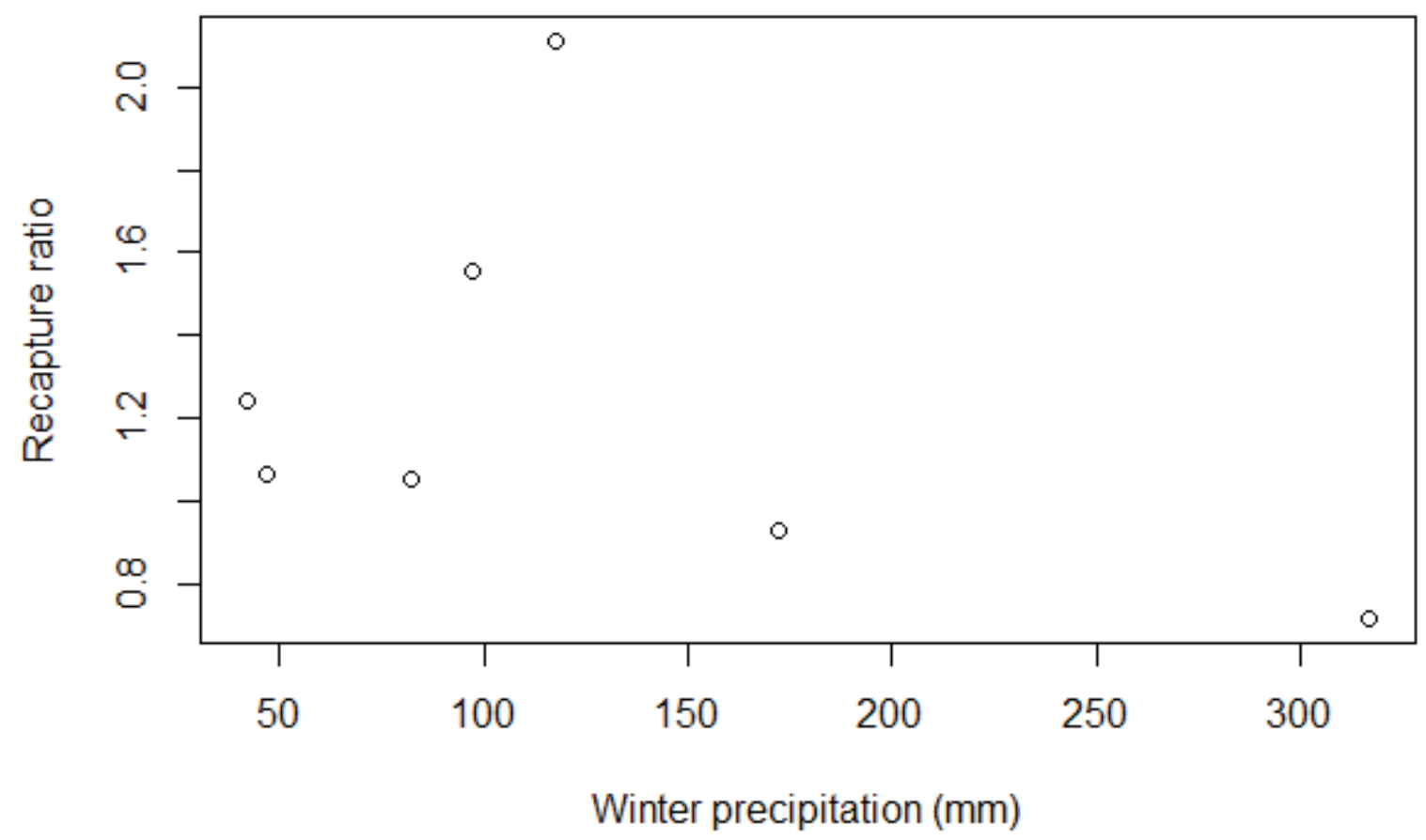

Figure 2. Tortoise recapture ratio in relationship to winter precipitation (in millimeters [mm]). Recapture ratio is a raw index of detectability calculated as the number of times a tortoise was recaptured in a given year divided by the number of times a tortoise was captured for the first time that year, ignoring any capture history from previous years.

\section{Results}

\section{Numbers of Captures}

Over the course of the period from 1979 to 2012, 1,120 desert tortoises were live captured and marked on surveys. An additional 3 desert tortoises were found dead and included with the 1,120 tortoises for modeling. Among the live captures, there were 420 females, 373 males, and 327 of unknown sex. Most (734) were AD, and 129 were IM and 257 were JV captures. Most (751) captures occurred inside, although 369 occurred outside. There were 1,119 live recapture events, with 606 female recaptures, 418 male recaptures, and 95 of unknown sex.

There were $58 \mathrm{JV}$ recaptures, $60 \mathrm{IM}$ recaptures, and $1,001 \mathrm{AD}$ recaptures. Most (825) recaptures occurred inside the fence compared with outside (294). Of these desert tortoises, 248 were recovered dead. Slightly more than one-half of the dead recoveries were female (136) compared to 87 males and 25 of unknown sex. Most (223) were AD, 10 were IM, and 15 were JV. Most dead recoveries occurred inside the fence (215) compared with outside (32).

\section{Convergence}

Following recommendations by Gelman and others (1997) that potential scale reduction factors $(\hat{r})$ should be close to 1 and much less than 1.2 for acceptable convergence, our JS model satisfied the Gelman-Rubin assessment for convergence for some but not all model parameters (appendix 2). We reached convergence for all model parameter coefficients associated with movement and the effects of sex and location on survival and detection probabilities after 142 hours of processing time. Our model did not reach convergence for any parameters associated with size-age variables, including all parameter coefficients for growth processes and the slope parameter coefficients for the effects of size-age on movement, survival, and detection probabilities. Repeated updates to the Markov chains culminating in approximately 200 hours of additional processing time resulted in no improvements to model convergence nor changes in the distributions of the chains. However, when samples from these chains were combined to estimate posterior distributions, their posterior distribution standard deviations were consistently smaller $(<1)$ than the wide prior standard deviations (100) we specified prior to modeling, indicating that there was information in the data to bring the chains closer together (for additional details, see appendix 2). 


\section{Probability of Tortoises Growing from One Size/ Age State to a Larger Size}

Among three size-age classes (JV, IM, AD), three growth transitions were possible across the wide range of intervals between censuses ( 1 month to 10 years). We modeled the transitions of JVs growing to IMs, JVs growing to ADs, and IMs growing to ADs. The probability of growth to a larger size-age is highest for the IMs growing to the AD transition, with this probability increasing rapidly between years 1 and 5 (fig. 3). Tortoises of the IM size-age can reach adulthood within about 7 years. Tortoises in the JV size-age state take more years to achieve adult size but have the potential to reach breeding size in 10 years, depending on initial size within the JV size-age state. The credible intervals are wide for both the JV and IM size-age states to transition to the AD size-age state. However, tortoises in the JV size-age state have a low probability of transitioning to the next size-age state, the IM tortoises, and the probability of transition has a narrow credible interval. As JV tortoises age, they pass into and out of the IM state over time, so that the probability of becoming IM increases for the first 3-4 years and decreases beyond that period as JVs that became IMs increasingly grow into the AD state.

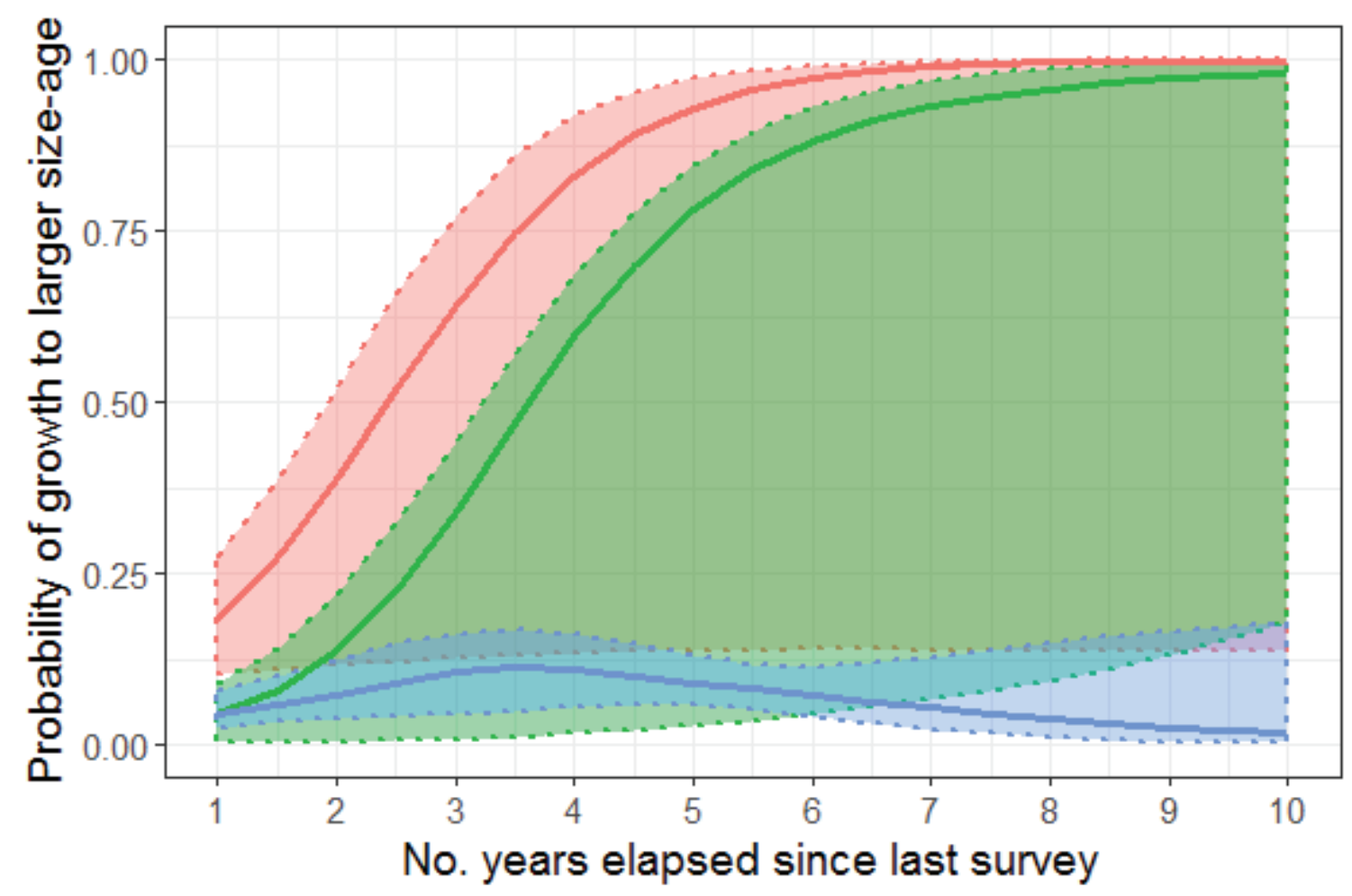

$\because \mathrm{IM}$ to $\mathrm{AD}=\mathrm{JV}$ to $\mathrm{AD}=\mathrm{JV}$ to IM

Figure 3. Estimated probabilities of a desert tortoise growing to a larger size based on intervals between years for the 34-year study at the Desert Tortoise Research Natural Area, western Mojave Desert, California. Bands of color refer to 90 -percent credible intervals. $A D$, small to large-sized adult tortoises; IM, large immature tortoises; JV, juvenile and small immature tortoises; No., Number of. 


\section{Probability of Desert Tortoises Changing Location}

Overall, the probability for tortoises to change locations regarding the boundary fence was low: from inside to outside the fence, the estimated probability ranged from a low of 0.019 to a high of 0.057 , and from outside to inside the fence, the estimated probability ranged from 0.068 to 0.145 . The probability of a tortoise moving from outside the boundary fence to inside was 184-percent greater (90-percent CI $=106$ to 300 percent) than vice versa (table 2). In general, the probability of a female changing location was lower than for males, but not significantly so. Females had a 27.8-percent lower probability of changing locations than males when averaging equally across the three size-age classes, but the 90-percent CI overlapped zero (90-percent CI $=-49.0$ percent to 3.2 percent). However, when considering only inside-to-outside movements, females were 48.5 percent less likely than males to change locations, with a significant credible interval (90-percent $\mathrm{CI}=-17.9$ to -68.0 percent). For tortoises changing location from outside to inside the fence, probabilities increased markedly with increasing size. When comparing movements between locations, the probabilities of movement from outside to inside the fence were higher for tortoises in the two larger size classes than vice versa, but not significantly so. Tortoises in the AD size-class were 70.3 percent more likely and tortoises in the IM size-class were 31.0 percent more likely than JV to move from outside to inside the fence; however, credible intervals overlapped zero (90-percent $\mathrm{CI}=-8.0$ to 198 percent, and -4.1 to 75.4 percent, respectively).

\section{Survival of Tortoises by Size/Age State}

The estimated probability of annual survival (survival of $>1$ year) did not differ much between sexes, size-age classes, and locations of tortoises: the median values for survival ranged from a low of 0.791 to a high of 0.862 (fig. 4). Annual survival for females averaged equally across all size classes and locations was 3.6 percent higher than for males, and statistically significant (90-percent $\mathrm{CI}=1.4$ to 5.8 percent). When averaging equally across size classes and for both sexes, annual survival was only 1.7 percent higher inside the fence than outside the fence, and not significant (90-percent $\mathrm{CI}=-0.76$ to 4.4 percent). When compounding the annual survival estimate over a longer period of 5 years, the estimated probability of a tortoise surviving $>5$ years was, overall, lower than 50 percent. Median estimates of 5 -year survival varied among cohorts based on different sex, size-age, and location (range $=0.324-0.477$; fig. 5), with 5-year survival of females 19.0 percent significantly higher than males (90-percent $\mathrm{CI}=7.0$ to 31.9 percent), and differences among locations and size-age classes remained not significant.

\section{Detection of Desert Tortoises between Censuses at the Annual Level}

For a given sex and size-age state, no significant differences existed between detections for tortoises occurring either inside or outside the boundary fence (fig. 6). The probability of detection was lowest for the smallest size-age class (range of median probabilities of detection: 0.578-0.593) and highest for largest size class (0.727-0.739), regardless of sex. Similarly, the 90-percent credible intervals were widest for the smallest size-age class and narrowest for the largest size-age class. Detection probabilities were significantly higher for larger tortoises than smaller tortoises. When averaging across both sexes, inside and outside, the detection probabilities were 24.8 percent $(90$-percent $\mathrm{CI}=13.9$ to 59.5 percent) higher for $\mathrm{AD}$ compared to $\mathrm{JV}$ tortoises, 10.4 percent (90-percent $\mathrm{CI}=6.2$ to 21.1 percent) higher for $\mathrm{AD}$ tortoises compared to IM tortoises, and 13.1 percent (90-percent $\mathrm{CI}=7.2$ to 31.7 percent) higher for IM tortoises compared to JV tortoises.

Table 2. Probability of desert tortoises moving from inside to outside the fence or from outside to inside the fence between consecutive surveys by sex and size-age class at the Desert Tortoise Research Natural Area, western Mojave Desert, California, during the 1979-2012 study period.

[The range of figures within the parentheses is 90 -percent credible intervals]

\begin{tabular}{ccc|cc}
\hline \multirow{2}{*}{$\begin{array}{c}\text { Size } \\
\text { class }\end{array}$} & \multicolumn{2}{c|}{ Females } & \multicolumn{2}{c}{ Males } \\
\cline { 2 - 5 } & Inside to outside & Outside to inside & Inside to outside & Outside to inside \\
\hline JV & 0.0190 & 0.0685 & 0.0374 & 0.0859 \\
& $(0.0064-0.0454)$ & $(0.0375-0.1317)$ & $(0.0143-0.0834)$ & $(0.0483-0.1586)$ \\
IM & 0.0238 & 0.0906 & 0.0458 & 0.1129 \\
& $(0.0124-0.0391)$ & $(0.0629-0.1295)$ & $(0.0274-0.0722)$ & $(0.0791-0.1599)$ \\
AD & 0.0293 & 0.1179 & 0.0568 & 0.1338 \\
& $(0.0201-0.0404)$ & $(0.0903-0.1507)$ & $(0.0411-0.0753)$ & $(0.1085-0.1894)$ \\
\hline
\end{tabular}




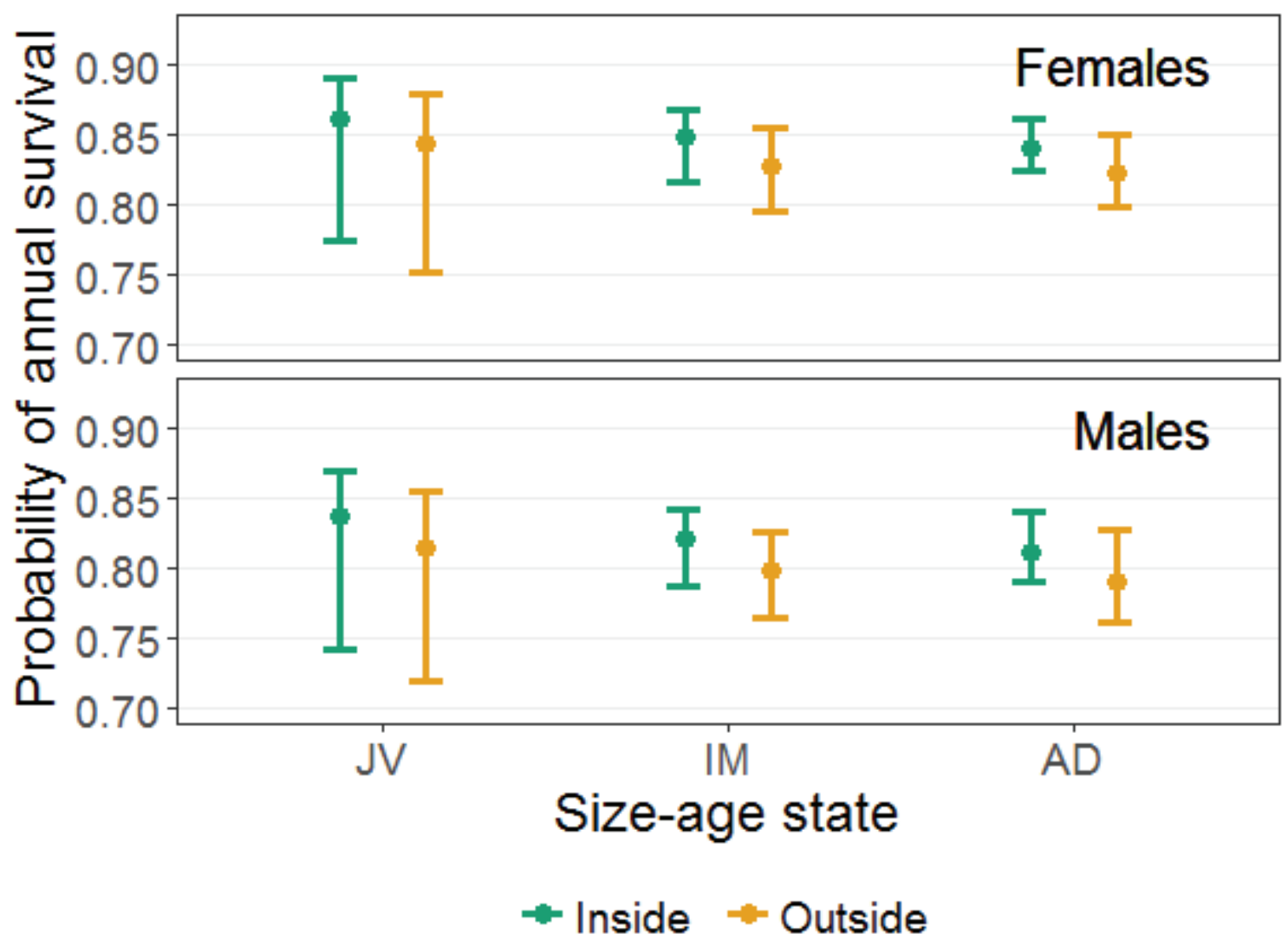

Figure 4. Estimated median probabilities (points) with 90-percent credible intervals (error bars) of annual survival by sex and size-age class state for desert tortoises developed from mark-recapture data collected over a 34-year period at the Desert Tortoise Research Natural Area, western Mojave Desert, California. AD, small to large-sized adult tortoises; IM, large immature tortoises; JV, juvenile and small immature tortoises. 


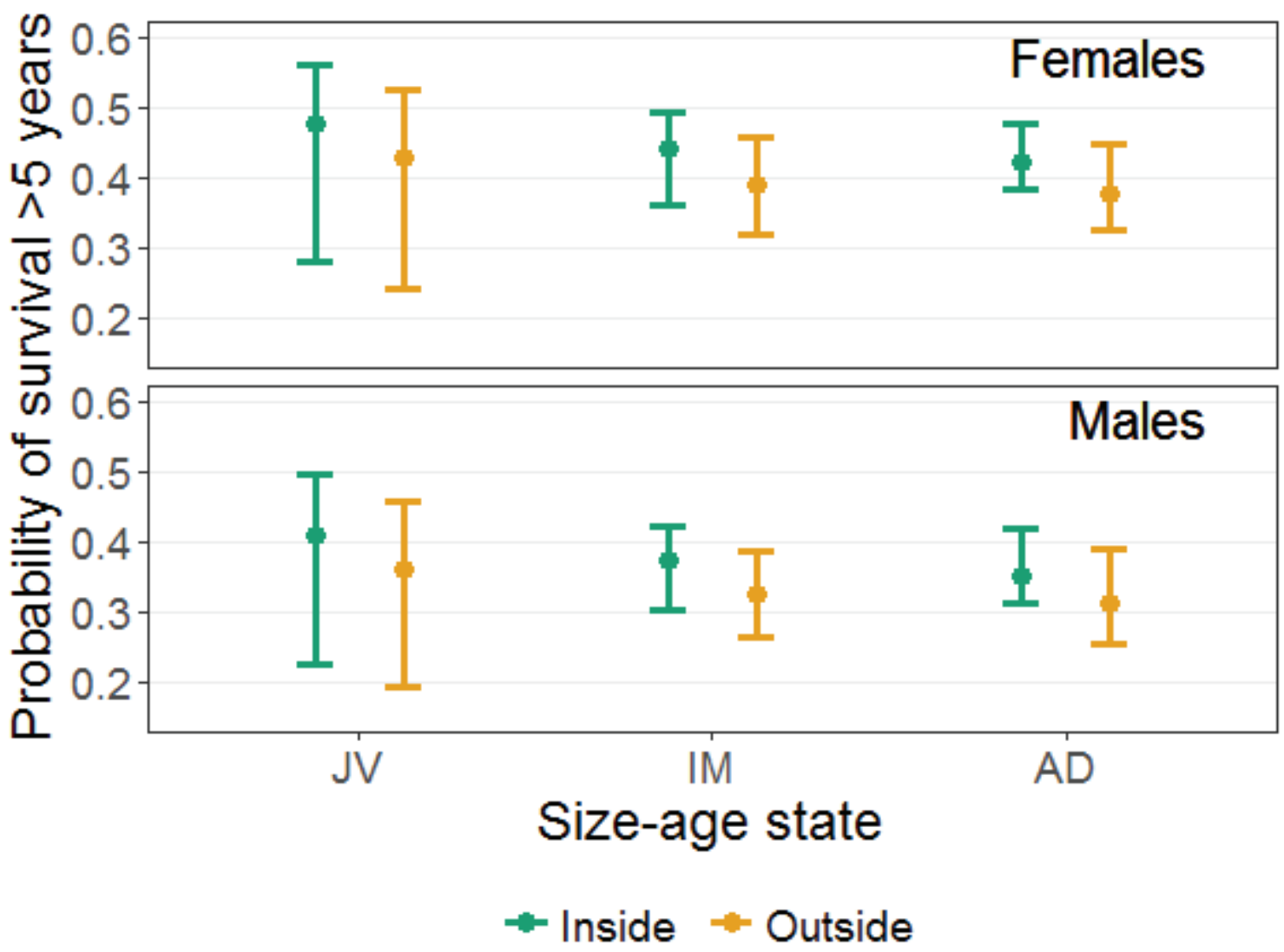

Figure 5. Estimated median probabilities (points) with 90-percent credible intervals (error bars) of desert tortoises surviving $>5$ years by sex and size-age at the Desert Tortoise Research Natural Area, western Mojave Desert, California. AD, small to large-sized adult tortoises; IM, large immature tortoises; JV, juvenile and small immature tortoises. 


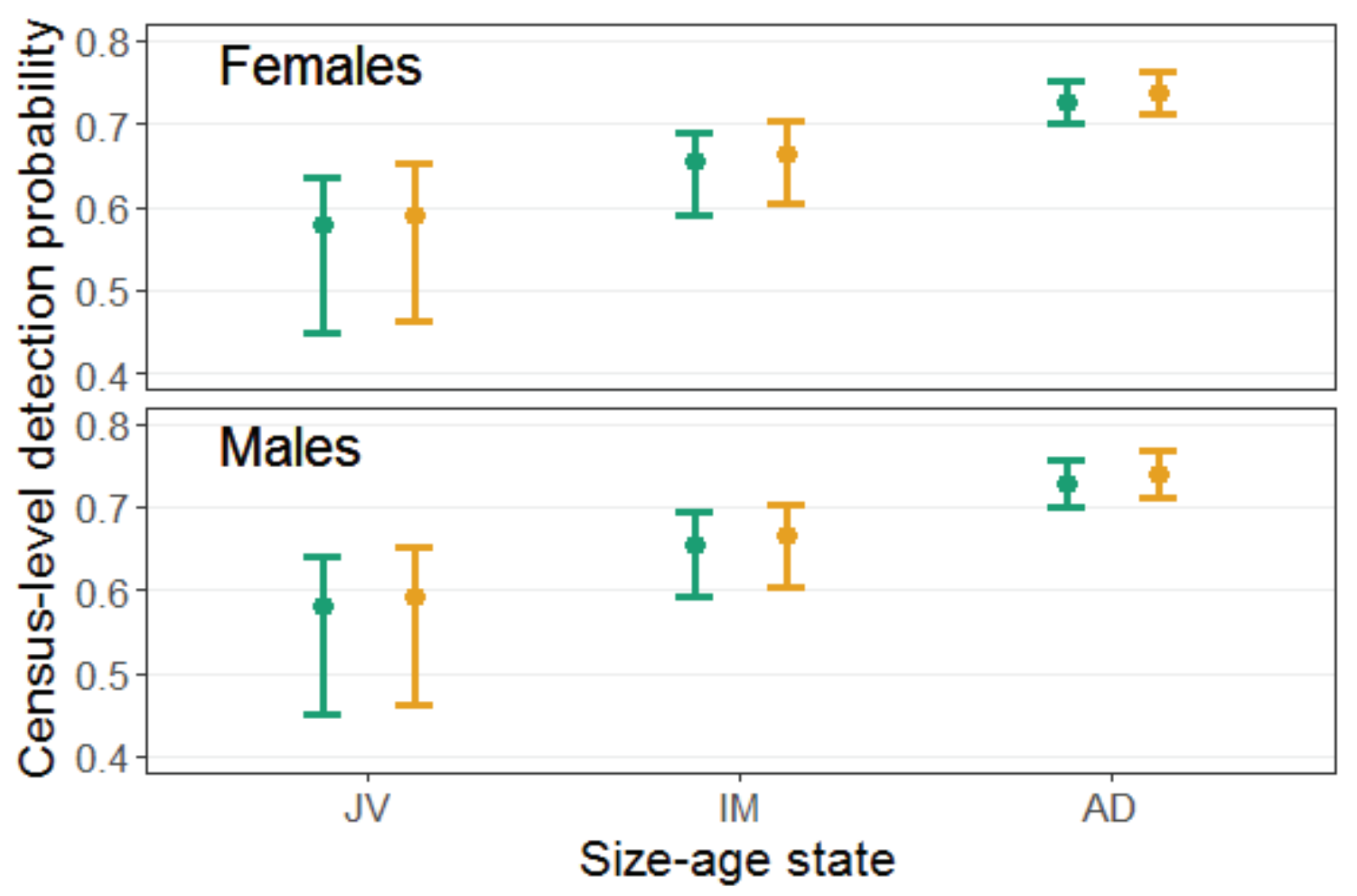

\section{Inside $\quad *$ Outside}

Figure 6. Median probabilities (points) with 90-percent credible intervals (error bars) of detecting desert tortoises at the census level, when a tortoise is available to be detected (that is, alive and present) at the Desert Tortoise Research Natural Area, western Mojave Desert, California. AD, small to large-sized adult tortoises; $\mathrm{IM}$, large immature tortoises; JV, juvenile and small immature tortoises.

\section{Changes in Densities}

Estimates of densities varied between censuses in a given survey year. Estimates were higher for the second censuses of years 1979, 1985, and 2012 inside the fence, and for 1979 and 1985 outside the fence (fig. 7). When estimated for the entire study area, densities of tortoises per square kilometer declined 87.5 percent $(90$-percent $\mathrm{CI}=86.3$ to 88.9 percent) from 80.6 to 10.2 tortoises per $\mathrm{km}^{2}$ (censuses 2 and 14) between 1979 and 2012 (fig. 8). Similar patterns were apparent when densities were arrayed separately by location (densities of tortoises occurring inside versus outside the boundary fence [fig. 7]). Overall, densities declined between the second censuses in 1979 and the second census in 2012 by 84.2 percent ( $82.5-86.0$ percent) inside the fence and 93.8 percent (92.0-95.2 percent) outside the fence. The lowest point in densities for both inside and outside the fence was in 2002, with lower densities overall outside the fence than inside. Between 2002 and 2012, densities of tortoises per square kilometer increased significantly from 9.9 to 14.3 inside the fence, whereas outside the fence, the changes in densities were not significant (from 4.17 to 4.32 tortoises per $\mathrm{km}^{2}$ ). By the last census in 2012, densities were 2.5 (90-percent $\mathrm{CI}=1.8$ to 3.3 ) times higher inside than outside the fence.

When densities were arrayed by sex, size-age class, and location (fig. 9), patterns similar to those shown in figures 7 and 8 are evident. The major factor influencing tortoise density was size-age class. Adults formed the larger portion in all survey years. However, for a population to recover and develop stability after catastrophic loss, sufficient juveniles must survive to maturity to ensure perpetuation of the population. Therefore, abundance and survival of juvenile tortoises is an important issue. 


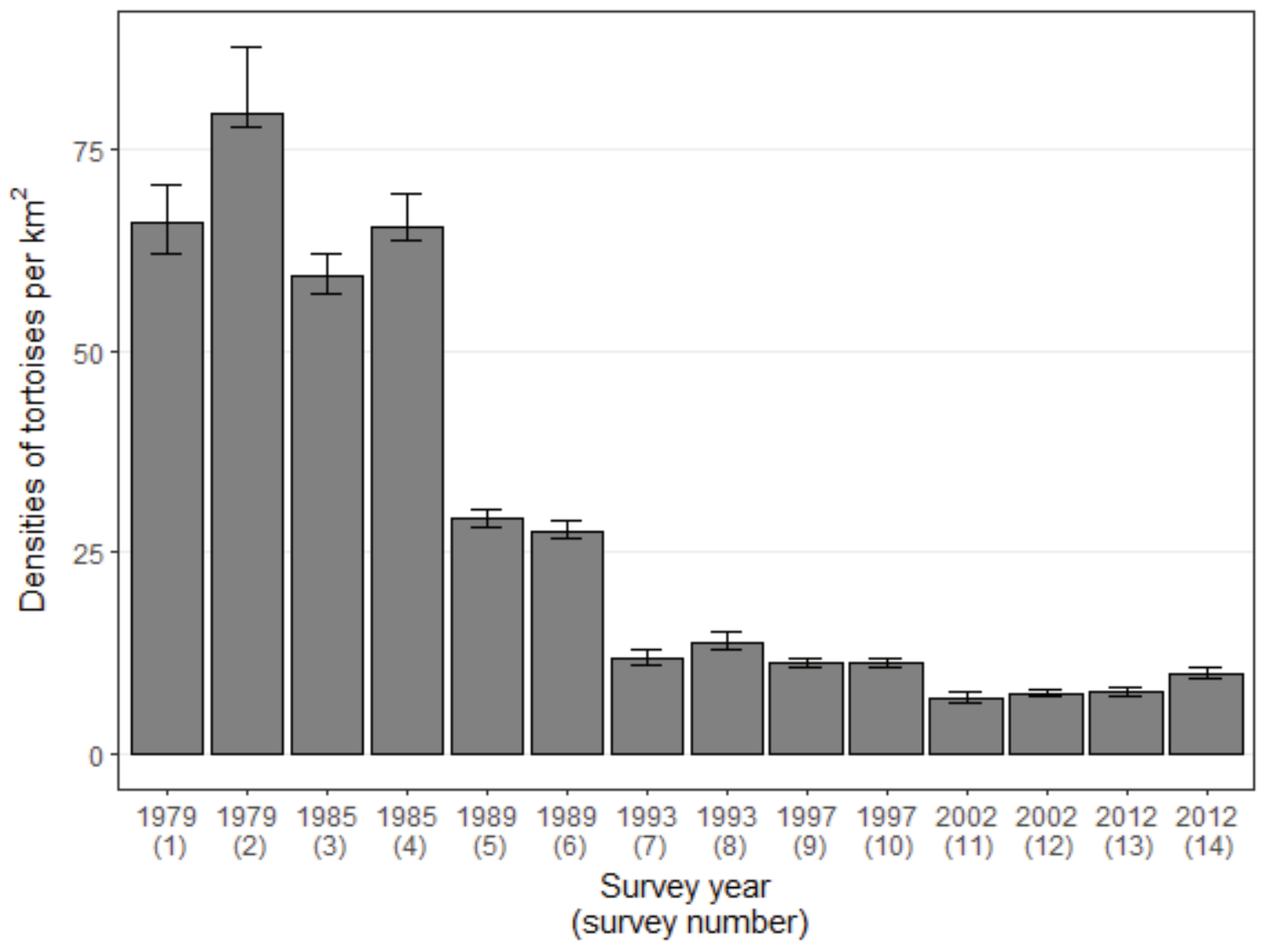

Figure 7. Density estimates of all sizes of desert tortoises per square kilometer $\left(\mathrm{km}^{2}\right)$ for the 14 censuses conducted between 1979 and 2012 at the Desert Tortoise Research Natural Area, western Mojave Desert, California. Error bars are 90-percent credible intervals. 


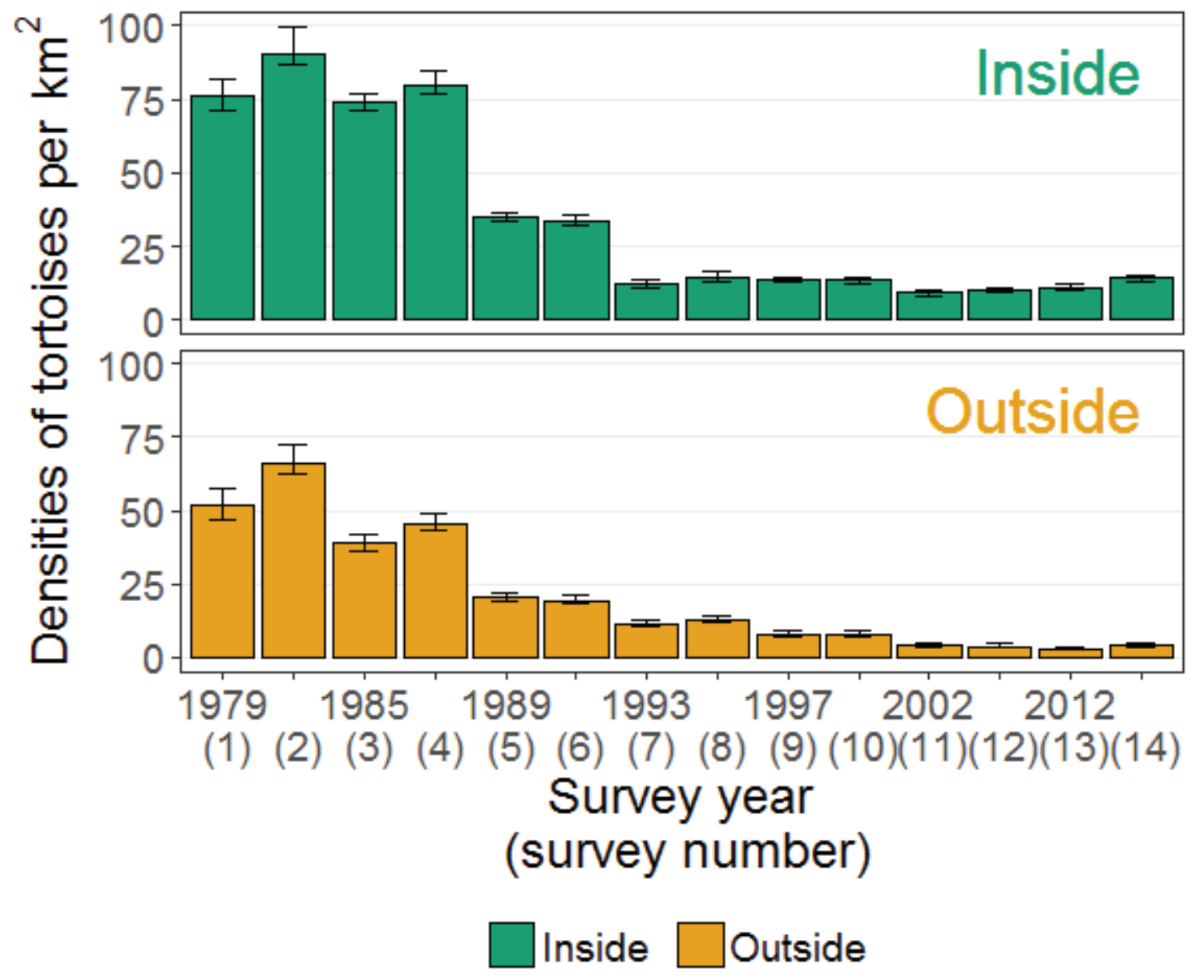

Figure 8. Density estimates of all sizes of desert tortoises per square kilometer $\left(\mathrm{km}^{2}\right)$ occurring inside the fence (top) and outside the fence (bottom) by census at the Desert Tortoise Research Natural Area, western Mojave Desert, California, 1979-2012. Error bars are 90-percent credible intervals. 


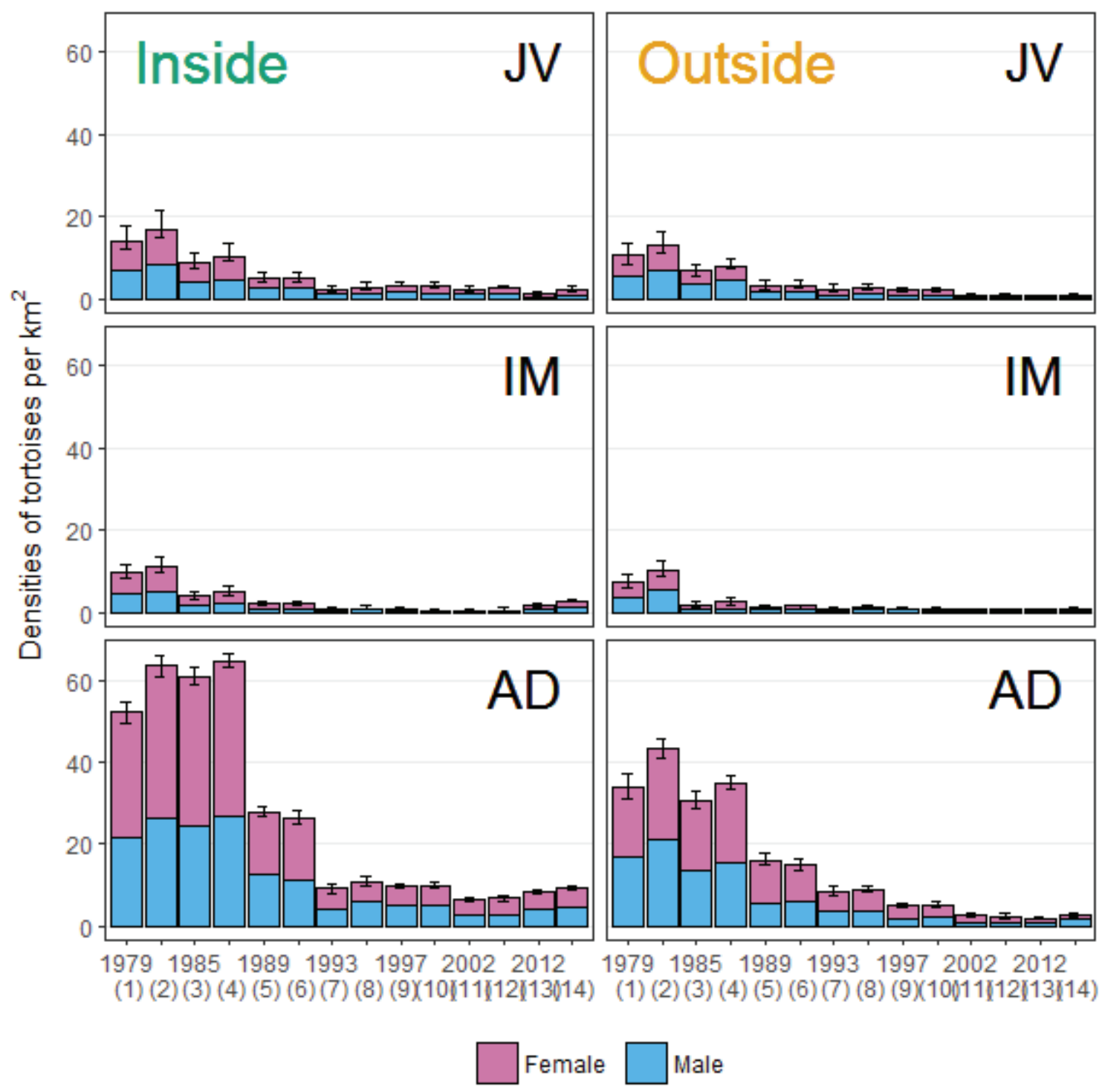

Figure 9. Density estimates of desert tortoises per square kilometer $\left(\mathrm{km}^{2}\right)$ by survey census, sex, size-age class, and location with regard to the fence at the Desert Tortoise Research Natural Area, western Mojave Desert, California. Error bars are 90-percent credible intervals for the sum total densities of females and males. AD, small to large-sized adult tortoises; IM, large immature tortoises; JV, juvenile and small immature tortoises. 


\section{Discussion}

\section{Model Convergence}

Our JS model satisfied the Gelman-Rubin test for convergence for some but not all model parameters. Our model included large matrices (14 survey censuses for 1,123 marked tortoises), which we augmented with several hundred more possible uncaptured tortoise records (appendix 1). Because most marked tortoises were not recaptured in most survey censuses, the Bayesian JS model undergoes an intensive data imputation process to fill information gaps with a distribution of likely values (for example, the size-age, location, and survival status of a tortoise during an interval when it has not been seen) in accordance with the model. The Markov chains track the imputation and model parameter estimates as they sample (explore) numerical solutions for our large matrix of tortoises and survey censuses. The multiple multistate variables (size-age, location, and survival status) require similarly large additional matrices. Gibbs sampling algorithms, although remarkably adept at handling complicated models, were noted by Betancourt (2017) for their sometimes inefficient sampling behavior and, hence, difficulties converging in high-dimensional spaces such as ours. Betancourt (2017) also showed that Hamiltonian Monte Carlo (HMC) can be more efficient at exploring high-dimensional spaces and thus better at converging to solutions; however, the HMC only applies to continuous variables, not to categorical multistate variables. More efficient sampling methods have yet to be developed for multistate models.

Although some of our Markov chains did not converge to the same solution, they appeared to converge to solutions that were near one another. We initialized different chains with very different values based on biologically opposing guesses about demographic and movement patterns (normal-growth/ high-survival versus slow-growth/low-survival, and minimal movement versus random movement; appendix 1). We also specified very large prior distributions for the range of parameter space in which we allowed the Markov chains to explore potential solutions. Despite our efforts to initialize chains so that they could explore very different solutions, all of our chains converged to a relatively narrow range of solutions, if not the same solution. All chains converged to estimates leading to similar interpretations about demographic patterns and population densities of our study population of tortoises.

The differences among chains might partly be explained by possible artifacts due to differences in the way we initialized them. The chains differed only for parameters involving size-age classification (that is, the growth model and effects of size-age on movement, survival, and detection; appendix 2). The chains that were initialized with the normal-growth/high-survival patterns converged together, but did not converge to the same set of solutions as the chain that was initialized with slow-growth/low-survival patterns (appendix 2). In the normal-growth/high-survival pattern, we initialized missing information gaps on tortoises based on optimistic guesses that they would have grown normally and died shortly before their recovery (or not died at all if never recovered; appendix 1). In the slow-growth/low-survival pattern, we initialized those gaps based on pessimistic guesses that they did not grow until shortly before their earliest recapture in a larger size-age class. This could create a bias in the slow-growth chain where it could appear that tortoises tend to be less detected while in the smaller size-age class and more detected immediately after growth to a larger size-age class. Indeed, although all chains indicate a positive correlation between size-age class and detection probability, the slow-growth chain suggests a larger positive correlation than the normal-growth chain does.

\section{Strengths and Weaknesses of Models}

Models can produce different results depending on assumptions and techniques employed. Berry and others (1986), in a demographic analysis of population attributes of the tortoise population at the Desert Tortoise Natural Area interpretive center, reported population densities that differed markedly from the JS model, specifically for 1979. The authors used the Stratified Lincoln Index (SLI) as described by Overton (1981). To better understand the sources of similarities and differences, we first compared assumptions inherent in the SLI and JS models (table 3) and then followed by determining the source of the differences.

The density estimates for 1979 and 1985, reported by Berry and others (1986) using the SLI, were generally higher with wider confidence intervals than the Bayesian credible intervals generated using the JS model. The most obvious differences were for density estimates of total population size inside and outside the fence in 1979: inside the fence, the midpoint of the density estimate was 131 tortoises per $\mathrm{km}^{2}$ from the SLI method versus the median density of 91 tortoises per $\mathrm{km}^{2}$ from the JS model (table 4). Outside the fence, the density estimate was 114 tortoises per $\mathrm{km}^{2}$ (SLI) versus 69 tortoises per $\mathrm{km}^{2}$ for the JS model. To explore potential reasons for the differences, we first compared methods of reporting - SLI produced a point estimate with a symmetric 95-percent confidence interval (lower and upper limits of confidence interval are equidistant to the point estimate), whereas the Bayesian JS model resulted in a probability density distribution for the estimates of population density. 
Table 3. Comparison of assumptions on population closure, and assumptions or abilities in the analysis of detection probability, movements, demographic processes, population estimation and other issues for the Stratified Lincoln Index (SLI) developed by Overton (1981) and Jolly-Seber (JS).

[Assumptions and abilities are described both generally and for the specific applications of SLI implemented by Berry and others (1986) or the JS model presented in this report. Abbreviations: i.e., that is; e.g., for example; >, greater than]

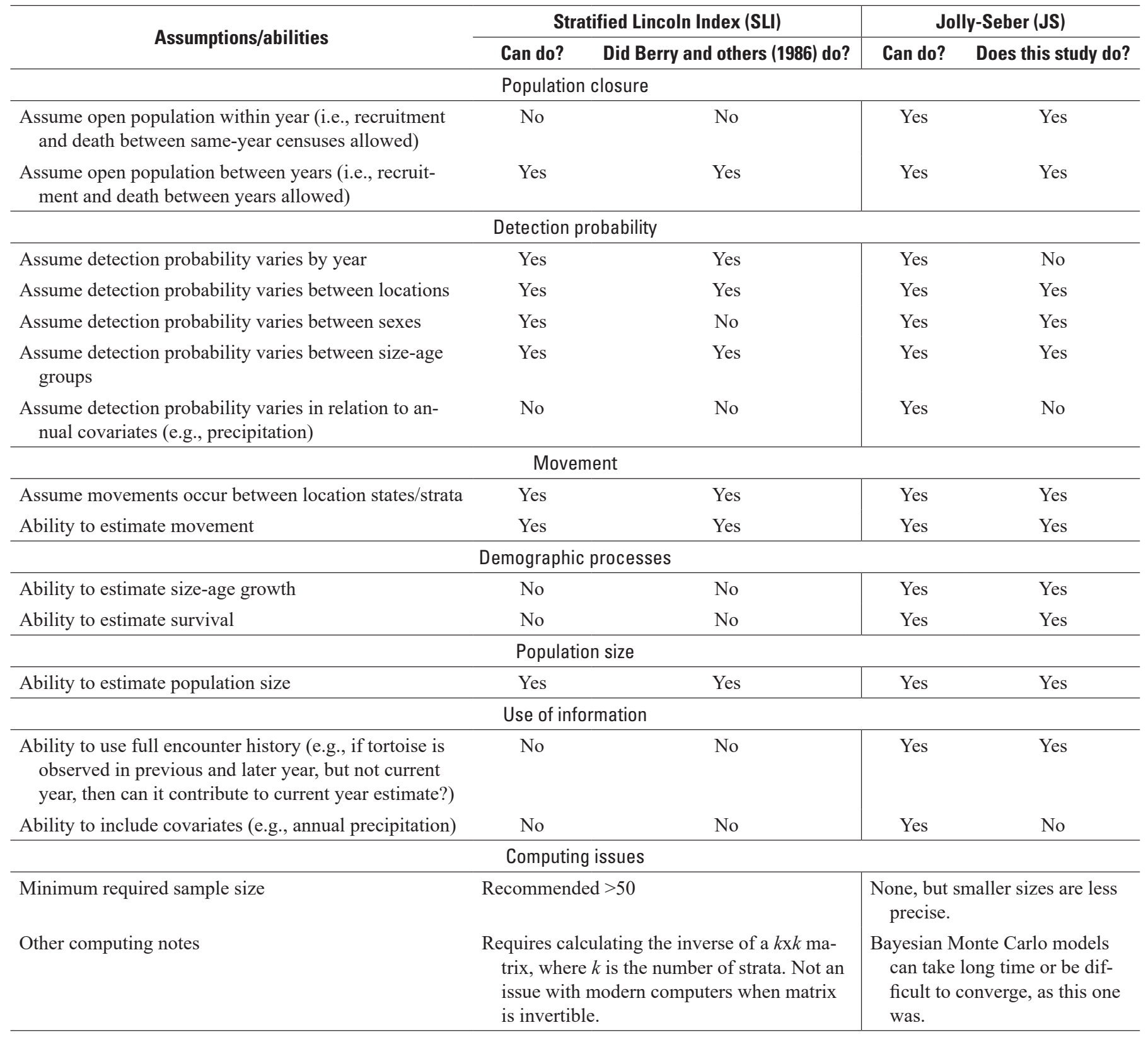


Table 4. Comparison of density estimates at the Desert Tortoise Research Natural Area for 1979 and 1985 using the Stratified Lincoln Index (Overton, 1981) method and the Jolly Seber model.

[Density estimates for the Stratified Lincoln Index for adult and all sizes are from Berry and others (1986); those with an asterisk (*) were calculated using the Stratified Lincoln Index for comparisons with Jolly-Seber size-age states. Abbreviations: AD, small to large-sized adult tortoises; JV, juvenile and small immature tortoises; $\mathrm{km}^{2}$, square kilometer; mm, millimeter; $<$, less than; $\geq$, greater than or equal to]

\begin{tabular}{lccc|cc}
\hline $\begin{array}{c}\text { Size-age class, } \\
\text { carapace length at } \\
\text { the midline, size } \\
\text { (mm [MCL]) }\end{array}$ & Year & \multicolumn{2}{c|}{$\begin{array}{c}\text { Stratified Lincoln Index: midpoint of } \\
\text { density estimate, numbers per km² } \\
\text { (95-percent confidence interval) }\end{array}$} & \multicolumn{2}{c}{$\begin{array}{c}\text { Jolly-Seber: Median density estimate } \\
\text { (numbers per km², 90-percent } \\
\text { credible interval) }\end{array}$} \\
\cline { 2 - 6 } & & Inside fence & Outside fence & Inside fence & Outside fence \\
\hline All sizes & 1979 & $131(111-155)$ & $114(90-146)$ & $91(86-100)$ & $69(65-77)$ \\
$<140$ mm MCL (JV) & 1979 & $44(18-89)^{*}$ & $42(9-154)^{*}$ & $17(15-22)$ & $13(11-17)$ \\
$\geq 180$ mm MCL (AD) & 1979 & $70(58-84)$ & $53(41-69)$ & $61(59-64)$ & $46(42-49)$ \\
All sizes & 1985 & $89(77-101)$ & $52(42-65)$ & $80(78-86)$ & $47(45-51)$ \\
$<140$ mm MCL (JV) & 1985 & $14(8-25)^{*}$ & $9(5-16)^{*}$ & $12(11-16)$ & $9(8-11)$ \\
$\geq 180$ mm MCL & 1985 & $69(60-79)$ & $40(32-52)$ & $62(61-64)$ & $35(33-37)$ \\
\hline
\end{tabular}

We reported our Bayesian modeling results in terms of the median estimate and a 90-percent credible interval based on lower 5-percent and upper 95-percent quantiles. Second, we noted that juvenile and small immature (JV in the JS model) tortoises numerically contributed more to these differences than other size-age classes: inside the fence, the SLI estimate was 44 compared to 17 tortoises per $\mathrm{km}^{2}$ using JS. Outside the fence, the SLI estimate was 42 tortoises $/ \mathrm{km}^{2}$ compared to 13 tortoises per $\mathrm{km}^{2}$ with JS. If we look at total tortoises captured in 1979 in the JV size-age state $(<140 \mathrm{~mm}$ MCL size class), the figure is 111 tortoises. For a crude density estimate, this count divided by the size of the total study area, $7.77 \mathrm{~km}^{2}$, yields 14.3 tortoises per $\mathrm{km}^{2}$, less than the 44 tortoises per $\mathrm{km}^{2}$ estimate from the SLI but very close to the median density estimate of 17 tortoises per $\mathrm{km}^{2}$ from the JS estimates. However, only 11 of the 51 JV tortoises captured in census 1 were recaptured in census 2 ( 8 of 36 inside, 5 of 15 outside), producing an overall detection probability of 0.216 ( 0.222 inside, 0.200 outside) for this size-age state during a single survey census. When compounded over two censuses in an annual survey year, the probability of detecting a given $\mathrm{JV}$ at least once during the two censuses is equal to the probability of not missing the JV twice in both censuses or $1-(40 / 51)^{2}=0.385$. The detection probability for JVs using SLI was approximately one-half the detection probability estimates from JS. Detection probabilities for a single survey census under the JS model for JV females inside the fence were $0.578(0.449-0.637)$ and for JV males inside the fence were $0.582(0.451-0.639)$. These same probabilities for JV females outside the fence were $0.589(0.463-0.652)$ and for JV males outside the fence were 0.593 (0.463-0.653; fig. 6). In 1985 , the density estimates of SLI and JS differed by only a few tortoises. As noted in table 3, the assumptions for detection probability differ between SLI and JS, contributing to the differences observed in the 1979 density estimates.
Differences in modeling assumptions may have also contributed to differences in results. The JS model made fewer assumptions than the SLI method with regard to population closure, with the difference being that the SLI method assumes that no entries or death/removals occurred between two censuses in the same year, whereas such changes were allowed in the JS model. Differences in closure assumptions might not have greatly affected the results because incidents of death or growth to a larger size-age during the short interval between consecutive censuses were infrequent, and we structured the JS model to estimate smaller transition probabilities in correspondence to short intervals. There may have been more significant differences between the JS and SLI methods when it came to detection probability. In our JS model, we assumed that detection probability could vary with certain factors such as sex, size-age, and location, but not with year. In contrast, the SLI model, which is calculated independently by year, is naturally structured to allow for annual variations in detection probability, but ignores information about sex, size-age, and tortoise capture information from other years. It is difficult to assess how these differences might have affected each model's estimates or contributed to their differences, but the differences in JV tortoise detection probability for 1979 between the SLI and JS models are striking and led to correspondingly large differences in population density for this size-age group (table 4). Because the JS model processes all information from all years at once, it can essentially average information (for example, detection probability information) and achieve greater precision in its estimates when a process (for example, detectability) is similar across years, as our model assumes. However, a drawback of this approach is that it could cause biases for particular years when that process (for example, detection) might have differed from the norm (for example, behavior and movements of tortoises in a dry versus a wet year; Duda and others, 1999). An alternative implementation of the JS model could include a year effect in the detection model to allow year-specific estimates of detection probability. 


\section{Limitations of Data}

Models can only be as reliable as the data on which they are based. For example, estimates for probability of growth, survival, and mortality rely on capture-recapture data. In accumulating long-term, accurate data for analyses of these topics, shortening the interval times for capture, recapture, and collection of remains of tortoises is highly desirable, shorter than the four- to ten-year intervals of this study. With lengthy intervals, critical information is lost on whether a tortoise was increasing in size, when a tortoise was last alive, and when and where deaths of individuals occurred. The investigators do not know if the animals walked away from the plot, were illegally collected, or died. Furthermore shell-skeletal remains deteriorate (Berry and Woodman, 1984) and need to be collected frequently. The shell-skeletal remains of very small tortoises (hatchlings, juveniles, and small immature tortoises) deteriorate more rapidly than remains of large immature and adult tortoises because of the early developmental stages of bone and scute (thin bones and few layers of laminae composing scutes). Shells of juveniles a few years old at the time of death are highly likely to disappear within a year, whereas bones and scutes of an adult may persist for 4 years or more. With the long sampling intervals in our study, remains of adults deteriorate, are scavenged, and the notches used to identify individuals are lost or obscured. More accurate estimates of survival could have been calculated if remains were collected annually. Similar statements could be made about some of the other population attributes.

The variables used in models need to be appropriate for a given situation. As mentioned in section, "Methods" and described in more detail in section, "Models," we explored preliminary models that included effects of precipitation on the detectability component of the model and ultimately discontinued that model development in favor of a model without precipitation. In general, an unnecessarily complex model can slow the convergence of chains, requiring many days for models to run with a possibility of non-convergence.

Finally, although models provide valuable information about several demographic attributes (for example, density, sex, size-ages, spatial distributions, and survival) of imperiled animal species, they also have limitations. For example, they may not be able to provide critical information about such topics as causes of population increases or decreases or death unless the appropriate variables are known and added to the models. The appearance of a new and emerging infectious disease is one example. The drivers of change are essential to understand for recovery efforts for federally and State-listed threatened and endangered species. When land managers are provided with such data on causes of population declines or mortality, they can institute adaptive management procedures to reduce human-caused deaths and thereby aid in recovery of the species.

\section{Low Detectability}

Detecting early life stages of reptiles and amphibians can be very difficult for some species and can lead to assumptions of poor survival (Pike and others, 2008; Refsnider and others, 2011; Durso and Seigel, 2015). Estimates of detection are an important part of modelling populations (Mazerolle and others, 2007; Mazerolle, 2015) and are especially valuable when the species or the smaller life states are cryptic (Pike and others, 2008). Morafka (1994) suggested that neonate and juvenile desert tortoises are cryptic and difficult to find, but Berry and Turner (1986) reported on habits of more than 1,400 small tortoises from long-term mark-recapture plots in the Mojave and Colorado Deserts. Although detection probabilities of adults are higher than observed in smaller tortoises, the JV (and IM tortoises) are detectable. With training and careful observations, field workers find JV and IM tortoises.

\section{Population Trends and Changes Over Time}

Our models show significant declines in the population at the southeastern part of the Desert Tortoise Research Natural Area over a 34-year period and concomitant low survival after 5 years, regardless of tortoise size or whether inside or outside the fence. Population declines were probably underway at the time our study area was first sampled. Similar declines were documented elsewhere in some populations in the Mojave and western Sonoran (Colorado) deserts at other sites first sampled in the late 1970s (Berry and Medica, 1995). Declines in desert tortoise populations were documented much earlier at the Woodbury-Hardy study population on the Beaver Dam Slope of Utah (Woodbury and Hardy, 1948). The Beaver Dam Slope population, first sampled using mark-recapture techniques in the 1930s, experienced a significant decrease by the 1970s, such that the U.S. Fish and Wildlife Service (USFWS) listed the local population as threatened in 1980 (U.S. Fish and Wildlife Service, 1980). Listing of the entire population north and west of the Colorado River/Grand Canyon complex followed in 1990 (U.S. Fish and Wildlife Service, 1990). At least one population in the eastern Mojave Desert appeared stable in the 1980s, followed by a decline in the 1990s. Turner and others (1987) developed a life table and age/size specific survival rates for a desert tortoise population at Goffs in the eastern Mojave Desert using mark-recapture data collected during annual surveys of differing lengths, efforts, and intervals between 1977 and 1986. The authors reported that survival rates varied by size and year. Annual survival rate after the first year of life ranged from 0.76 to 0.97 ; for tortoises 50 to $100 \mathrm{~mm}$ MCL, annual rates of survival were $0.77-0.80$. Adult tortoises had survival rates of 0.88-0.94. During the brief time Turner and others (1987) developed data for the life table, the population appeared to be stable or increasing. 
However, the Goffs population declined precipitously between 1994 and 2000, apparently due to a shell disease, cutaneous dyskeratosis, possibly herpesvirus, and other diseases

(Christopher and others, 2003; Jacobson and others, 2012). One local population outside of critical habitat in the western Colorado Desert did not experience declines over 18 years beginning in 1997. Agha and others (2015) studied survival of adult tortoises with radio-transmitters at a site with two parts, one with wind turbines and adjacent to a second part in designated wilderness. The authors reported high survival rates of adults in both parts of the site; the site had little human use, unlike our case study described here.

We compared our results from the JS model with results from other studies using different methods and report similarities in results. In 2004, the USFWS initiated distance sampling throughout designated critical habitat for adult desert tortoises (U.S. Fish and Wildlife Service, 2015). Sampling was undertaken annually and analyzed separately by critical habitats or Desert Wildlife Management Areas, also known as Tortoise Conservation Areas. The distance sampling result for the critical habitat outside and adjacent to the Desert Tortoise Research Natural Area, called the Fremont-Kramer critical habitat, was 2.2 adult tortoises per $\mathrm{km}^{2}$ in 2012 (U.S. Fish and Wildlife Service, 2014), the year of our study, compared with our figure of 2.32 per $\mathrm{km}^{2}\left(1.85-2.93\right.$ per $\left.\mathrm{km}^{2}\right)$ from the JS model for densities of adults outside the fence. Another source of data is available from outside the boundary fence from a study undertaken in 2011 both inside and outside the Desert Tortoise Research Natural Area using randomly placed hectare plots (Berry and others, 2014). In the hectare plot study, the authors estimated adults at 2.4 per $\mathrm{km}^{2}$ (2.3-2.6 per $\mathrm{km}^{2}$, 95-percent confidence intervals) in critical habitat outside the Natural Area fence and 3.7 per km² (3.6-3.8 per km², 95-percent confidence intervals) on adjacent private land. Basically, outside the fenced boundary of the Natural Area, estimates of densities for adults during 2011-12 were similar in the Fremont-Kramer region regardless of method used-JS, line-distance sampling, or hectare plots. Results for densities of adults inside the protective fence were higher than outside the fence and also similar, whether measured by the JS model (9.16 adults per $\mathrm{km}^{2}$ [8.71-9.71 adults per $\left.\mathrm{km}^{2}\right]$ ) or hectare sampling plots (10.2 adults per $\mathrm{km}^{2}$, 95-percent confidence interval=9.9-10.4 adults per $\mathrm{km}^{2}$; Berry and others, 2014).

\section{Low Survival and High Mortality Rates}

The low survival rates observed at our study site were associated with the steep declines in population density observed over a relatively short time. Study populations of desert tortoises have experienced high mortality rates (or low survival) over short periods in other desert regions, and the authors have associated the high death rates of adults with drought (for example, 18.4 percent of adults in 1 year in the northeastern Mojave Desert in Ivanpah Valley, California; Turner and others, 1984) and low survival probability (0.269) of adults over 7 years at one of two sites in southern Nevada in the eastern Mojave Desert (Longshore and others, 2003). High mortality rates also were associated with drought in a study of adult tortoises in the western Mojave Desert, although infectious disease probably played a significant role (Peterson, 1994; but see Jacobson and others, 1991; Brown and others, 1999). Drought is only one potential source of population loss. Population declines, low densities, and high mortality rates also are associated with other human-related activities such as predation, off-highway recreation vehicle use, livestock grazing, and loss and deterioration of habitat (Keith and others, 2008; U.S. Fish and Wildlife Service, 2010; Berry and others, 2014). Tortoises living inside the fenced boundary of the Natural Area did not experience threats from off-highway recreational vehicle use, livestock grazing, and loss and deterioration of habitat, but these were common threats to tortoises living outside the fence. Tortoises in both locations experienced drought, disease, and predation. Survival of adults was low for several reasons, but the appearance of a new and emerging infectious disease, mycoplasmosis, contributed to the high death rate (Jacobson and others, 1991, 2014). For the juvenile tortoises, hyperpredation by the common raven contributed to low survival (Berry and others, 1986; Kristan and Boarman, 2003). The common raven (Corvus corax) is a species with a growing population, fueled by subsidies of food, water, and perch sites from human activities (Boarman and Berry, 1995).

High mortality rates of adults in long-lived freshwater and terrestrial chelonians can have catastrophic consequences, because many species of turtles and tortoises require several years to reach reproductive maturity, produce relatively few eggs annually, and have low survival rates of young turtles (Brooks and others, 1991; Congdon and others, 1993). Female desert tortoises, for example, may require 12-20 years to reach reproductive maturity, and even then may produce an average of one or two (or no) clutches of 4.5 eggs annually (Turner and others, 1987). Recovery of a population after either a period of high mortality or long-term elevated and chronic mortality may require a very long time (for example, sudden mortality in the common snapping turtle associated with predation, Brooks and others, 1991). 


\section{Potential Future Developments of the Models}

We developed a Bayesian multistate or state-space, hierarchical JS model that can be used for analyzing demographic data for animal or plant populations. We used selected long-term datasets from Agassiz's desert tortoise at the Desert Tortoise Research Natural Area as a case study. For future work with desert tortoises and other long-lived species in long-term studies, our models can be modified by altering the underlying assumptions. Some modifications might include different numbers of size-age states, study areas, and intervals between surveys; use of opportunistic captures; and allowing for year-specific effects in probabilities of detection and (or) survival models. Environmental variables (precipitation, drought) and probability of hyperpredation events are other possibilities to add to the models. Models drawn from a dataset with brief intervals between surveys may be easier to work with than those with long intervals between surveys.

\section{References Cited}

Agha, M., Lovich, J.E., Ennen, J.R., Augustine, B., Arundel, T.R., Murphy, M.O., Meyer-Wilkins, K., Bjurlin, C., Delaney, D., Briggs, J., Austin, M., Madrak, S.V., and Price, S.J., 2015, Turbines and terrestrial vertebrates - Variation in tortoise survivorship between a wind energy facility and an adjacent undisturbed wildland area in the desert Southwest (USA): Environmental Management, v. 56, no. 2, p. 332-341, https://doi.org/10.1007/s00267-015-0498-9.

Berry, K.H., and Aresco, M.J., 2014, Threats and conservation needs for North American tortoises, in Rostal, D.C., McCoy, E.D., and Mushinsky, H.R., eds., Biology and conservation of North American tortoises: Baltimore, Maryland, Johns Hopkins University Press, p. 149-158.

Berry, K.H., and Christopher, M.M., 2001, Guidelines for the field evaluation of desert tortoise health and disease: Journal of Wildlife Diseases, v. 37, no. 3, p. 427-450, https://doi.org/10.7589/0090-3558-37.3.427.

Berry, K.H., Lyren, L.M., Yee, J.L., and Bailey, T.Y., 2014, Protection benefits desert tortoise (Gopherus agassizii) abundance - The influence of three management strategies on a threatened species: Herpetological Monograph, v. 28, no. 1, p. 66-92, https://doi.org/10.1655/ HERPMONOGRAPHS-D-14-00002.
Berry, K.H., and Medica, P.A., 1995, Desert tortoises in the Mojave and Colorado deserts, in LaRoe, E.T., Farris, G.S., Puckett, C.E., Doran, P.D., and Mac, M.J., eds., Our living resources-A report to the nation on the distribution, abundance, and health of U.S. plants, animals, and ecosystems: U.S. Department of the Interior, National Biological Service, p. 135-137.

Berry, K.H., Shields, T., Woodman, A.P., Campbell, T., Roberson, J., Bohuski, K., and Karl, A., 1986, Changes in desert tortoise populations at the Desert Tortoise Research Natural Area between 1979 and 1985: Proceedings of the Desert Tortoise Council Symposium 1986, p. 100-123.

Berry, K.H., and Turner, F.B., 1986, activities and habits of juvenile desert tortoises, Gopherus agassizii, in California: Copeia, v. 1986, no. 4, p. 1010-1012, https://doi.org/10.2307/1445302.

Berry, K.H., and Woodman, A.P., 1984, Methods used in analyzing mortality data for most tortoise populations in California, Nevada, Arizona, and Utah, Appendix 7 of Berry, K.H., ed., The status of the desert tortoise (Gopherus agassizii) in the United States: Report from Desert Tortoise Council to the US Fish and Wildlife Service, Sacramento, California, Order No. 11310-00083-81.

Berry, K.H., Yee, J.L., Shields, T.A., and Stockton, L., 2020, The catastrophic decline of torotises at a fenced Natural Area: Wildlife Monographs, v. 205, no. 1, p. 1-53, https://doi.org/10.1002/wmon.1052.

Beissinger, S.R., and Westphal, M.I., 1998, On the use of demographic models of population viability in endangered species management: The Journal of Wildlife Management, v. 62, no. 3, p. 821-841, https://doi.org/10.2307/3802534.

Betancourt, M., 2017, A conceptual introduction to Hamiltonian Monte Carlo: ArXiv e-prints 1701.02434v1, https://arxiv.org/abs/1701.02434.

Boarman, W.I., and Berry, K.H., 1995, Common ravens in the southwestern United States, 1968-92, in LaRoe, E.L., Farris, G.S., Puckett, C.E., Doran, P.D., and Mac, M.J., eds., Our living resources-A report to the nation on the distribution, abundance, and health of U.S. plants, animals, and ecosystems: U.S. Department of the Interior, National Biological Service, p. 73-75.

Brooks, R.J., Brown, G.P., and Galbraith, D.A., 1991, Effects of a sudden increase in natural mortality of adults on a population of the common snapping turtle (Chelydra serpentina): Canadian Journal of Zoology, v. 69, no. 5, p. 1314-1320, https://doi.org/10.1139/z91-185. 
Brown, M.B., Berry, K.H., Schumacher, I.M., Nagy, K.A., Christopher, M.M., and Klein, P.A., 1999, Seroepidemiology of upper respiratory tract disease in the desert tortoise in the western Mojave Desert of California: Journal of Wildlife Diseases, v. 35, no. 4, p. 716-727, https://doi.org/10.7589/0090-3558-35.4.716.

California Department of Fish and Game, 2010, List of vegetation alliances and associations. Vegetation classification and mapping program: California Department of Fish and Game.

California Department of Fish and Wildlife, 2016, State and federally listed endangered and threatened animals of California: California Department of Fish and Wildlife, Biogeographic Data Branch, California Natural Diversity Database.

Christopher, M.M., Berry, K.H., Henen, B.T., and Nagy, K.A., 2003, Clinical disease and laboratory abnormalities in free-ranging desert tortoises in California (1990-1995): Journal of Wildlife Diseases, v. 39, no. 1, p. 35-56, https://doi.org/10.7589/0090-3558-39.1.35.

Congdon, J.D., Dunham, A.E., and Van Loben Sels, R.C., 1993, Delayed sexual maturity and demographics of Blanding's turtles (Emydoidea blandingii)—Implications for conservation and management of long-lived organisms: Conservation Biology, v. 7, no. 4, p. 826-833, https://doi.org/10.1046/j.1523-1739.1993.740826.x.

Doak, D., Kareiva, P., and Klepetka, B., 1994, Modeling population viability for the desert tortoise in the western Mojave Desert: Ecological Applications, v. 4, no. 3, p. 446-460, https://doi.org/10.2307/1941949.

Duda, J.J., Krzysik, A.J., and Freilich, J.E., 1999, Effects of drought on desert tortoise movement and activity: The Journal of Wildlife Management, v. 63, no. 4, p. 1181-1192, https://doi.org/10.2307/3802836.

Durso, A.M., and Seigel, R.A., 2015, A snake in the hand is worth 10,000 in the bush: Journal of Herpetology, v. 49, no. 4, p. 503-506, https://doi.org/10.1670/15-49-04.1.

Edwards, T., Karl, A.E., Vaughn, M., Rosen, P.C., Meléndez Torres, C., and Murphy, R.W., 2016, The desert tortoise trichotomy-Mexico hosts a third, new sister-species of tortoise in the Gopherus morafkai-G. agassizii group: ZooKeys, v. 562, p. 131-158, https://doi.org/10.3897/zookeys.562.6124.

Folt, B., Jensen, J.B., Teare, A., and Rostal, D., 2016, Establishing reference demography for conservation-A case study of Macrochelys temminckii in Spring Creek, Georgia: Herpetological Monograph, v. 30, no. 1, p. 21-33, https://doi.org/10.1655/HERPMONOGRAPHS-D15-00004.
Gelman, A.B., Carlin, J.S., Stern, H.S., and Rubin, D.B., 1997, Bayesian data analysis: New York, Chapman and Hall, 526 p.

Harless, M.L., Walde, A.D., Delaney, D.K., Pater, L.L., and Hayes, W.K., 2009, Home range, spatial overlap, and burrow use of the desert tortoise in the west Mojave Desert: Copeia, v. 2009, no. 2, p. 378-389, https://doi.org/10.1643/CE-07-226.

Hazard, L.C., Morafka, D.J., and Hillard, S., 2015, Post-release dispersal and predation of head-started juvenile desert tortoises (Gopherus agassizii) —A preliminary assessment of age effects: Herpetological Conservation and Biology, v. 10, p. 504-515.

Hellgren, E.C., Kazmaier, R.T., Ruthven, D.C., III, and Synatzske, D.R., 2000, Variation in tortoise life historyDemography of Gopherus berlandieri: Ecology, v. 81, no. 5, p. 1297-1310, https://doi.org/10.1890/0012-9658(2000)081 [1297:VITLHD]2.0.CO;2.

Henen, B.T., Peterson, C.C., Wallis, I.R., Berry, K.H., and Nagy, K.A., 1998, Effects of climatic variation on field metabolism and water relations of desert tortoises: Oecologia, v. 117, no. 3, p. 365-373, https://doi.org/10.1007/s004420050669.

Heppell, S.S., Crowder, L.B., and Crouse, D.T., 1996, Models to evaluate headstarting as a management tool for long-lived turtles: Ecological Applications, v. 6, no. 2, p. 556-565, https://doi.org/10.2307/2269391.

Jacobson, E.R., 2014, Health issues of North American tortoises, in Rostal, D.C., McCoy, E.D., and Mushinsky, H.R., eds., Biology and conservation of North American tortoises: Baltimore, Maryland, Johns Hopkins University Press, p. 60-76.

Jacobson, E.R., Gaskin, J.M., Brown, M.B., Harris, R.K., Gardiner, C.H., LaPointe, J.L., Adams, H.P., and Reggiardo, C., 1991, Chronic upper respiratory tract disease of free-ranging desert tortoises (Xerobates agassizii): Journal of Wildlife Diseases, v. 27, no. 2, p. 296-316, https://doi.org/10.7589/0090-3558-27.2.296.

Jacobson, E.R., Berry, K.H., Wellehan, J.F.X., Jr., Origgi, F., Childress, A.L., Braun, J., Schrenzel, M., Yee, J., and Rideout, B., 2012, Serologic and molecular evidence for Testudinid herpesvirus 2 infection in wild Agassizi's desert tortoises, Gopherus agassizii: Journal of Wildlife Diseases, v. 48, no. 3, p. 747-757, https://doi.org/10.7589/0090-3558-48.3.747. 
Jacobson, E.R., Brown, M.B., Wendland, L.D., Brown, D.R., Klein, P.A., Christopher, M.M., and Berry, K.H., 2014, Mycoplasmosis and upper respiratory tract disease of tortoises - A review and update: Veterinary Journal (London, England), v. 201, no. 3, p. 257-264, https://doi.org/10.1016/j.tvj1.2014.05.039.

Jolly, G.M., 1965, Explicit estimates from capture-recapture data with both death and immigration-stochastic model: Biometrika, v. 52, nos. 1-2, p. 225-248, https://doi.org/10.1093/biomet/52.1-2.225.

Keith, K., Berry, K.H., and Weigand, J.F., 2008, When desert tortoises are rare-Testing a new protocol for assessing status: California Fish and Game, v. 94, p. 75-97.

Kellner, K., 2016, jagsUI-A wrapper around 'rjags' to streamline 'JAGS' analyses, R package version 1.4.2: The Comprehensive R Archive Network website, https://CRAN.R-project.org/package=jagsUI.

Kéry, M., and Schaub, M., 2012, Bayesian population analysis using WinBUGS - A hierarchical perspective: Oxford, United Kingdom, Elsevier, Inc. Academic Press, 554 p.

Kristan, W.B., III, and Boarman, W.I., 2003, Spatial pattern of risk of common raven predation on desert tortoises: Ecology, v. 84, no. 9, p. 2432-2443, https://doi.org/10.1890/02-0448.

Link, W.A., and Barker, R.J., 2010, Bayesian inference with ecological applications: London, Academic Press, 354 p.

Longshore, K.M., Jaeger, J.R., and Sappington, J.M., 2003, Survival at two eastern Mojave Desert sites - Death by short-term drought?: Journal of Herpetology, v. 37, no. 1, p. 169-177, https://doi.org/10.1670/0022-1511(2003)037 [0169:DTGASA]2.0.CO;2.

Mazerolle, M.J., 2015, Estimating detectability and biological parameters of interest with the use of the R environment: Journal of Herpetology, v. 49, no. 4, p. 541-559, https://doi.org/10.1670/14-075.

Mazerolle, M.J., Bailey, L.L., Kendall, W.L., Royle, J.A., Converse, S.J., and Nichols, J.D., 2007, Making great leaps forward-Accounting for detectability in herpetological field studies: Journal of Herpetology, v. 41, no. 4, p. 672-689, https://doi.org/10.1670/07-061.1.

Monk, M.H., Berkson, J., and Rivalan, P., 2011, Estimating demographic parameters for loggerhead sea turtles using mark-recapture data and a multistate model: Population Ecology, v. 53, no. 1, p. 165-174, https://doi.org/10.1007/s10144-010-0205-x.
Morafka, D.J., 1994, Neonates-Missing links in the life histories of North American tortoises, in Bury, R.B., and Germano, D.J., eds., Biology of North American tortoises-U.S. Department of the Interior, National Biological Survey, Fish and Wildlife Research 13 p. 161-173.

Murphy, R.W., Berry, K.H., Edwards, T., Leviton, A.E., Lathrop, A., and Riedle, J.D., 2011, The dazed and confused identity of Agassiz's land tortoise, Gopherus agassizii (Testudines, Testudinidae) with the description of a new species, and its consequences for conservation: ZooKeys, v. 113, p. 39-71, https://doi.org/10.3897/zookeys.113.1353.

Norris, K., and McCulloch, N., 2003, Demographic models and the management of endangered species - A case study of the critically endangered Seychelles magpie robin: Journal of Applied Ecology, v. 40, no. 5, p. 890-899, https://doi.org/10.1046/j.1365-2664.2003.00840.x.

Overton, W.C., 1981, Estimating the numbers of animals in wildlife populations, in Giles, R.H., ed., Wildlife management techniques: Washington, D.C., The Wildlife Society, p. 403-456.

Pearson, R.G., Stanton, J.C., Shoemaker, K.T., Aiello-Lammens, M.E., Ersts, P.J., Horning, N., Fordham, D.A., Raxworthy, C.J., Ryu, H.Y., McNees, J., and Akcçakaya, H.R., 2014, Life history and spatial traits predict extinction risk due to climate change: Nature Climate Change (Letters), v. 4, no. 3, p. 217-221, https://doi.org/10.1038/nclimate2113.

Peterson, C.C., 1994, Different rates and causes of high mortality in two populations of the threatened desert tortoise Gopherus agassizii: Biological Conservation, v. 70, no. 2, p. 101-108, https://doi.org/10.1016/0006-3207(94)90277-1.

Pike, D.A., Pizzatto, L., Pike, B.A., and Shine, R., 2008, Estimating survival rates of uncatchable animals - The myth of high juvenile mortality in reptiles: Ecology, v. 89, no. 3, p. 607-611, https://doi.org/10.1890/06-2162.1.

Plummer, M., 2003, JAGS: A program for analysis of Bayesian graphical models using Gibbs sampling: Proceedings of the 3rd International Workshop on Distributed Statistical Computing (DSC 2003), March 20-22, 2003, Vienna, Austria, ISSN 1609-395X.

Plummer, M., 2016, rjags: Bayesian graphical models using MCMC, R package version 4-6: The Comprehensive R Archive Network website, https://CRAN.R-project.org/package=rjags.

R Core Team, 2016, R: A language and environment for statistical computing: Vienna, Austria, R Foundation for Statistical Computing, https://www.R-project.org/. 
Reed, J.M., Fefferman, N., and Averill-Murray, R.C., 2009, Vital rate sensitivity analysis as a tool for assessing management actions for the desert tortoise: Biological Conservation, v. 142, no. 11, p. 2710-2717, https://doi.org/10.1016/j.biocon.2009.06.025.

Refsnider, J.M., Mitchell, T.S., Streby, H.M., Strickland, J.T., Warner, D.A., and Janzen, F.J., 2011, A generalized method to determine detectability of rare and cryptic species using the ornate box turtle as a model: Wildlife Society Bulletin, v. 35, no. 2, p. 93-100, https://doi.org/10.1002/wsb.14.

Rowlands, P.G., 1995, Regional bioclimatology of the California desert, in Latting, J., and Rowlands, P.G., eds., The California desert-An introduction to natural resources and man's impact v. 1: Riverside, California, June Latting Books, p. 95-134.

Royle, J.A., and Dorazio, R.M., 2008, Hierarchical modeling and inference in ecology, The analysis of data from populations, metapopulations, and communities: New York, Academic Press, 444 p.

Royle, J.A., and Dorazio, R.M., 2012,

Parameter-expanded data augmentation for

Bayesian analysis of capture-recapture models:

Journal of Ornithology, v. 152, no. S2, p. 521-537, https://doi.org/10.1007/s10336-010-0619-4.

Schwarz, C.J., and Arnason, A.N., 1996, A general methodology for the analysis of capture-recapture experiments in open populations: Biometrics, v. 52, no. 3 , p. 860-873, https://doi.org/10.2307/2533048.

Seber, G.A.F., 1965, A note on the multiple recapture census: Biometrika, v. 52, nos. 1-2, p. 249-260, https://doi.org/10.1093/biomet/52.1-2.249.

Turner, F.B., Medica, P.A., and Lyons, C.L., 1984, Reproduction and survival of the desert tortoise (Scaptochelys agassizii) in Ivanpah Valley, California: Copeia, v. 1984, no. 4, p. 811-820, https://doi.org/10.2307/1445322.

Turner, F.B., Berry, K.H., Randall, D.C., and White, G.C., 1987, Population ecology of the desert tortoise at Goffs, California, 1983-1986: Rosemead, California: Southern California Edison Company, 90 p. plus appendixes.
U.S. Fish and Wildlife Service, 1980, Endangered and threatened wildlife and plants - Listing as threatened with critical habitat for the Beaver Dam Slope population of the desert tortoise in Utah: Federal Register, v. 45, p. 55654-55666.

U.S. Fish and Wildlife Service, 1990, Endangered and threatened wildlife and plants; determination of threatened status for the Mojave population of the desert tortoise: Federal Register, v. 55, p. 12178-12191.

U.S. Fish and Wildlife Service, 2010, Mojave population of the desert tortoise (Gopherus agassizii), 5-year reviewSummary and evaluation: Nevada, U.S. Fish and Wildlife Service, Desert Tortoise Recovery Office.

U.S. Fish and Wildlife Service, 2014, Range-wide monitoring of the Mojave Desert tortoise (Gopherus agassizii)—2012 annual report: Nevada, U.S. Fish and Wildlife Service, Desert Tortoise Recovery Office.

U.S. Fish and Wildlife Service, 2015, Range-wide monitoring of the Mojave Desert tortoise (Gopherus agassizii)—2013 and 2014 annual report: Nevada, U.S. Fish and Wildlife Service, Desert Tortoise Recovery Office.

Williams, B.K., Nichols, J.D., and Conroy, M.J., 2002, Analysis and management of animal populations: San Diego, Academic Press, 817 p.

Wisdom, M.J., Mills, L.S., and Doak, D.F., 2000, Life stage simulation analysis - Estimating vital rate effects on population growth for conservation: Ecology, v. 81, no. 3, p. 628-641, https://doi.org/10.1890/0012-9658(2000)081 [0628:LSSAEV]2.0.CO;2.

Woodbury, A.M., and Hardy, R., 1948, Studies of the desert tortoise, Gopherus agassizi: Ecological Monographs, v. 18, no. 2, p. 145-200, https://doi.org/10.2307/1948638.

Zimmerman, L.C., O’Connor, M.P., Bulova, S.J., Spotila, J.R., Kemp, S.J., and Salice, C.J., 1994, Thermal ecology of desert tortoises in the eastern Mojave Desert-Seasonal patterns of operative and body temperatures, and microhabitat utilization: Herpetological Monograph, v. 8, p. 45-59, https://doi.org/10.2307/1467069. 


\section{Appendix 1. Technical Details of Modeling Methods}

\section{Model Development}

We used a combination of modeling examples presented by Kéry and Schaub (2012; multistate capture-recapture model in section 9.2, and multistate Jolly-Seber [JS] model in section 10.3.2) as starting points for developing our desert tortoise population model (see also Jolly, 1965; Seber, 1965; Schwarz and Arnason, 1996; Link and Barker, 2010; Royle and Dorazio, 2012). These models address key features of our desert tortoise population study: (1) an open population with entry (or birth) and removal (or death); (2) movements between two areas of interest (inside and outside the Desert Tortoise Research Natural Area [hereinafter "Natural Area"] boundary fence); and (3) a mark-recapture framework that enables estimation of survival probability, capture probability, and population size. We defined a state-space to represent the location (inside or outside the fence) of a given tortoise at a given time, and we used a state transition matrix to represent the probabilities of location change (inside to outside, or outside to inside). We also defined a state-space to represent the status of a tortoise in the population (not-yet-entered, entered/alive, or dead/removed), and we used another state transition matrix to represent the probabilities of its entry and survival.

We made several modifications or accommodations to this model to address several circumstances unique to our study design. These circumstances included (1) uneven interval spacing between census occasions; (2) state processes and detection processes likely influenced by the variable interval spacing, other state variables, or covariates; (3) removal of tortoise carcasses from the study area whenever found; (4) extraneous information on capture, recapture, or recovery of tortoises during intervals between censuses (non-census data); (5) large numbers of census occasions and multiple state processes (size-age states, location states, and survival states) generated a very large number of latent states (unobserved states) for tortoises at census occasions when they were not captured and, although the model is capable of handling latent states if time and memory are adequate, we took additional measures to eliminate some whenever possible; and (6) our state processes necessitated special consideration when setting the initial values of chains in the Markov-Chain Monte Carlo (MCMC) process, and we developed a customized set of initialization rules. We discuss our handling of these circumstances separately in the next six sections.

Throughout this report, unless otherwise noted, we use the term "capture" to refer to the first-time capture of an unmarked tortoise or recapture of a marked tortoise. We also use the term "detection" to refer to the capture of a tortoise or recovery of a dead tortoise. In our model, we assume that the first-time capture probability, recapture probability, and recovery probability of a given tortoise are equal, and can be referred to equivalently as detection probability.

\section{Intervals}

Two month-long censuses were conducted in each spring of 7 years $(1979,1985,1989,1993,1997,2002$, and 2012), with each pair of censuses occurring consecutively (that is, the second census in the pair beginning immediately after the first census concluded, so that the two censuses were approximately 1 month apart). Because of the short time separating both censuses per given year, we weighed the advantages and disadvantages of collapsing the information from each pair of censuses and modeling as a single census, for a 7-occasion model, versus modeling each census separately, for a 14-occasion model. We chose the 14-occasion model because of its similarity to Pollock's Robust Design Model (http://www.phidot.org/software/mark/docs/book/pdf/chap15.pdf), which constitutes primary sampling periods (long intervalsin our case, different years - when entry and removals from the open population can easily occur) and secondary sampling periods (very short intervals - in our case, the pairs of consecutive censuses - when the population is essentially closed). An important advantage to this framework is the power to estimate recapture probabilities based on the repeated censuses each year when the population is essentially closed. The Robust Design Model is well-documented and will not be presented here, but interested readers may see an overview at the website noted earlier in this paragraph as well as in key papers (Pollock, 1982; Kendall and others, 1997).

We did not assume complete closure between consecutive censuses in the same year. A small number of tortoises suffered mortality between the two censuses (for example, captured or recaptured alive in the first census, then dead or moribund in the following month's census). Rather than assuming population closure (that is, forcing probability of survival to equal 1), we modeled the probability of survival between a pair of censuses by taking annual survival probability and raising it to the power of $1 / 12$ to represent monthly survival probability (see section "Mathematical Models"). We also allowed new tortoises to enter the population at any census. 
To estimate population size as well as allow new tortoises to enter the population, the Bayesian implementation of the JS model includes a strategy called parameter-expanded data augmentation (Royle and Dorazio, 2012). As a brief description, we take the set of marked tortoises and list their encounter histories (detection and non-detection data records), and then we augment the list with an additional set of all-zero encounter histories (non-detection records) belonging to an implausibly large number of hypothetical never-captured tortoises that could potentially have existed in the population. We know by observation the number of tortoises in the subset of the population that have been captured at least once. The problem of population estimation is then reduced to that of estimating the number of tortoises in the remainder of the population that have never been captured. Using recapture probabilities estimated by other components of the model, it is possible to estimate the probability for an unmarked tortoise to never be captured, and consequently the most likely number of hypothetical tortoises to have been present, but never captured. The implementation is presented with detailed examples by Kéry and Schaub (2012), and those details will not be included here. However, it is useful to know that this strategy requires the addition of a "dummy" occasion so that all tortoises start in a "not-yet-entered" state prior to the first census. Thus the 14-occasion model actually used a 15-occasion framework.

The indexing of occasions was important to our modeling. Each tortoise contributes information about the mark-recapture population model at every census occasion (whether or not the tortoise is observed at that occasion), except a tortoise does not contribute information to census occasions after it is recovered dead and removed. We calculated our model by iterating the likelihood of each tortoise's data from occasions 1-15, except for recovered tortoises, which were iterated over a narrower range of occasions (see also sections "Death Records" and "Non-Census Data Modeling").

Table 1.1. Relation of survey years, census numbers, and their corresponding occasion numbers in the model.

\begin{tabular}{ccc}
\hline Year & Census & Occasion \\
\hline Dummy & Dummy & 1 \\
1979 & 1 & 2 \\
1979 & 2 & 3 \\
1985 & 3 & 4 \\
1985 & 4 & 5 \\
1989 & 5 & 6 \\
1989 & 6 & 7 \\
1993 & 7 & 8 \\
1993 & 8 & 9 \\
1997 & 9 & 10 \\
1997 & 10 & 11 \\
2002 & 11 & 12 \\
2002 & 12 & 13 \\
2012 & 13 & 14 \\
2012 & 14 & 15 \\
\hline
\end{tabular}




\section{Mathematical Models}

We used recapture data across all 14 survey occasions to model population demographic patterns (rates of transition to larger size-age groups, and survival rates) and movement (rates of transition between inside and outside the fence) in a Bayesian JS modeling framework (Kéry and Schaub, 2012), which is used to also estimate population size and distribution inside and outside the fence by sex and size-age group. We grouped size-age classes into three groups: (1) juveniles through immature 1 ( $<140 \mathrm{~mm}$; hereafter "JV"), (2) immature 2 (140-179 mm; hereinafter "IM"), and (3) subadults through adults ( $\geq 180 \mathrm{~mm}$; hereinafter “AD”).

In these models, we represented the status of size-age (JV, IM, AD), location (IN, OUT), and live-dead (not-yet-entered, entered/alive, or dead/removed) as states; and growth, movement, and survival processes as transitions between states. We used logit functions to express the probabilities of state transition in relationships to predictor variables such as sex, length of time between surveys, and other states. Specifically, we used multinomial logistic regression for transitions between the three size-age states as a function of time between surveys, and binomial logistic regression for transitions between location states as a function of sex and size-age and for transitions between live-dead states as a function of sex, size-age, and location. We accounted for imperfect detection by incorporating another binomial logistic regression for detection probability as a function of sex, size-age, and location.

The transition probabilities for a JV tortoise follow a multinomial logistic function:

$$
\begin{gathered}
\operatorname{Pr}\{J V \text { transition to IM }\}=\frac{\exp \left(\xi_{J I} X_{Y r s}\right)}{c} \\
\operatorname{Pr}\{J V \text { transition to AD }\}=\frac{\exp \left(\xi_{0 J A}+\xi_{J A} X_{Y r s}\right)}{c} \\
\operatorname{Pr}\{J V \text { remain JV }\}=\frac{\exp \left(\xi_{0 J J}+\xi_{J J} X_{Y r s}\right)}{c}
\end{gathered}
$$

where

$\xi_{0 J I}, \xi_{O J A}$, and $\xi_{0 J J}$ are intercept coefficients;

$\xi_{J I}, \xi_{J A}$, and $\xi_{J J}$ are slope coefficients for the number of years since previous survey $\left(X_{Y r s}\right)$; and

$c$ is a scaling factor equal to the sum of the three numerators ensuring that all three probabilities sum to 1.

The gamma parameters are not uniquely identified, that is, an arbitrary constant can be added to all parameters without affecting the model; therefore, we set $\xi_{O J J}=\xi_{J J}=0$, or, equivalently, the last numerator to 1 . The transition probabilities for an IM tortoise are similar, except simplify to a binomial logistic function because there is 0 probability of transitioning backward from IM to JV:

$$
\begin{gathered}
\operatorname{Pr}\{I M \text { transition to } A D\}=\frac{\exp \left(\xi_{0 I A}+\xi_{I A} X_{Y r s}\right)}{1+\exp \left(\xi_{0 I A}+\xi_{I A} X_{Y r s}\right)}=\frac{1}{1+\exp \left(-\left(\xi_{0 I A}+\xi_{I A} X_{Y r S}\right)\right)} \\
\operatorname{Pr}\{I M \text { remain } I M\}=\frac{1}{1+\exp \left(\xi_{0 I A}+\xi_{I A} X_{Y r s}\right)}
\end{gathered}
$$

where

$\xi_{O I A}$ and $\xi_{I A}$ are intercept and slope coefficients.

No further changes to size-age occur after a tortoise reaches AD size, and transition probabilities are set to 0 .

We also used logistic functions to express transition probabilities between the location states, inside and outside the fenced area, as a function of sex and size-age. 


$$
\begin{aligned}
& \operatorname{Pr}\{I N \text { transition to } O U T\}=\frac{1}{1+\exp \left(-\left(\psi_{0 I O}+\psi_{F I O} X_{F}+\psi_{S z I O} X_{S z}\right)\right)} \\
& \operatorname{Pr}\{O U T \text { transition to } I N\}=\frac{1}{1+\exp \left(-\left(\psi_{0 O I}+\psi_{F O I} X_{F}+\psi_{S z O I} X_{S z}\right)\right)}
\end{aligned}
$$

where

$$
\begin{aligned}
\psi_{O I O} \text { and } \psi_{O O I} & \text { are intercept coefficients; } \\
\psi_{F I O}, \psi_{S z I O}, \psi_{F O I} \text { and } \psi_{S z O I} & \text { are slope coefficients; } \\
X_{F} & \text { is an indicator of sex (1 if female, 0 if male); and } \\
X_{S z} & \text { is an index of size (1 for JV, } 2 \text { for IM, and } 3 \text { for AD). }
\end{aligned}
$$

We used a logistic function to represent annual survival:

$$
\operatorname{Pr}\{\text { survive year }\}=\frac{1}{1+\exp \left(-\left(\phi_{0}+\phi_{F} X_{F}+\phi_{S z} X_{S z}+\phi_{L} X_{L}\right)\right)}
$$

where

$$
\begin{aligned}
\phi_{0} & \text { is the intercept coefficient; and } \\
\phi_{F}, \phi_{S z} \text { and } \phi_{L} & \text { are slope coefficients for sex, size-age }\left(X_{F}, X_{S z}\right) \text { and } \\
X_{L} & \text { is an index of location (1 for inside fence, } 2 \text { for outside). }
\end{aligned}
$$

We raised the annual survival probability to the power of $k$, the number of years since the previous census. For two consecutive month-long surveys in the spring, we raised annual survival probability to the power of $1 / 12$ to represent survival from one month to the next.

We defined detection probability, the probability of detecting a tortoise conditional on it being alive and present:

$$
\operatorname{Pr}\{\text { detection }\}=\frac{1}{1+\exp \left(-\left(p_{0}+p_{F} X_{F}+p_{S z} X_{S z}+p_{L} X_{L}\right)\right)}
$$

where

$\begin{array}{cl}p_{0} & \text { is the intercept coefficient; and } \\ p_{F}, p_{S z} \text { and } p_{L} & \text { are slope coefficients for sex, size-age, and location }\left(X_{F}, X_{S z}, X_{L}\right) .\end{array}$

We applied the data augmentation technique to estimate the number of undetected tortoises living according to each sex, size-class state, and location state (Kéry and Schaub, 2012). We fit all demographic models using the "jagsUI" package of R statistical software as an interface to the Bayesian modeling software JAGS (Plummer, 2003; Kellner, 2016; R Core Team, 2016).

\section{Death Records}

Out of 1,123 tortoises analyzed, 141 were recovered dead on a census and 107 others were recovered dead on non-census detections. As carcasses were recovered, they were removed from the study area and unavailable for detection. Tortoises that were never found dead had the possibility of being dead or alive throughout the remainder of the study and were modeled at all occasions from censuses 1-14 (that is, occasions 1-15, including the dummy occasion; see section "Intervals"). Conversely, recovered tortoises were modeled over a truncated range of occasions from census 1 through the last census up to its removal. For example, a tortoise (call it "Tortoise A") that is recovered in census 3 was modeled from censuses 1 through 3 (that is, occasions 1-4). Every recovered tortoise was assigned a "last occasion" index ranging from 2 to 15 depending on when its recovery occurred, and tortoises that were never recovered were assigned a "last occasion" index of 15. 


\section{Non-Census Data Modeling}

Occasionally, between census occasions and during the course of other non-census tortoise research activities at the Natural Area, tortoises were sometimes encountered. When this occurred, they were processed in a similar manner as tortoises captured or recaptured during a census occasion - that is, new captures were assigned an ID; their ID was recorded along with their location, size, and sex (when MCL $\geq 180$ only); and dead tortoises were removed. In cases of non-census recoveries (carcass removals) of marked tortoises, then those individuals became unavailable for detection in subsequent censuses. We incorporated non-census recovery data into our model because they were too valuable to ignore. All recoveries, whether census or non-census related, provide certain information of a tortoise's death and contribute directly to estimates of survival probability. If we had restricted our analysis to tortoise capture and recapture data collected only during censuses, then any tortoise that was removed during a non-census recovery would have only live encounters recorded for it; in other words, the model would be unable to separate these dead removed tortoises from surviving tortoises that simply evaded further recapture.

The standard mark-recapture model is structured around an interval-based framework, with captures and recaptures occurring in relatively short capture periods (in our case census occasions, which divide those intervals). Because non-census recoveries did not occur during census occasions, we considered several approaches: (1) assign the non-census recovery to the nearest census occasion, thus treating it as if it had occurred on a census; (2) assign the non-census recovery to the next census occasion, thus treating it as if had occurred on a later census; or (3) modifying the definition of an occasion so that it could represent non-census detection events. We rejected the first approach because it introduced potential data conflicts for tortoises actually captured or recaptured alive in the census immediately before being recovered dead. We rejected the second approach because the gap between censuses (except for consecutive censuses from the same year) ranged from 4 to 10 years, and we were uncertain of the potential biases in misattributing the year of recovery. We chose the third approach; for tortoises with non-census recoveries, we modified its next occasion by assigning it to the time of the non-census recovery.

For example, a tortoise (call it "Tortoise B") that is recovered in 1981 is modeled for two census occasions (censuses 1 and 2 in 1979) and an additional occasion for 1981. The data for Tortoise B resemble that of Tortoise A (from section, "Death Records" example) in the sense that (1) they are both modeled the same number of occasions with respect to demographic processes such as growth, movement, and survival, and (2) they are both dead on the last occasion. There are also two important differences. First, the timing of the third occasion differs (1985 for Tortoise A, and 1981 for Tortoise B), and consequently the "time since last census" variable, which is used to model growth and survival, also differs (for example, since the last census would be 1979, then 6 years for Tortoise A, and 2 years for Tortoise B). Second, the recovery of Tortoise A occurred as part of a census and is admissible for modeling the detection process, but the recovery of Tortoise B is not. Therefore, whereas Tortoise A is modeled through census 3 (that is, occasion 4) for both detection as well as demographic processes (growth, movement, and survival), Tortoise B is handled slightly differently and modeled through census 2 (occasion 3 ) for the detection process and through a modified version of occasion 4 (modified for the non-census recovery timing) for the demographic processes.

To manage the different occasions that were admissible for the different processes (demographic or detection), for non-census recovered tortoises, we defined a "last census" index equal to the last census occasion prior to the non-census recovery (for example, for Tortoise B, occasion 3). For non-census recovered tortoises, the "last census" index was also one occasion less than the "last occasion" index (see section "Death Records"; for Tortoise B, occasion 4). Demographic processes were modeled through the "last occasion" index, whereas detection processes were modeled through the "last census" index. For tortoises that were recovered on a census, the "last census" index was equal to the "last occasion" index. For tortoises that were never recovered nor confirmed dead, the "last census" index and "last occasion" index were both equal to 15.

In addition to non-census recoveries, we considered incorporating records of non-census live captures or recaptures into the model. These live records, when they occur prior to the first detection on a census or after the last detection on a census, can provide some additional information about the period of years when a tortoise was present. We visually inspected first and last non-census live records and found that they generally occurred close in time to the nearest detection on a census. We decided that there was little to gain from incorporating live non-census records into the model. 
Table 1.2. Years when non-census detections (captures, recaptures, or recoveries) occurred, their timing in relation to census surveys, and the corresponding occasion in the model to which they were assigned.

\begin{tabular}{clc}
\hline Year & Timing in relation to censuses & Assigned occasion \\
\hline 1978 & Before census 1 & 1 \\
1981 & Between censuses 2 and 3 & 4 \\
1982 & Between censuses 2 and 3 & 4 \\
1986 & Between censuses 4 and 5 & 6 \\
1987 & Between censuses 4 and 5 & 6 \\
1988 & Between censuses 4 and 5 & 6 \\
1989 & Between censuses 6 and 7 & 8 \\
1990 & Between censuses 6 and 7 & 8 \\
1991 & Between censuses 6 and 7 & 8 \\
1992 & Between censuses 6 and 7 & 8 \\
1997 & Between censuses 9 and 10 & 11 \\
1998 & Between censuses 10 and 11 & 12 \\
1999 & Between censuses 10 and 11 & 12 \\
2000 & Between censuses 10 and 11 & 12 \\
2001 & Between censuses 10 and 11 & 12 \\
2014 & After census 14 & NA \\
\hline
\end{tabular}

\section{Latent States}

Latent states (unobserved states) of tortoises occurred on census occasions when they were not captured or recaptured and hence were unavailable for us to observe their states. As part of the Bayesian analysis, the MCMC follows an iterative process that simulates the distributions of likely values for all latent variables. Because the MCMC process can be extremely time-consuming and memory-intensive, especially when large numbers of parameters or latent variables are involved, we reduced the number of latent variables by applying constraints and filling data gaps whenever possible. Specifically, we filled data gaps in size-age or survival states when a comparison of observed states in previous and successive occasions indicated that the tortoise must have remained in the same state during any intervening occasions. We also reduced the number of occasions that we input into the model whenever a tortoise was recovered and removed and unavailable for detection in subsequent occasions.

For example, Tortoise 1023 was captured alive on occasions 2, 4, and 5 (that is, censuses 1, 3, and 4), and recovered dead on occasion 8 (census 7). Survival state variables are coded as $1=$ not-yet-entered, $2=$ live, $3=$ dead, or NA=not captured or recaptured. Occasion 1 is the dummy census (see section "Intervals"), and all tortoises are set to the "not-yet-entered" state (table 1.3).

Although the tortoise was not observed at occasion 3, we know that it must have been alive in that occasion because it was recaptured alive in two later occasions. We filled the gap in occasion 3 with a live code (2); however, we could not fill the gaps for occasions 6 and 7. Because the tortoise was found dead in occasion 8, we only needed to model this tortoise's data through occasion 8, thus leaving 2 latent survival state variables for the MCMC to model (table 1.4).

As a second example, Tortoise 907 was captured alive on occasions 4 and 5 (that is, censuses 3 and 4) and never encountered again (table 1.5).

Table 1.3. Observed survival states ( $1=$ not-yet-entered, $2=$ alive, $3=$ dead) and latent survival states (NA) by occasion number, for Tortoise 1023.

\begin{tabular}{cccccccccccccccc}
\hline Occasion & $\mathbf{1}$ & $\mathbf{2}$ & $\mathbf{3}$ & $\mathbf{4}$ & $\mathbf{5}$ & $\mathbf{6}$ & $\mathbf{7}$ & $\mathbf{8}$ & $\mathbf{9}$ & $\mathbf{1 0}$ & $\mathbf{1 1}$ & $\mathbf{1 2}$ & $\mathbf{1 3}$ & $\mathbf{1 4}$ & $\mathbf{1 5}$ \\
\hline Survival state & 1 & 2 & NA & 2 & 2 & NA & NA & 3 & NA & NA & NA & NA & NA & NA & NA \\
\hline
\end{tabular}


Table 1.4. Model input on survival states (1=not-yet-entered, $2=$ alive, $3=$ dead) and latent survival states (NA) by occasion number, for Tortoise 1023.

\begin{tabular}{ccccccccc}
\hline 0ccasion & $\mathbf{1}$ & $\mathbf{2}$ & $\mathbf{3}$ & $\mathbf{4}$ & $\mathbf{5}$ & $\mathbf{6}$ & $\mathbf{7}$ & $\mathbf{8}$ \\
\hline Survival state & 1 & 2 & 2 & 2 & 2 & NA & NA & 3 \\
\hline
\end{tabular}

Table 1.5. Observed survival states (1=not-yet-entered, $2=$ =alive) and latent survival states (NA) by occasion number, for Tortoise 907.

\begin{tabular}{cccccccccccccccc}
\hline Occasion & $\mathbf{1}$ & $\mathbf{2}$ & $\mathbf{3}$ & $\mathbf{4}$ & $\mathbf{5}$ & $\mathbf{6}$ & $\mathbf{7}$ & $\mathbf{8}$ & $\mathbf{9}$ & $\mathbf{1 0}$ & $\mathbf{1 1}$ & $\mathbf{1 2}$ & $\mathbf{1 3}$ & $\mathbf{1 4}$ & $\mathbf{1 5}$ \\
\hline Survival state & 1 & NA & NA & 2 & 2 & NA & NA & NA & NA & NA & NA & NA & NA & NA & NA \\
\hline
\end{tabular}

Because the survival status of Tortoise 907 was unknown throughout the remainder of the study, the state variables for occasions 6 through 15 are latent. The state variables for occasions 2 and 3 are also latent because we do not have data indicating whether this tortoise had entered the population at those occasions. We modeled this tortoise's data through occasion 15 and had 12 latent survival state variables to model.

\section{Initializing Markov Chains}

We iterated (MCMC) simulations to generate statistical distributions for the probable values of latent state variables (see section "Latent States") and, thus jointly, of model coefficients (see section "Mathematical Models"). A list of these parameters is shown in table 1.6. We initialized three Markov chains with different sets of starting estimates. We initialized model coefficients by using random number generating functions based on diffuse prior distributions, based on a normal distribution with mean 0 and standard deviation 100, except for one coefficient for the effect of location on detection probability, $\theta_{L}$. We were concerned that estimates of detection probability could confound with estimates of survival probability due to declining numbers of detections in the later occasions. We also expected that tortoises should be at least as easy to detect when they were outside the fence as compared to when they were inside the fence because the area outside of the fence deteriorated with large denuded areas and the ground compacted owing to off-road vehicle activity and sheep grazing. To incorporate this relationship, we constrained our prior distribution for $\theta_{L}$ to range uniformly from 0 to 1 .

The latent states included survival state (1=not-yet-entered, $2=$ live, or $3=\mathrm{dead})$, size-age state $(1=\mathrm{JV}, 2=\mathrm{IM}$, or $3=\mathrm{AD})$, and location state ( $1=$ Inside or $2=$ Outside). We did not simply apply random generation to initialize all of these states because of the high chance of generating contradictory sequences (for example, AD size-age in one occasion and IM in the next, or dead in one occasion and live in the next). It was impossible for the model to process a chain when it was initialized with a contradictory state sequence.

We considered two alternative approaches to initializing state variables in the chains: (1) initialize the chains randomly but constrained by a set of rules that ensured allowable state sequences, or (2) initialize the chains deterministically using a set of rules that ensured allowable state sequences but assign different chains with different rules based on very different assumptions about survival and growth. We chose the latter approach because it had two advantages over the former approach: (1) it was easier to implement and (2) it allowed us to choose rules that produce very different sets of initial values (that is, greater over-dispersion) between the chains to better assess model convergence. When multiple chains converge to the same solutions, after being initialized with widely varying values, then those solutions are considered to be robust (Gilks and others, 1996). 
Table 1.6. Model parameters in three different Markov chains initialized using random distributions (normal, uniform, and Bernoulli) and contrasting deterministic rules to maximize differences in starting values among the chains.

[Parameter coefficients and sex were initialized at random from $N(0,100)$ (normal distributions with mean 0 and standard deviation 100), $U(0,1)$ (uniform distributions with range 0 to 1 ), and $B(0.5)$, (Bernoulli distributions with probability 0.5 ) distributions]

\begin{tabular}{|c|c|c|}
\hline Parameter & Description & Initialization method \\
\hline$\xi_{O J I}, \xi_{J I}, \xi_{O J A}, \xi_{J A}$ & JV to IM or AD growth coefficients & $N(0,100)$ \\
\hline$\xi_{O I A}, \xi_{I A}$ & IM to $\mathrm{AD}$ growth coefficients & $N(0,100)$ \\
\hline$\psi_{O O I}, \psi_{F O I}, \psi_{S z O I}$ & OUT to IN movement coefficients & $N(0,100)$ \\
\hline$\phi_{0}, \phi_{F}, \phi_{S z}, \phi_{L}$ & Annual survival coefficients & $N(0,100)$ \\
\hline$p_{L}$ & Detection coefficient, location effect & $U(0,1)$ \\
\hline$X_{F, i}$ & $\operatorname{Sex}(1=F, 0=M)$ of tortoise $i$, if latent & $B(0.5)$ \\
\hline$X_{S z, i t}$ & Size-age $(1=\mathrm{JV}, 2=\mathrm{IM}, 3=\mathrm{AD})$ of tortoise $\mathrm{i}$ at occasion $\mathrm{t}$, if latent & $\begin{array}{l}\text { Chain 1: normal-growth rule } \\
\text { Chain 2: normal-growth rule } \\
\text { Chain 3: slow-growth rule }\end{array}$ \\
\hline
\end{tabular}

We initialized chains using biologically contrasting scenarios about the population demographics. For the best-case scenario, we initialized the first two chains by assigning the latent size-age and survival state variables to initial values that were consistent with normal-growth and high-survival rates. We varied the two "best-case scenario" chains according to different movement scenarios. Specifically, for the first chain we initialized location state variables according to a minimal-movement rule by initializing latent locations to last known previous location or next soonest location, whichever was more immediate. We initialized the second chain using a random-movement rule by initializing latent locations randomly as inside or outside. For the worst-case scenario, we initialized a third chain by initializing the latent size-age and survival state variables with values consistent with slow-growth and low-survival rates. For example, under low survival, we initialized tortoises as dead for latent survival states after the last live observation, and we initialized size-age states to the slowest growth possible within the intervals that tortoises were detected or initialized live (growth could not occur after death). We describe our rules for initializing survival and size-age states in greater depth in the following section. We initialized movement states in the worst-case scenario chain according to minimal-movement rules, also respecting the rule that tortoises would not move after death.

\section{Rules for Initializing Latent Survival States}

We applied two different initialization rules for latent variables of survival state based on worst-case (low-survival) and best-case (high-survival) scenarios for survival rates. Under the high-survival rule, we initialized all latent survival state variables to the "live" state. Under the low-survival rule, we initialized all latent survival state variables to the "dead" state, except in cases where a tortoise was later observed alive. To illustrate, we return to the examples of Tortoises 1023 and 907 (see section "Latent States"). Because Tortoise 1023 was last captured alive in occasion 5 and recovered dead in occasion 8, we assigned two different sets of initial values for the latent survival state in occasions 6 and 7.

The other occasions have data; therefore, they do not require initial values. Tortoise 907 was known to be alive in the population during occasions 4 through 5. The latent variables after the last occasion on which it was seen alive were all initialized to a live status under the high-survival rule, and to a dead status under the low-survival rule. We initialized the occasions prior to the first capture (occasions 2 and 3) to a not-yet-entered state under both rules. 
Table 1.7. Initialized values of latent survival states ( $1=$ not-yet-entered, $2=$ live, $3=$ dead) under high-survival and low-survival rules for Tortoise 1023, which was recovered dead in occasion 8.

[States for occasions 1-5 and 8 do not require initialization because they were not latent states. The observed survival state is copied from table 1.4 for reference]

\begin{tabular}{lcccccccc}
\hline \multicolumn{1}{c}{ Occasion } & $\mathbf{1}$ & $\mathbf{2}$ & $\mathbf{3}$ & $\mathbf{4}$ & $\mathbf{5}$ & $\mathbf{6}$ & $\mathbf{7}$ & $\mathbf{8}$ \\
\hline Observed survival state & 1 & 2 & 2 & 2 & 2 & NA & NA & 3 \\
Initialized latent survival state (High-survival rule) & NA & NA & NA & NA & NA & 2 & 2 & NA \\
Initialized latent survival state (Low-survival rule) & NA & NA & NA & NA & NA & 3 & 3 & NA \\
\hline
\end{tabular}

Table 1.8. Initialized values of latent survival states (1=not-yet-entered, $2=a$ live, $3=$ dead) under high-survival and low-survival rules for Tortoise 907, which was last seen alive in occasion 5.

[States for occasions 1, 4, and 5 do not require initialization because they were not latent states. The observed survival state is copied from table 1.5 for reference]

\begin{tabular}{lccccccccccccccc}
\hline \multicolumn{1}{c}{ Occasion } & $\mathbf{1}$ & $\mathbf{2}$ & $\mathbf{3}$ & $\mathbf{4}$ & $\mathbf{5}$ & $\mathbf{6}$ & $\mathbf{7}$ & $\mathbf{8}$ & $\mathbf{9}$ & $\mathbf{1 0}$ & $\mathbf{1 1}$ & $\mathbf{1 2}$ & $\mathbf{1 3}$ & $\mathbf{1 4}$ & $\mathbf{1 5}$ \\
\hline Observed survival state & 1 & $\mathrm{NA}$ & $\mathrm{NA}$ & 2 & 2 & $\mathrm{NA}$ & $\mathrm{NA}$ & $\mathrm{NA}$ & $\mathrm{NA}$ & $\mathrm{NA}$ & $\mathrm{NA}$ & NA & NA & NA & NA \\
$\begin{array}{l}\text { Initialized latent survival state } \\
\quad \text { (High- survival rule) }\end{array}$ & $\mathrm{NA}$ & 1 & 1 & $\mathrm{NA}$ & $\mathrm{NA}$ & 2 & 2 & 2 & 2 & 2 & 2 & 2 & 2 & 2 & 2 \\
$\begin{array}{l}\text { Initialized latent survival state } \\
\text { (Low-survival rule) }\end{array}$ & $\mathrm{NA}$ & 1 & 1 & $\mathrm{NA}$ & $\mathrm{NA}$ & 3 & 3 & 3 & 3 & 3 & 3 & 3 & 3 & 3 & 3 \\
\hline
\end{tabular}

\section{Latent Size-Age States}

We also applied two different initialization rules for latent variables of size-age state based on worst-case (slow-growth) and best-case (normal-growth) scenarios for growth rates. We initialized latent size-age states using a combination of information based on size-age and number of years since the last previous detection, size-age and number of years until the next soonest detection, and the survival status at the next soonest detection.

Under the slow-growth rule, we initialized all latent size-age state variables to the last known size-age state, except in cases where the next detection of the tortoise was as a dead recovery. Because we only used the slow-growth rule in combination with the low-survival rule, for initializing the worst-case scenario chain, we were constrained to initializing latent size-age states in a manner that was consistent with initialized latent survival states under the low-survival rule. For any latent states preceding a dead recovery, we initialized the latent size-age to the size-age at the time of recovery because the latent survival state would have been initialized to the dead state and tortoises cannot grow when dead.

Under the normal-growth rule, we initialized size-age based on a combination of information about the observed size-age of that tortoise during any previous or successive detections, and the timing or occasion numbers of those detections. For any latent states that preceded the very first detection of a tortoise, we initialized the latent size-age to the first detected size-age. For any latent states after the first detection, we developed a hierarchy of rules for choosing which detection event (the last previous or the next successive) would provide more useful information from a biological perspective for initializing the latent size-age under normal growth conditions:

1. If $<5$ years since last previous detection, then initialize latent size-age to the size-age observed at the last previous detection; or

2. If $\geq 5$ years since last previous detection but $<5$ years until the next successive detection, then initialize size-age to the size-age observed at the next successive detection; or

3. If $\geq 5$ years since last previous detection, and either $\geq 5$ years until the next successive detection or no successive detections, then initialize size-age based on the size-age state at the time of the last previous detection and the number of years since the last previous detection; and

A. If the tortoise was in the JV size-age class at the time of the last previous detection, and there were $\geq 5$ years and $<15$ years since the last previous detection, and $\geq 5$ years since the next detection, then initialize size-age to the IM size-age class; or 
B. If the tortoise was in the JV size-age class at the time of the last previous detection, and there were $\geq 15$ years since the last previous detection, and $\geq 5$ years until the next detection, then initialize size-age to the AD size-age class; or

C. If the tortoise was in the IM size-age class at the time of the last previous detection, and there were $<10$ years since the last previous detection, and $\geq 5$ years since the next detection, then initialize size-age to the IM size-age class.

For example, the size-age states for Tortoises 1023 and 907, respectively, are presented in tables 1.9 and 1.10 , with observed size-age states shown for reference and the corresponding initial values under the slow-growth and normal-growth rules.

Table 1.9. Observed size-age states and initialized values of latent size-age states (1=JV, $2=I M, 3=A D$ ) under slow-growth and normal-growth rules for Tortoise 1023, which was recovered dead in occasion 8 .

[Under the slow-growth rule for the worst-case scenario Markov chain, the latent size-age states in occasions 6 and 7 are initialized to the same size-age (AD) of the tortoise when it was recovered dead in occasion 8 , for consistency with latent survival states having been set to the dead state under the low-survival rule (see table 1.7)]

\begin{tabular}{lcccccccc}
\hline \multicolumn{1}{c}{ Occasion } & $\mathbf{1}$ & $\mathbf{2}$ & $\mathbf{3}$ & $\mathbf{4}$ & $\mathbf{5}$ & $\mathbf{6}$ & $\mathbf{7}$ & $\mathbf{8}$ \\
\hline Year & - & 1979 & 1979 & 1985 & 1985 & 1989 & 1989 & 1993 \\
Observed size-age & $\mathrm{NA}$ & 1 & $\mathrm{NA}$ & 2 & 2 & $\mathrm{NA}$ & $\mathrm{NA}$ & 3 \\
Initial values (slow-growth) & 1 & $\mathrm{NA}$ & 1 & $\mathrm{NA}$ & $\mathrm{NA}$ & 3 & 3 & NA \\
Initial values (normal-growth) & 1 & NA & 1 & NA & NA & 2 & 2 & NA \\
\hline
\end{tabular}

Table 1.10. Observed size-age states and initialized values of latent size-age states $(1=J V, 2=I M, 3=A D)$ under slow-growth and normal-growth rules for Tortoise 907, which was captured in the JV size-age state in occasions 4 and 5 .

\begin{tabular}{lccccccccccccccc}
\hline \multicolumn{1}{c}{ Occasion } & $\mathbf{1}$ & $\mathbf{2}$ & $\mathbf{3}$ & $\mathbf{4}$ & $\mathbf{5}$ & $\mathbf{6}$ & $\mathbf{7}$ & $\mathbf{8}$ & $\mathbf{9}$ & $\mathbf{1 0}$ & $\mathbf{1 1}$ & $\mathbf{1 2}$ & $\mathbf{1 3}$ & $\mathbf{1 4}$ & $\mathbf{1 5}$ \\
\hline Year & - & 79 & 79 & 85 & 85 & 89 & 89 & 93 & 93 & 97 & 97 & 02 & 02 & 12 & 12 \\
Obs. size-age & NA & NA & NA & 1 & 1 & NA & NA & NA & NA & NA & NA & NA & NA & NA & NA \\
Slow-growth & 1 & 1 & 1 & NA & NA & 1 & 1 & 1 & 1 & 1 & 1 & 1 & 1 & 1 & 1 \\
Normal-growth & 1 & 1 & 1 & NA & NA & 1 & 1 & 2 & 2 & 2 & 2 & 3 & 3 & 3 & 3 \\
\hline
\end{tabular}




\section{Convergence}

We used the "jagsUI" package in R software as an interface for using Just Another Gibbs Sampler (JAGS) software to conduct MCMC simulations with Gibbs sampling algorithms (Plummer, 2003, 2016; Kellner, 2016; R Core Team, 2016). We parallel-processed the Markov chains in batches that could complete in a day, approximately 5,000 iterations per chain, at a thinning rate of 25. Following each day's updates, we examined trace plots and potential scale reduction factors to assess the chains for convergence (Gelman and others, 1997). We monitored burn-in activity (large shifts in the trace plots) and convergence of some parameters, and we continued after burn-in until there were no further discernible shifts or convergence among the trace of chains, nor improvements in the Gelman-Rubin tests for at least 2 days of simulations in a row, about 35,000 iterations total.

When chains had still not reached convergence or failed to mix, we adapted our model to address the possibility that our initial values could be too overdispersed or that our prior distributions could be too diffuse to converge to the correct solution. Gibbs sampling methods, and more generally Metropolis-Hastings algorithms, have been noted to have problems converging in high-dimensional models (Betancourt, 2017). We repeated our analysis, except that we divided it into two stages. In the first stage, we simplified our model to a Cormack-Jolly-Seber (hereinafter "CJS") model, which only estimates the parameter coefficients of the growth, movement, and survival processes. In the second stage, we refit our JS model with revised sets of initial values and prior distributions based on information resulting from the CJS model.

More specifically, we simplified our model by omitting population estimation, which contributes to the high dimensionality of our model with parameter-extended data-augmentation, the dummy occasion, and the "not-yet-entered" survival state. This essentially reduced our model to a CJS model, but we retained the same model equations with the same diffuse priors and specifications as our JS model. Another difference between the CJS model and the JS model is that the CJS model only uses data from a tortoise conditional upon its first capture. We ran simulations based on the CJS model and assessed convergence in the same manner as for the JS model.

When the CJS model reached convergence, we took the posterior distributions of model coefficients and used them to generate new initial values and new prior distributions for model coefficients in our JS model (table 1.11). We generated new initial values for model coefficients of our JS model by randomly sampling directly from the posterior distributions from the CJS model. For those model coefficients that had converged chains, we kept the original diffuse prior, $N(0,100)$; that is, normal distribution with mean of 0 and standard deviation of 100 . For model coefficients that did not converge, we revised the prior so that it was centered around the corresponding posterior distribution from the CJS model but with a variance larger than the CJS posterior variance and smaller than the original diffuse variance. We repeated simulations using the revised prior distributions and initial values and assessed convergence in the same manner. 
Table 1.11. Prior and initialization distributions for model coefficient parameters of the Jolly-Seber model after revisions based on a converged Cormack-Jolly-Seber model.

[Parameters were initialized at random from $N(\mu, \sigma)$ (normal distribution with mean $\mu$ and standard deviation $\sigma$ ), $U(0,1)$ (uniform distribution with range 0 to 1 ), and $G(\alpha, \beta)$ (Gamma distribution shape $\alpha$, and scale $\beta$ ) distributions]

\begin{tabular}{llcc}
\hline Parameter & \multicolumn{1}{c}{ Description } & $\begin{array}{c}\text { Revised initial } \\
\text { values }\end{array}$ & $\begin{array}{c}\text { Revised prior } \\
\text { distribution }\end{array}$ \\
\hline$\gamma_{O J I}$ & JV to IM growth intercept & $N(-2.7,0.41)$ & $N(-2.7,1.12)$ \\
$\gamma_{O J A}$ & JV to AD growth intercept & $N(-5.5,1.00)$ & $N(-5.6,1.41)$ \\
$\gamma_{J I}$ & Effect of years on JV to IM growth & $N(0.46,0.11)$ & $N(0.5,0.79)$ \\
$\gamma_{J A}$ & Effect of years on JV to AD growth & $N(0.76,0.18)$ & $N(0.8,0.91)$ \\
$\gamma_{O I A}$ & IM to AD growth intercept & $N(-1.8,0.40)$ & $N(-1.8,1.12)$ \\
$\gamma_{I A}$ & Effect of years on IM to AD growth & $N(0.58,0.15)$ & $N(0.6,0.88)$ \\
$\lambda_{O I O}$ & IN to OUT movement intercept & $N(-4.2,1.30)$ & $N(0,100)$ \\
$\lambda_{F I O}$ & Movement of females vs males & $N(-0.49,0.32)$ & $N(0,100)$ \\
$\lambda_{S Z I O}$ & Movement of larger vs smaller sizes & $N(0.39,0.43)$ & $N(0,100)$ \\
$\lambda_{O O I}$ & OUT to IN movement intercept & $N(-2.2,0.85)$ & $N(0,100)$ \\
$\lambda_{F O I}$ & Movement of females vs males & $N(-0.53,0.31)$ & $N(0,100)$ \\
$\lambda_{S z O I}$ & Movement of larger vs smaller sizes & $N(0.24,0.29)$ & $N(0,100)$ \\
$\psi_{O}$ & Annual survival intercept & $N(0.60,0.27)$ & $N(0.6,1.0)$ \\
$\psi_{F}$ & Survival of females vs males & $N(0.28,0.08)$ & $N(0,100)$ \\
$\psi_{S Z}$ & Survival of larger vs smaller sizes & $N(0.29,0.08)$ & $N(0.3,0.77)$ \\
$\psi_{L}$ & Survival outside vs inside fence & $N(-0.14,0.10)$ & $N(0,100)$ \\
$\theta_{O}$ & Detection intercept & $N(-1.3,0.31)$ & $N(-1.6,1.0)$ \\
$\theta_{F}$ & Detection of females vs males & $N(-0.023,0.13)$ & $N(0,100)$ \\
$\theta_{S z}$ & Detection of larger vs smaller sizes & $N(0.79,0.10)$ & $N(0.8,0.79)$ \\
$\theta_{L}$ & Detection outside vs inside fence & $G(1.4,1 / 0.06)$ & $U(0,1)$ \\
\hline & & &
\end{tabular}




\section{References Cited}

Betancourt, M., 2017, A conceptual introduction to Hamiltonian Monte Carlo: ArXiv e-prints 1701.02434v1, https://arxiv.org/abs/1701.02434.

Gelman, A.B., Carlin, J.S., Stern, H.S., and Rubin, D.B., 1997, Bayesian data analysis: New York, Chapman and Hall, 526 p.

Gilks, W.R., Richardson, S., and Spiegelhalter, D.J., 1996, Markov chain Monte Carlo in practice: New York, Chapman and Hall, $486 \mathrm{p}$.

Jolly, G.M., 1965, Explicit estimates from capture-recapture data with both death and immigration-stochastic model: Biometrika, v. 52, nos. 1-2, p. 225-248, https://doi.org/10.1093/biomet/52.1-2.225.

Kellner, K., 2016, jagsUI—A wrapper around 'rjags' to streamline 'JAGS' analyses, R package version 1.4.2: The Comprehensive R Archive Network website, https://CRAN.R-project.org/package=jagsUI.

Kendall, W.L., Nichols, J.D., and Hines, J.E., 1997, Estimating temporary emigration using capture-recapture data with Pollock's robust design: Ecology, v. 78, p. 563-578.

Kéry, M., and Schaub, M., 2012, Bayesian population analysis using WinBUGS-A hierarchical perspective: Elsevier, Inc. Academic Press, 554 p.

Link, W.A., and Barker, R.J., 2010, Bayesian inference with ecological applications: London, Academic Press, 354 p.

Plummer, M., 2003, JAGS - A program for analysis of Bayesian graphical models using Gibbs sampling: Proceedings of the 3rd International Workshop on Distributed Statistical Computing (DSC 2003), March 20-22, 2003, Vienna, Austria, ISSN 1609-395X.

Plummer, M., 2016, rjags—Bayesian graphical models using MCMC, R package version 4-6: The Comprehensive R Archive Network website, https://CRAN.R-project.org/package=rjags.

Pollock, K.H., 1982, A capture-recapture design robust to unequal probability of capture: The Journal of Wildlife Management, v. 46, no. 3, p. 752-760, https://doi.org/10.2307/3808568.

R Core Team, 2016, R-A language and environment for statistical computing: Vienna, Austria, R Foundation for Statistical Computing, https://www.R-project.org/.

Royle, J.A., and Dorazio, R.M., 2012, Parameter-expanded data augmentation for Bayesian analysis of capture-recapture models: Journal of Ornithology, v. 152, no. S2, p. 521-537, https://doi.org/10.1007/s10336-010-0619-4.

Schwarz, C.J., and Arnason, A.N., 1996, A general methodology for the analysis of capture-recapture experiments in open populations: Biometrics, v. 52, no. 3, p. 860-873, https://doi.org/10.2307/2533048.

Seber, G.A.F., 1965, A note on the multiple recapture census: Biometrika, v. 52, nos. 1-2, p. 249-260, https://doi.org/10.1093/biomet/52.1-2.249. 


\section{Appendix 2. Technical Details of Modeling Results}

We ran Markov chain Monte Carlo (MCMC) simulations on our model as described in appendix 1. Based on trials running MCMC simulations on previous versions of our model, we observed that the chains wandered for the first several thousand iterations and then stabilized after approximately 15,000 iterations. For the final version of our model, we started the chains with a burn-in of 15,000 iterations per chain to discard, followed by another set of 15,000 iterations, with a thinning rate of 25 , yielding 600 posterior samples per chain, for a total of 1,800 samples across the three chains. The processing time to run the chains using parallel processing was 142 hours (nearly 6 days). Based on visual inspection of trace plots of the chains, the chains did not appear to settle into their posterior distributions until approximately the 20,000th iteration, about 5,000 iterations beyond the 15,000 burn-in iterations we originally planned to discard. The chains for some of the parameters indicated high autocorrelations and low effective sample sizes. We continued to process additional iterations, in increments of 15,000 , to update the model and monitor the chains for further improvements in their convergence. We repeated four updates of the model, with each update processing an additional 15,000 iterations with a thinning rate of 25 and yielding 1,800 new samples. We examined trace plots after each successive update and saw no further improvements or changes to the chains. The four updates took 75, 59, 33 , and 33 hours, respectively ( $8-9$ days processing time). We report results from the fourth and final update.

Following recommendations by Gelman and others (1997) that potential scale reduction factors $(\hat{r})$ should be close to 1 and much less than 1.2 for acceptable convergence, our Jolly-Seber model satisfied the Gelman-Rubin test for convergence for some but not all model parameters. We reached convergence for all model parameter coefficients associated with movement and the effects of sex and location on survival and detection probabilities (table 2.1). When combining the samples from the three Markov chains, and accounting for autocorrelations within the chains, the effective sample sizes describing the posterior distributions of these coefficients varied from 39 to 1,800 .

Table 2.1. Model coefficient parameters and summaries of Markov chain Monte Carlo simulations of posterior distribution estimates.

[Model coefficients are listed in terms of their mathematical symbol in model equations (see appendix 1) and their programming code name as used in figures 2.1-2.5. (Note: Greek letter naming conventions were not consistent between symbols and code names.) Posterior distribution summaries include mean, standard deviation (SD), median (50-percent quantile), and 90-percent credible interval (5-percent and 95-percent quantiles). Potential scale reduction factors (PSRF; $\hat{r}$ ), indicating chains converged when $<1.1$, and effective sample sizes are presented. Abbreviation: \%, percent; SD, standard deviation]

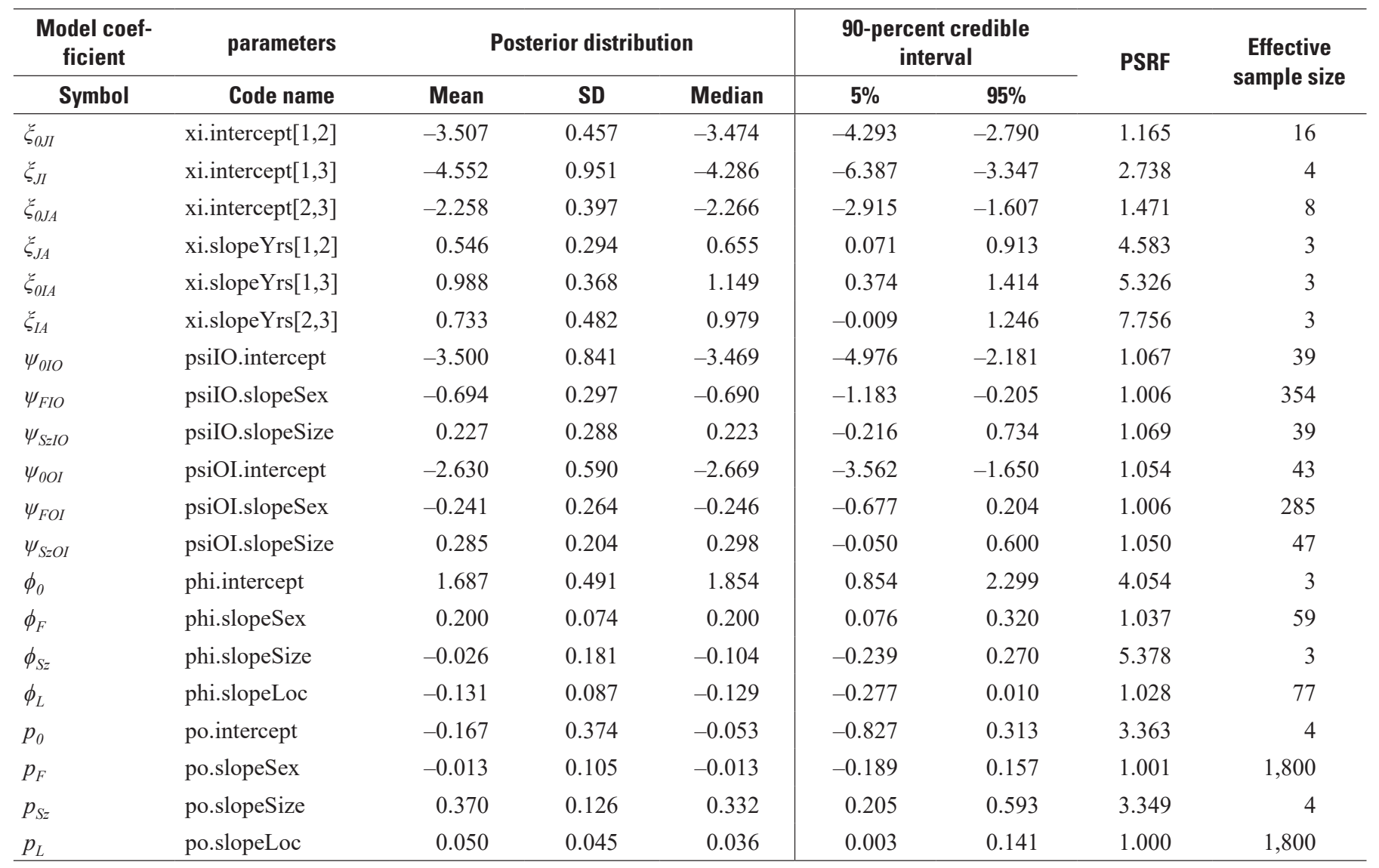


Our model did not reach convergence for any parameters associated with size-age variables, including all parameter coefficients for growth processes and the slope parameter coefficients for the effects of size-age on movement, survival, and detection probabilities (table 2.1). Intercept parameter coefficients also did not converge, as intercept parameter coefficients are correlated with slope parameter coefficients. For these parameters, the $\hat{r}$ statistic ranged from 1.4 to 7.8. Combining the samples of the three Markov chains, the effective sample sizes for the posterior distributions of these coefficients were $\leq 16$, and in some cases only 3 .

When examining individual chains for the non-converged parameters, for example, the effect of time (in years) on growth rates, there were consistent patterns (figs. 2.1 and 2.2). Both chains based on normal-growth and high-survival (chains 1 and 2 , red and black) were always well mixed, whereas the third chain based on slow-growth and low-survival (chain 3, green) was different from the other two, and in some cases completely separate from the other two. In cases when the third chain did not overlap with the other two chains, the effective sample size was equal to 3 , the number of chains. Although chains did not mix for these parameters, they exhibited stationary behavior (that is, did not display trends with increasing iterations) at least over the last 60,000 out of 90,000 iterations (339 hours) that we ran for this model. Thus, although these parameter estimates did not converge in the sense of reaching agreement between all three chains, individual chains appeared to have converged to a distribution. Different chains appeared to converge to different distributions depending on whether they were initialized according to normal-growth/high-survival starting values or slow-growth/low-survival starting values.

When differences between chains occurred, the median values of model parameters never differed by more than approximately 2 (figs. 2.1-2.5), which is a relatively small difference when considering that model parameters from different chains were randomly initialized from normal distributions with a standard deviation of 100. This indicates that our model managed to extract some information from the data with regard to these parameters. However, differences of 2 in the parameters can still translate into large inconsistencies in derived parameters (for example, probability and population density estimates). For example, -1 and 1 on the logit scale translate to 27 -percent and 73-percent probabilities, respectively. The uncertainty in our estimates due to the lack of convergence among chains is reflected by widened 90-percent credible intervals that represent the majority range of estimates across all three chains omitting the lowest 5 percent and highest 5 percent of values. A 90-percent level is high enough to ensure that the credible interval will include median estimates from the highest and lowest chains no matter how different they are.

Having converged chains is important when making statistical inferences. When chains are unconverged or when they converge to different posterior distributions, they cannot all be correct. This calls into question the validity of results from any one chain, and we are unable to determine the true posterior distribution or even which chain is closest to it. We present posterior estimates based on the combined results of unconverged chains because, although less ideal than those of converged chains, they can still be useful when they provide similar inferences to one another. Differences among chains reveal some sensitivities to their initial values, which we had systematically set to opposite ends of the biological spectrum for growth (normal or slow), survival (high or low), and movement (minimal or random). We believe that the truth falls somewhere between the ends of the spectrum, and that our 90-percent credible intervals from the posterior distribution based on unconverged chains likely encapsulate most of the true posterior distribution. Therefore, unconverged chains can still be useful when they indicate similar population inferences (figs. 2.6, 2.7, and 2.8). For example, consider the parameters for the effect of time (in years) since the previous survey on the probability of growth from JV to IM, JV to AD, and IM to AD size-age states (fig. 2.1, bottom row, and fig. 2.2, first two rows). When combining the chains together, the posterior distribution densities were bimodal, displaying two separate concentrations of estimates for the effect of years on growth. These estimates were mostly positive, and almost completely positive for growths from JV to IM or from JV to AD. The positive estimates suggest a positive correlation wherein an increased time (in years) since the last survey will increase the probability of growth to a larger size-age state. The third chain in green, which was initialized based on slow-growth starting values, rests lower on the plots than the other two chains (red and black), which were initialized based on normal-growth starting values. Both chains support a positive effect, at least for the JV to IM and the JV to $\mathrm{AD}$ growths, with the effect being greater with the normal-growth chain than the slow-growth chain (figs. 2.6 and 2.7). Likewise, all three chains consistently indicate similar patterns of large decreases in population size over time (fig. 2.8). 
Trace of xi.intercept[1,2]

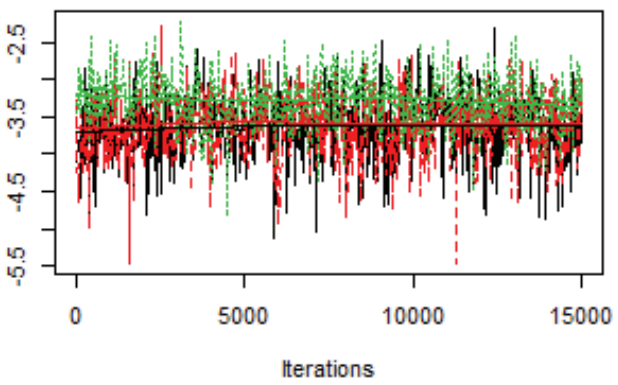

Trace of xi.intercept[1,3]

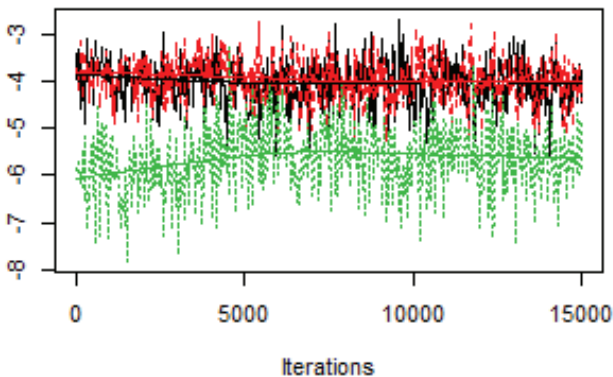

Trace of xi.intercept[2,3]

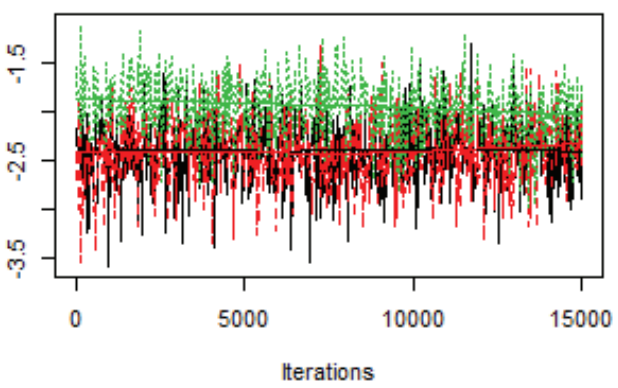

Trace of xi.slopeYrs[1,2]

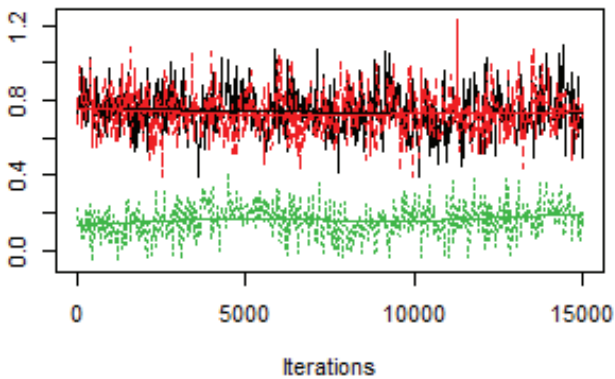

Density of xi.intercept[1,2]

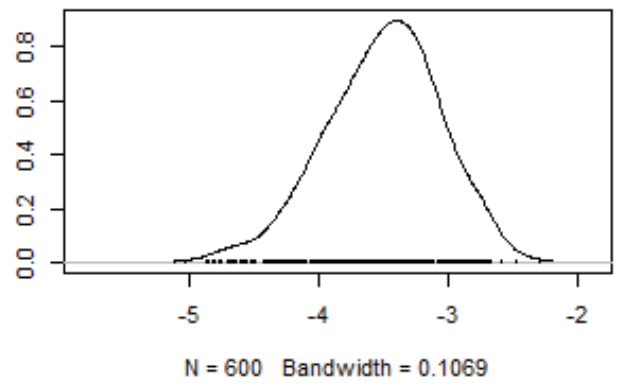

Density of xi.intercept[1,3]

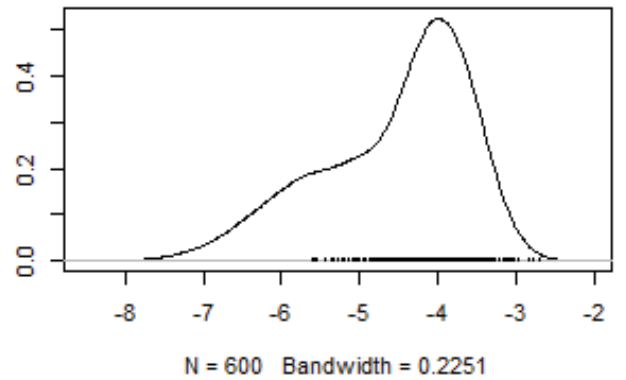

Density of xi.intercept[2,3]

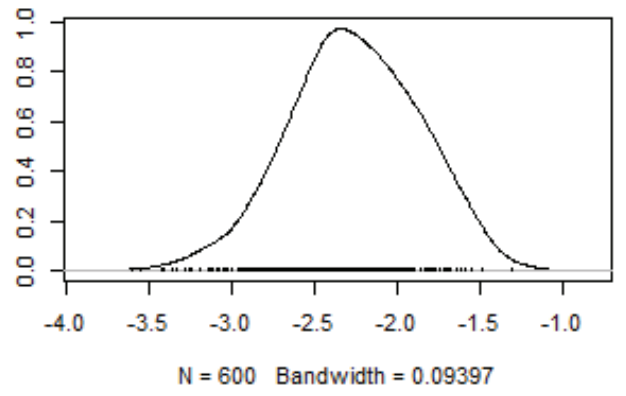

Density of xi.slopeYrs[1,2]

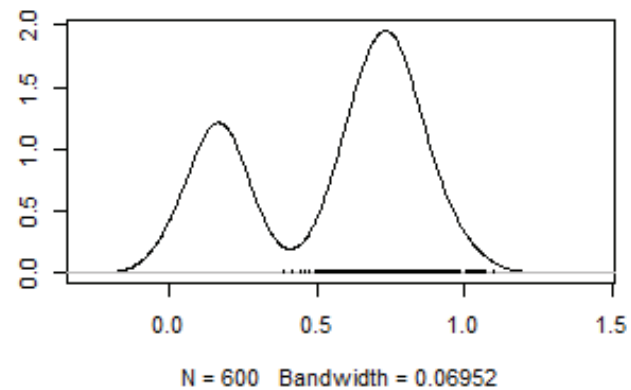

Figure 2.1. Trace plots and posterior distribution density plots of three Markov chains for four parameters the intercepts of growth models from JV to IM size-age (xi.intercept [1,2]) (top row), JV to AD size-age (xi. intercept [1,3]) (second from top row), IM to AD size-age (xi.intercept [2,3]) (third from top row), and the effect of time (in years) since previous survey on growth from JV to IM size-age (xi.slopeYrs [1,2] (bottom row). Two chains (red and black) were started with normal-growth and high-survival initial values, and the third chain (green) was started with slow-growth and low-survival initial values. 
Trace of xi.slopeYrs[1,3]

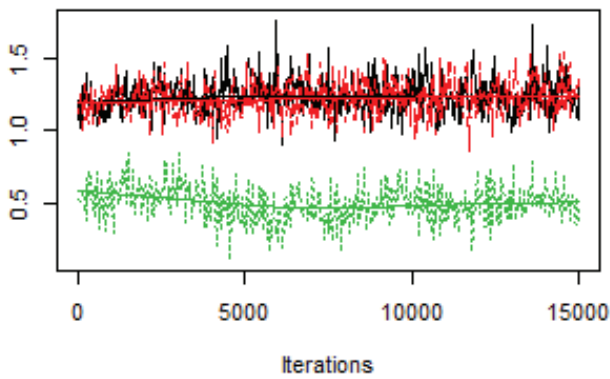

Trace of xi.slopeYrs[2,3]

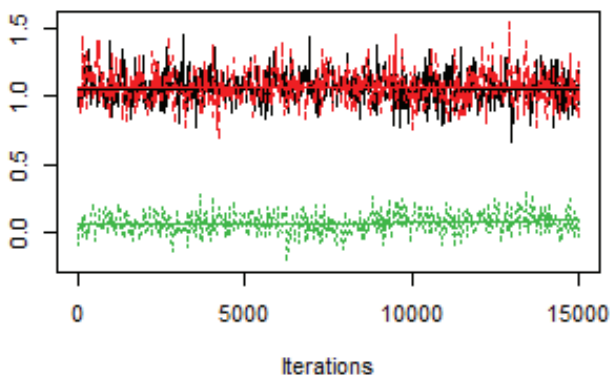

Trace of psilO.intercept

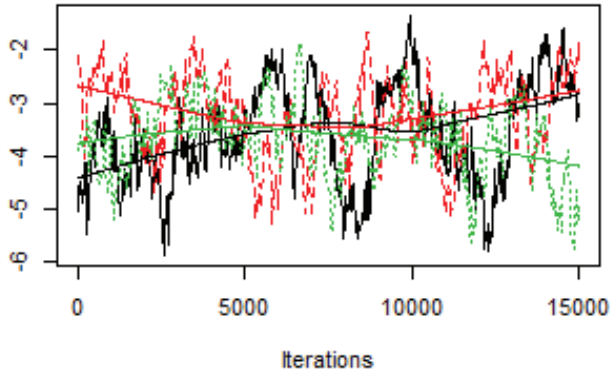

Trace of psilO.slopeSex

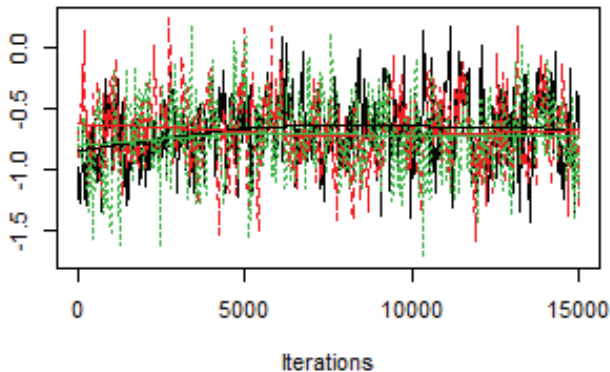

Density of xi.slopeYrs[1,3]

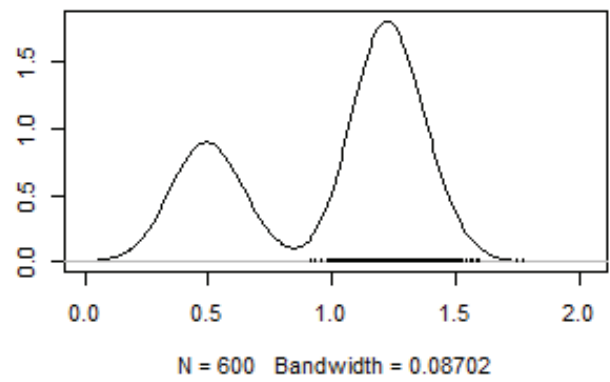

Density of xi.slopeYrs[2,3]

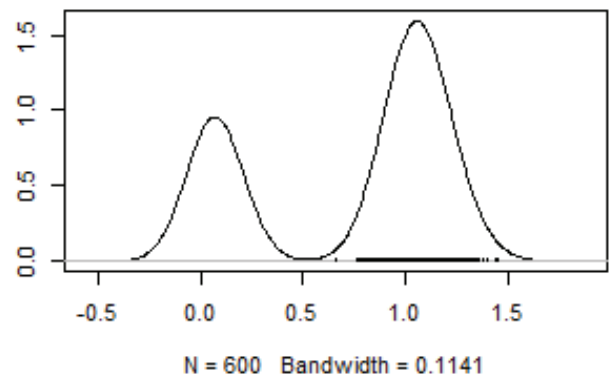

Density of psilO.intercept

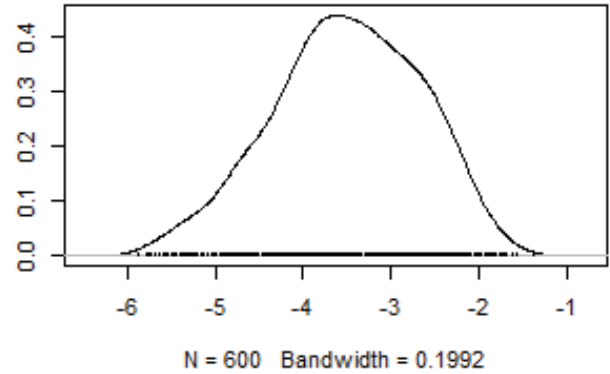

Density of psilO.slopeSex

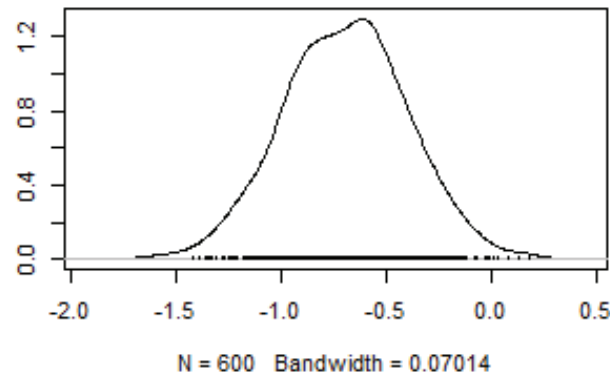

Figure 2.2. Trace plots and posterior distribution density plots of three Markov chains for four parameters - the effect of time (in years) since previous survey on growth from JV to AD size-age (xi. slopeYrs [1,3]) (top row), IM to AD size-age (xi.slopeYrs [2,3]) (second from top row), and the intercept and effect of sex (being female) in the movement model from inside to outside (psil0.intercept [third from top row], psil0.slopeSex [bottom row]). Two chains (red and black) were started with normal-growth and high-survival initial values, and the third chain (green) was started with slow-growth and low-survival initial values. 
Trace of psilO.slopeSize

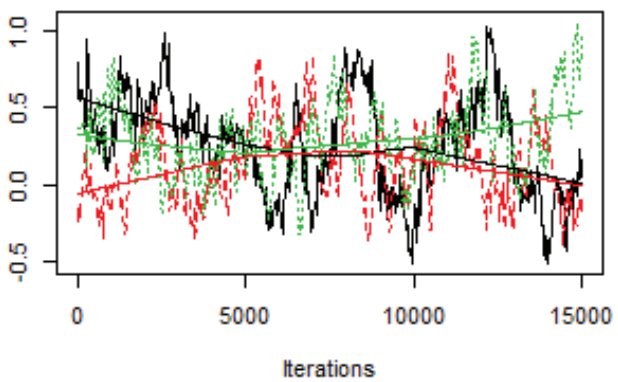

Trace of psiOl.intercept

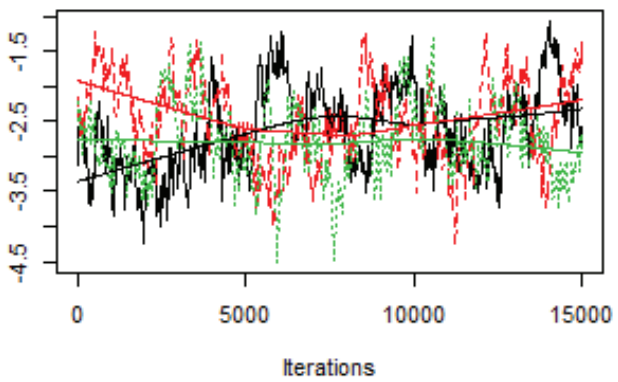

Trace of psiOl.slopeSex

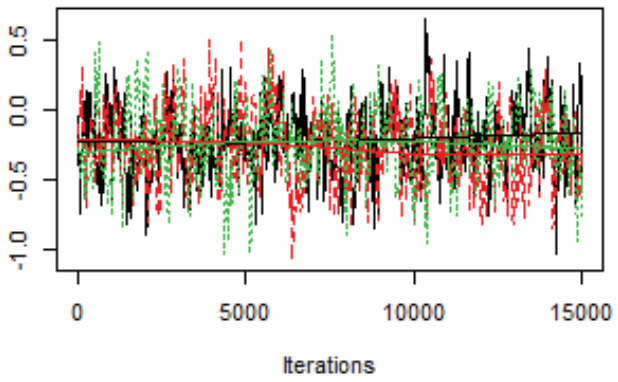

Trace of psiOI.slopeSize

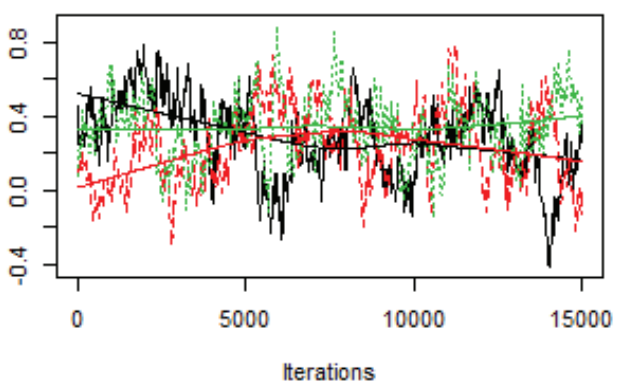

Density of psilO.slopeSize

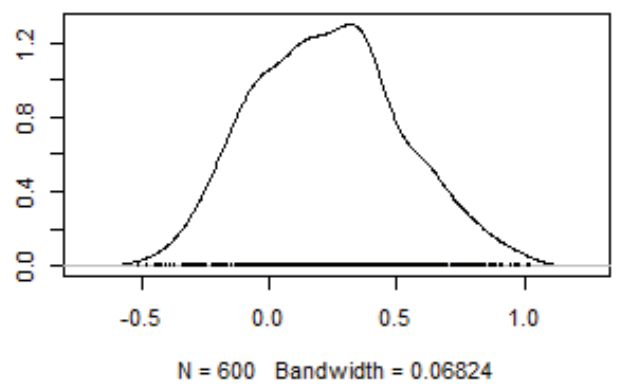

Density of psiOl.intercept

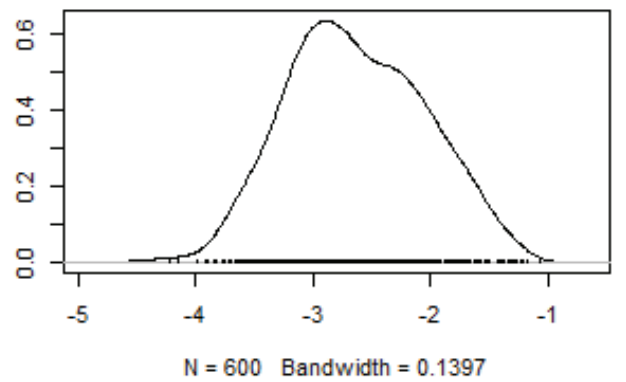

Density of psiOl.slopeSex

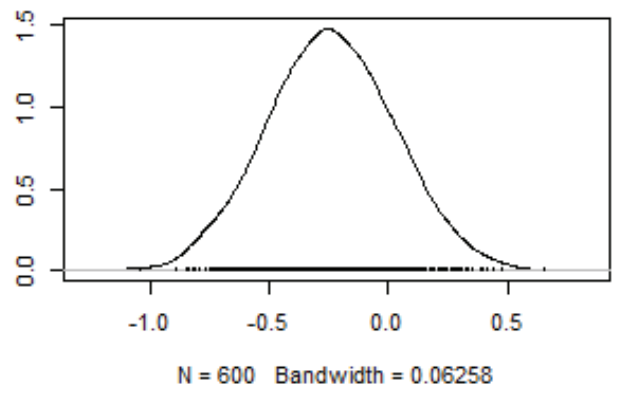

Density of psiOI.slopeSize

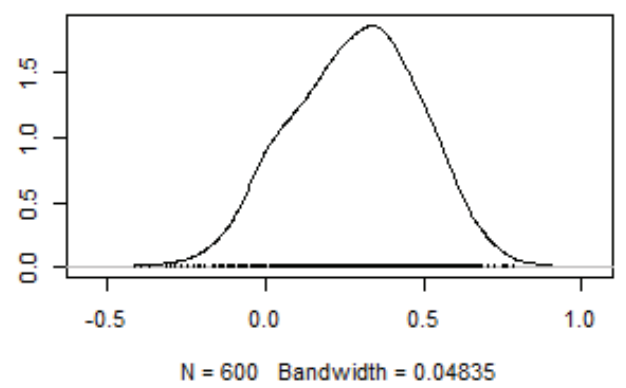

Figure 2.3. Trace plots and posterior distribution density plots of three Markov chains for four parameters - the effect of size-age on inside-to-outside movements (psil0.slopeSize) (top row), intercept in the outside-to-inside movement model (psiOl.intercept) (second from top row), and effects of sex (being female) and size-age on outside-to-inside movements (psiOl.slopeSex [third from top row], psiOl.slopeSize [bottom row]). Two chains (red and black) were started with normal-growth and high-survival initial values, and the third chain (green) was started with slow-growth and low-survival initial values. 
Trace of phi.intercept

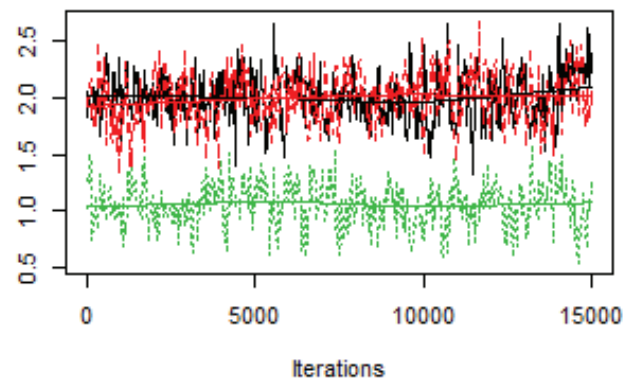

Trace of phi.slopeSex

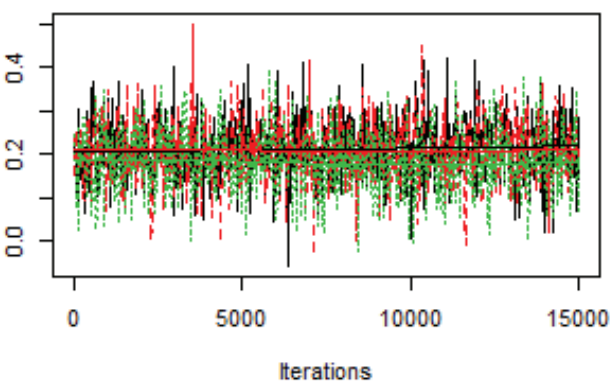

Trace of phi.slopeSize

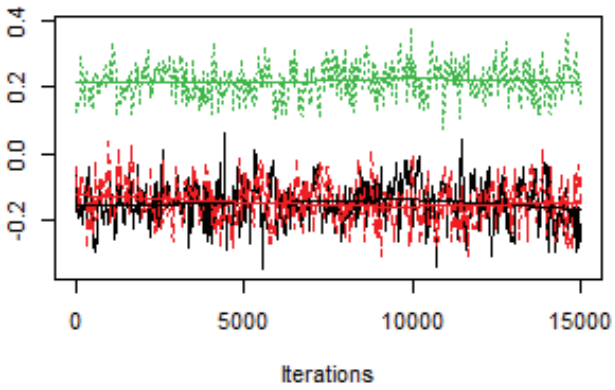

Trace of phi.slopeLoc

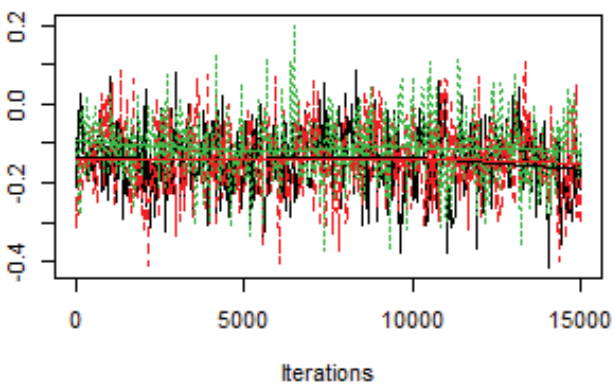

Density of phi.intercept

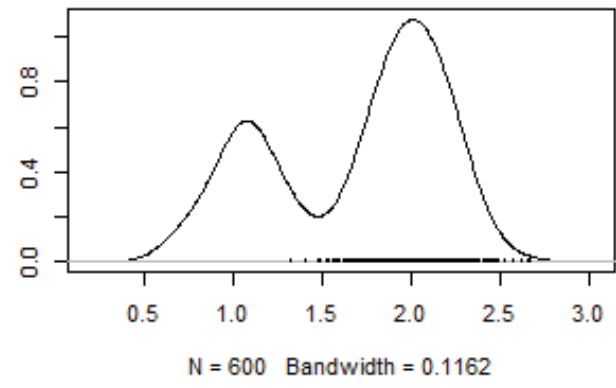

Density of phi.slopeSex

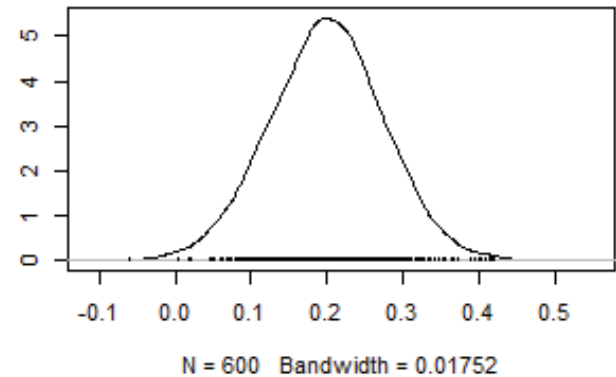

Density of phi.slopeSize

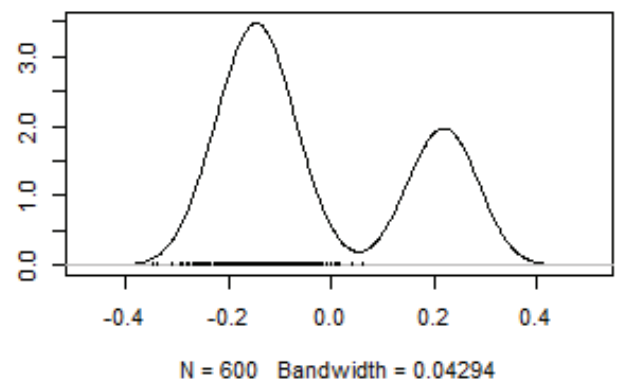

Density of phi.slopeLoc

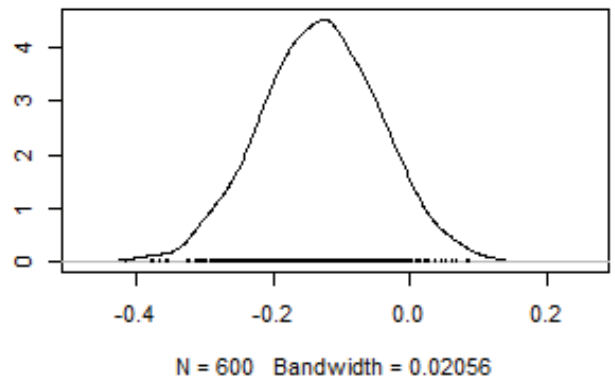

Figure 2.4. Trace plots and posterior distribution density plots of three Markov chains for four parameters - the intercept in the survival model (phi.intercept) (top row), and effects of sex (being female; phi.slopeSex) (second from top row), size-age (phi.slopeSize) (third from top row), and location (phi. slopeLoc) (bottom row) on survival. Two chains (red and black) were started with normal-growth and high-survival initial values, and the third chain (green) was started with slow-growth and low-survival initial values. 
Trace of po.intercept

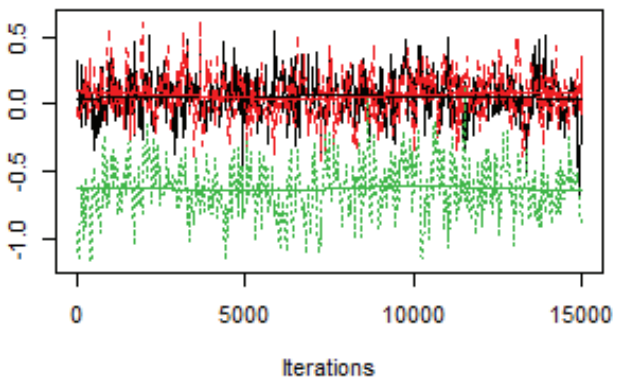

Trace of po.slopeSex

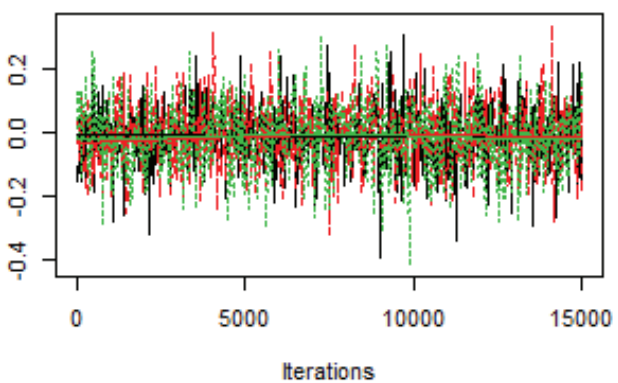

Trace of po.slopeSize

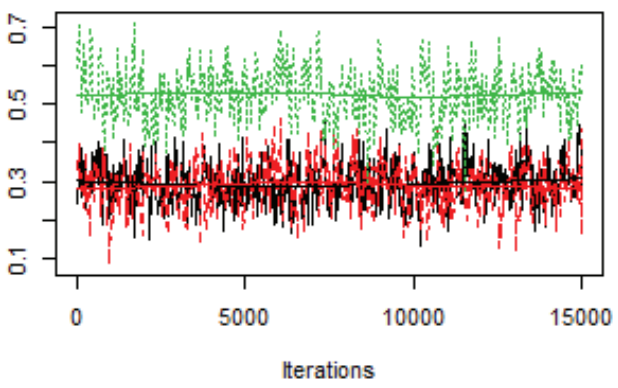

Trace of po.slopeLoc

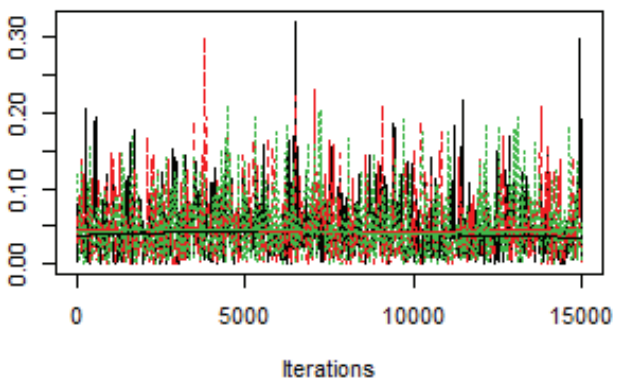

Density of po.intercept

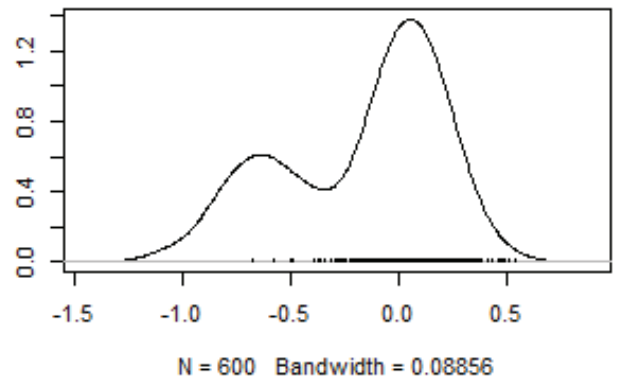

Density of po.slopeSex

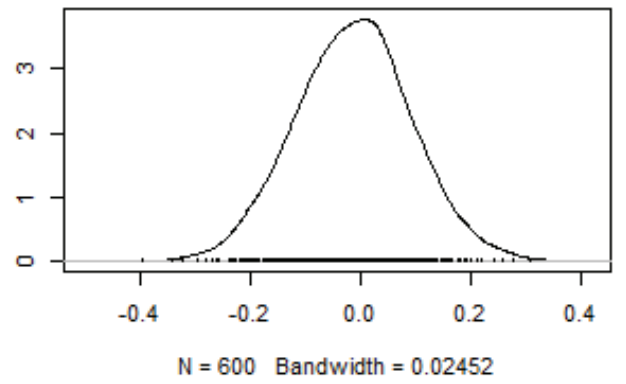

Density of po.slopeSize

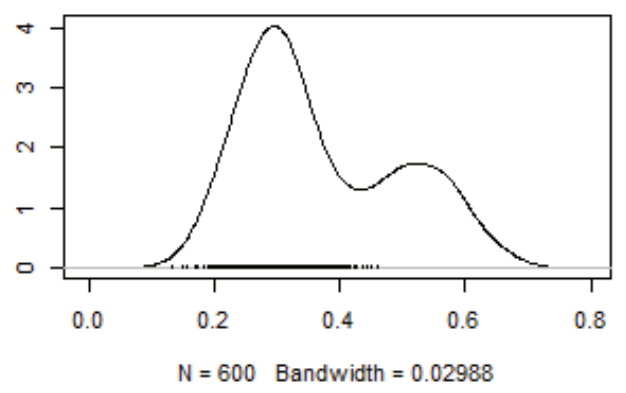

Density of po.slopeLoc

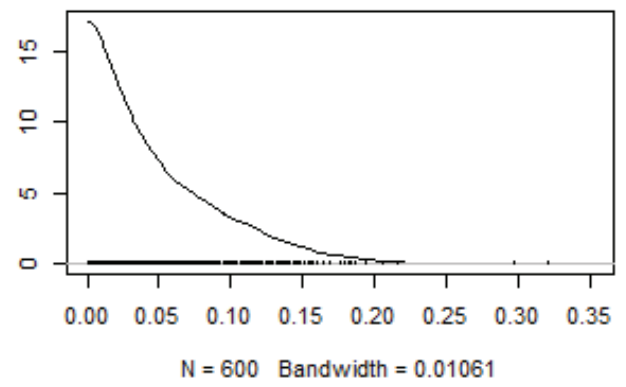

Figure 2.5. Trace plots and posterior distribution density plots of three Markov chains for four parameters - the intercept in the detection model (po.intercept) (top row), and effects of sex (being female; po.slopeSex) (second from top row), size-age (po.slopeSize) (third from top row), and location (po.slopeLoc) (bottom row) on survival. Two chains (red and black) were started with normal-growth and high-survival initial values, and the third chain (green) was started with slow-growth and low-survival initial values. 


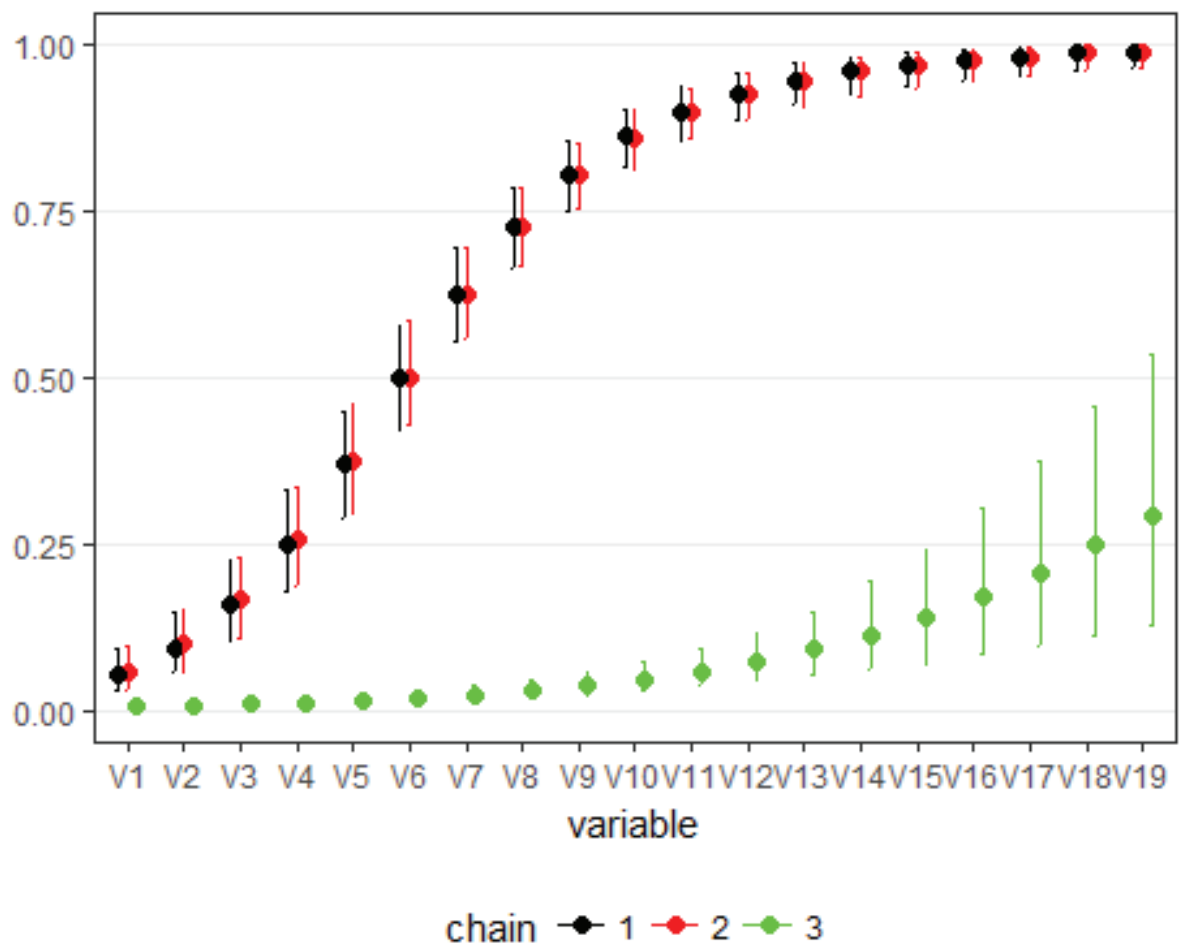

Figure 2.6. Medians (dots) and 90-percent credible intervals (bars) from posterior distributions based on three separate Markov chains for estimating the probability of transitioning from $\mathrm{JV}$ to $\mathrm{AD}$ size-age in relationship to increasing time since the previous survey. Variables V1-V19 correspond to time intervals (time since previous survey) ranging from 1 to 10 years in increments of one-half-years. Two chains (red and black) were started with normal-growth and high-survival initial values, and the third chain (green) was started with slow-growth and low-survival initial value. 


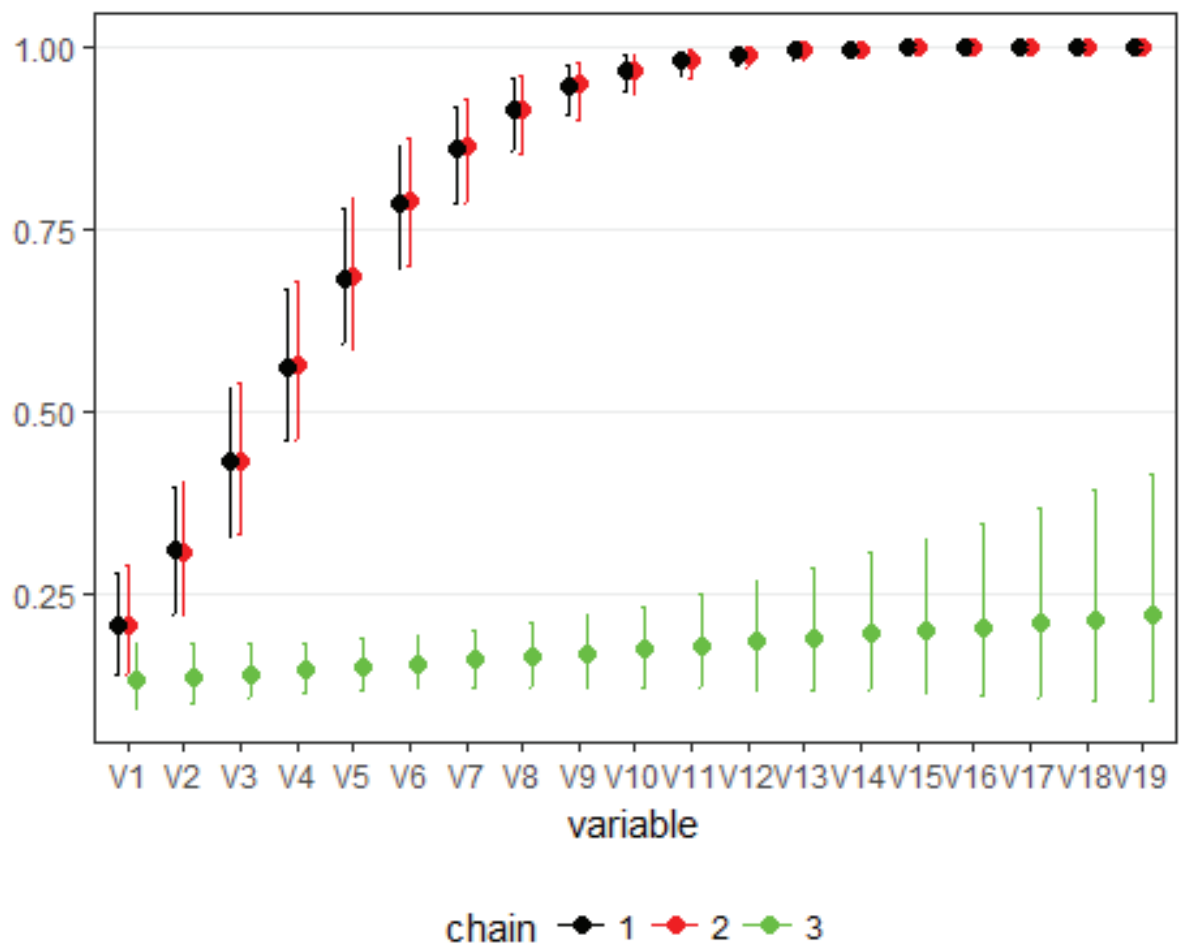

Figure 2.7. Medians (dots) and 90-percent credible intervals (bars) from posterior distributions based on three separate Markov chains for estimating the probability of transitioning from IM to $A D$ size-age in relationship to increasing time since the previous survey. Variables V1-V19 correspond to time intervals (time since previous survey) ranging from 1 to 10 years in increments of one-half-years. Two chains (red and black) were started with normal-growth and high-survival initial values, and the third chain (green) was started with slow-growth and low-survival initial value. 


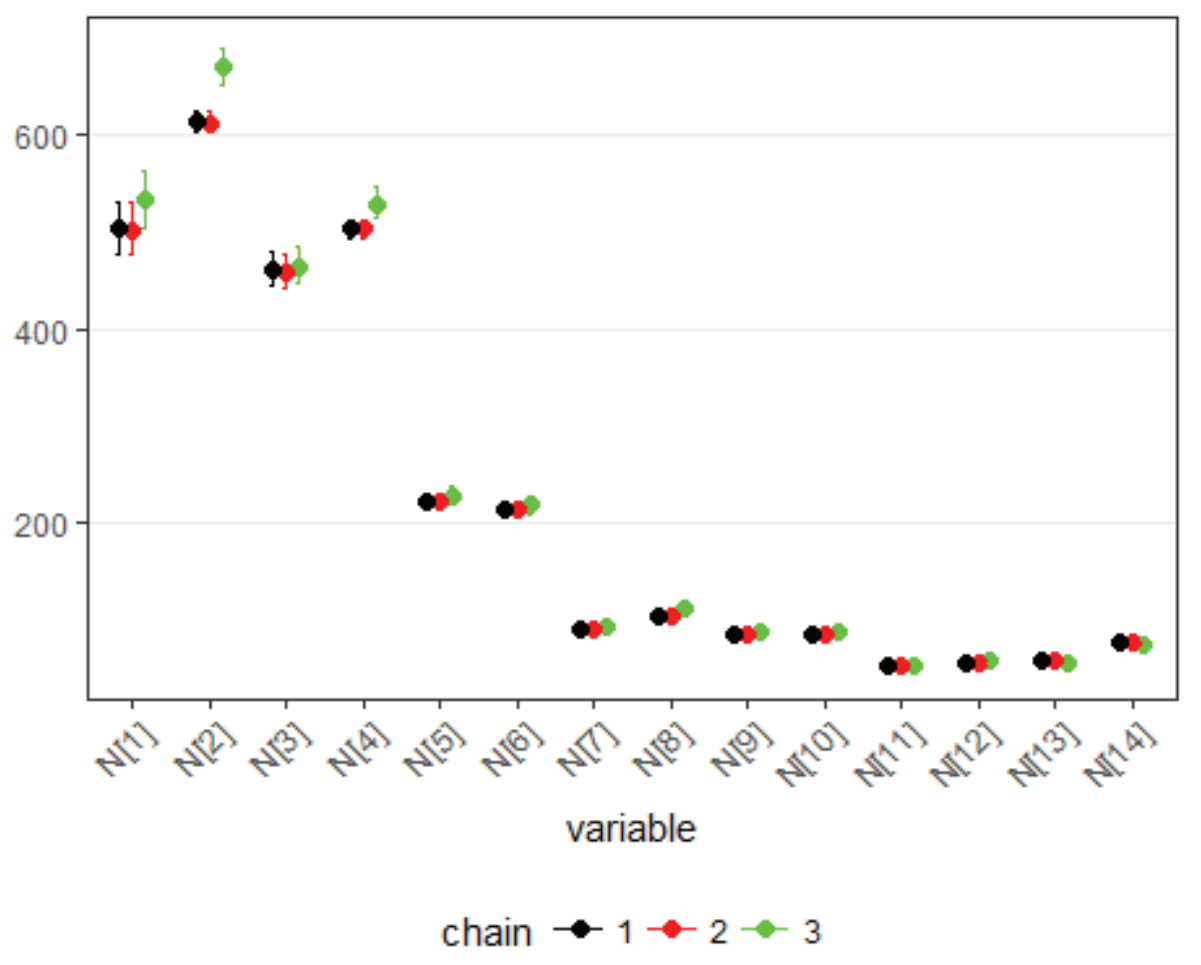

Figure 2.8. Medians (dots) and 90-percent credible intervals (bars) from posterior distributions based on three separate Markov chains for estimating the population size of desert tortoises across 14 surveys in 1979 (N[1] and N[2]), 1985 (N[3] and N[4]), 1989 (N[5] and $N[6]), 1993$ (N[7] and N[8]), 1997 (N[9] and N[10]), 2002 (N[11] and N[12]), and 2012 (N[13] and $\mathrm{N}[14])$. Two chains (red and black) were started with normal-growth and high-survival initial values, and the third chain (green) was started with slow-growth and low-survival initial value.

\section{Reference Cited}

Gelman, A.B., Carlin, J.S., Stern, H.S., and Rubin, D.B., 1997, Bayesian data analysis: New York, Chapman and Hall, 526 p. 


\section{Appendix 3. JAGS Code for Multistate JS Model}

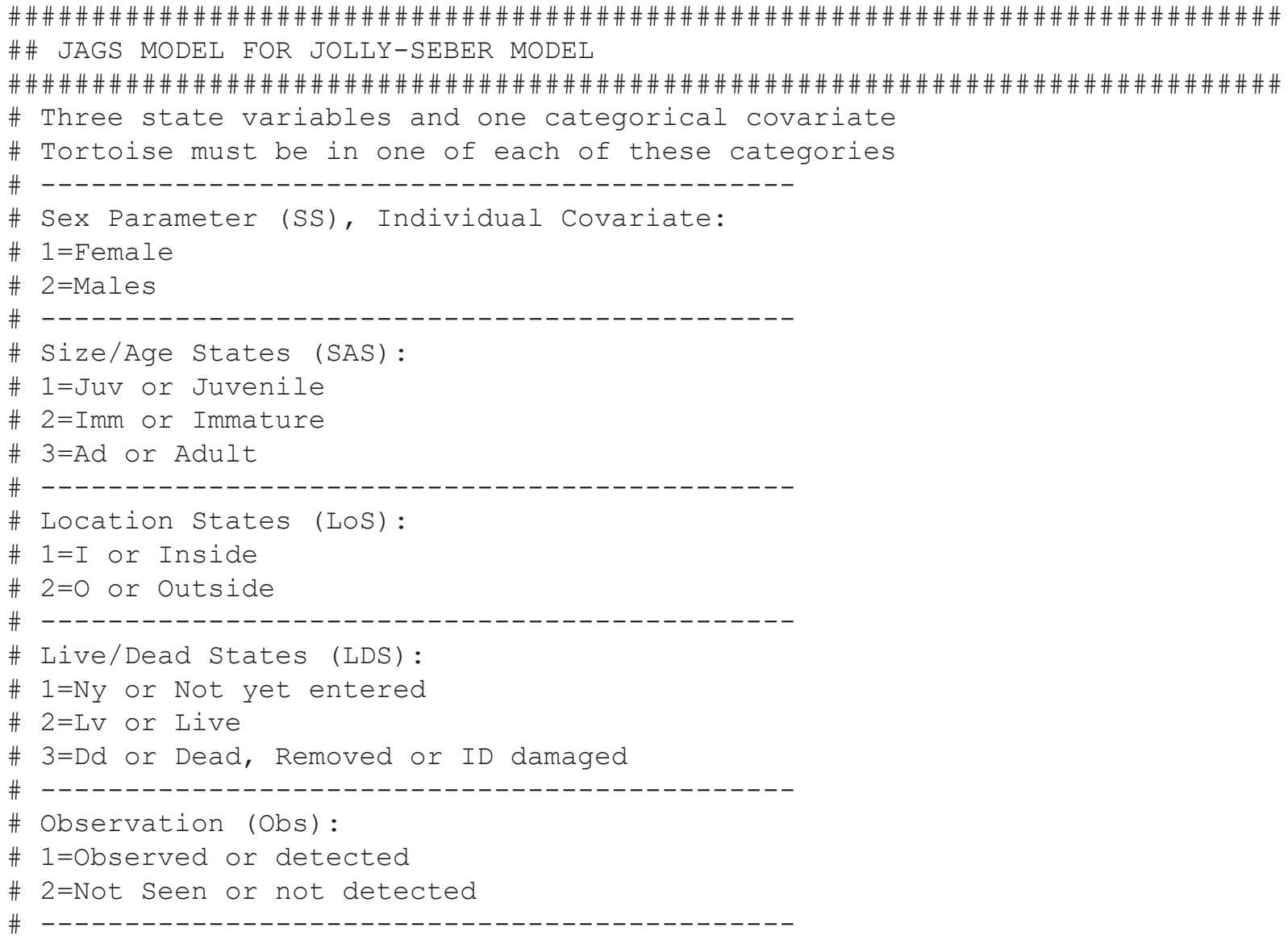

model \{

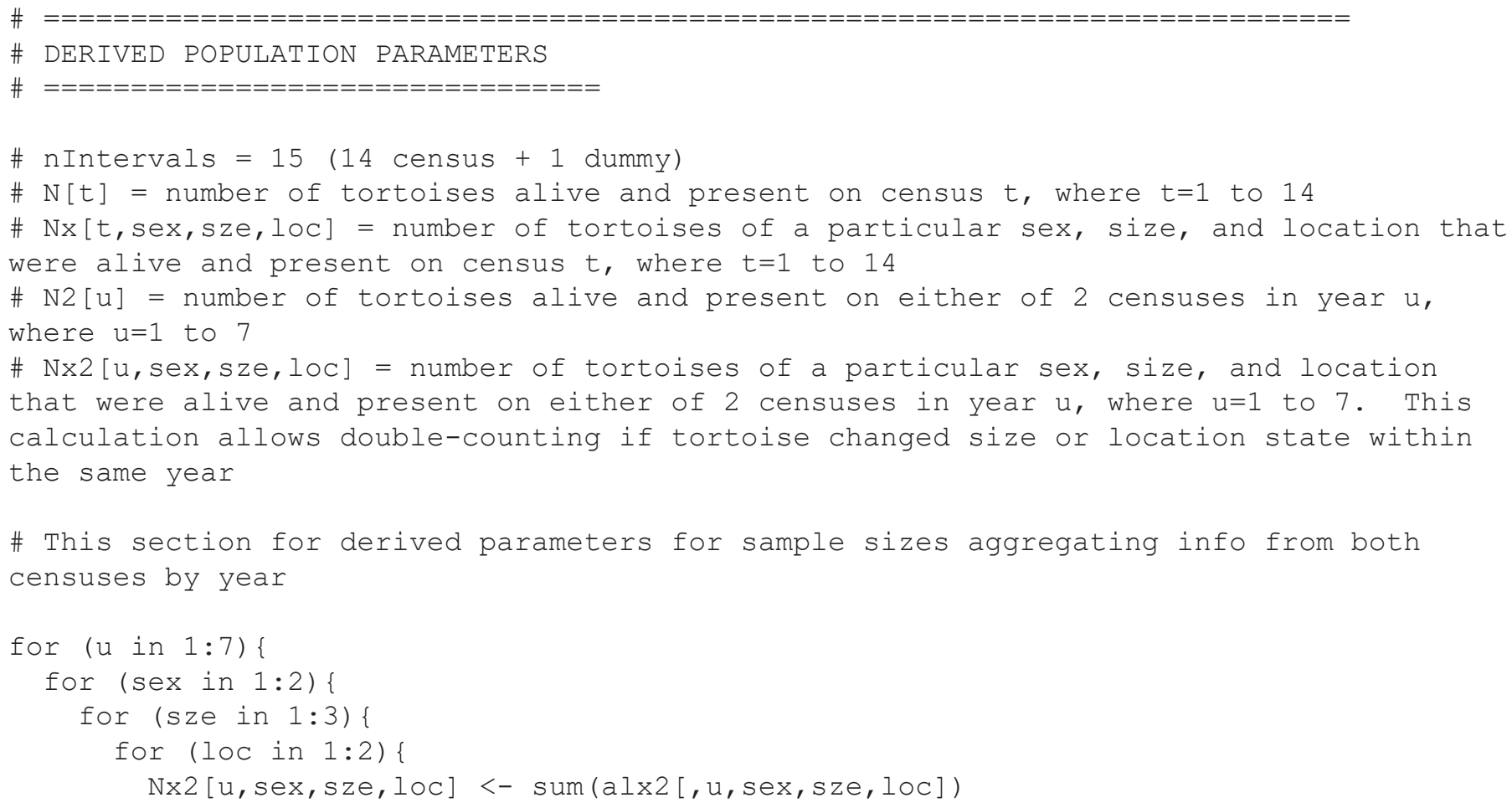




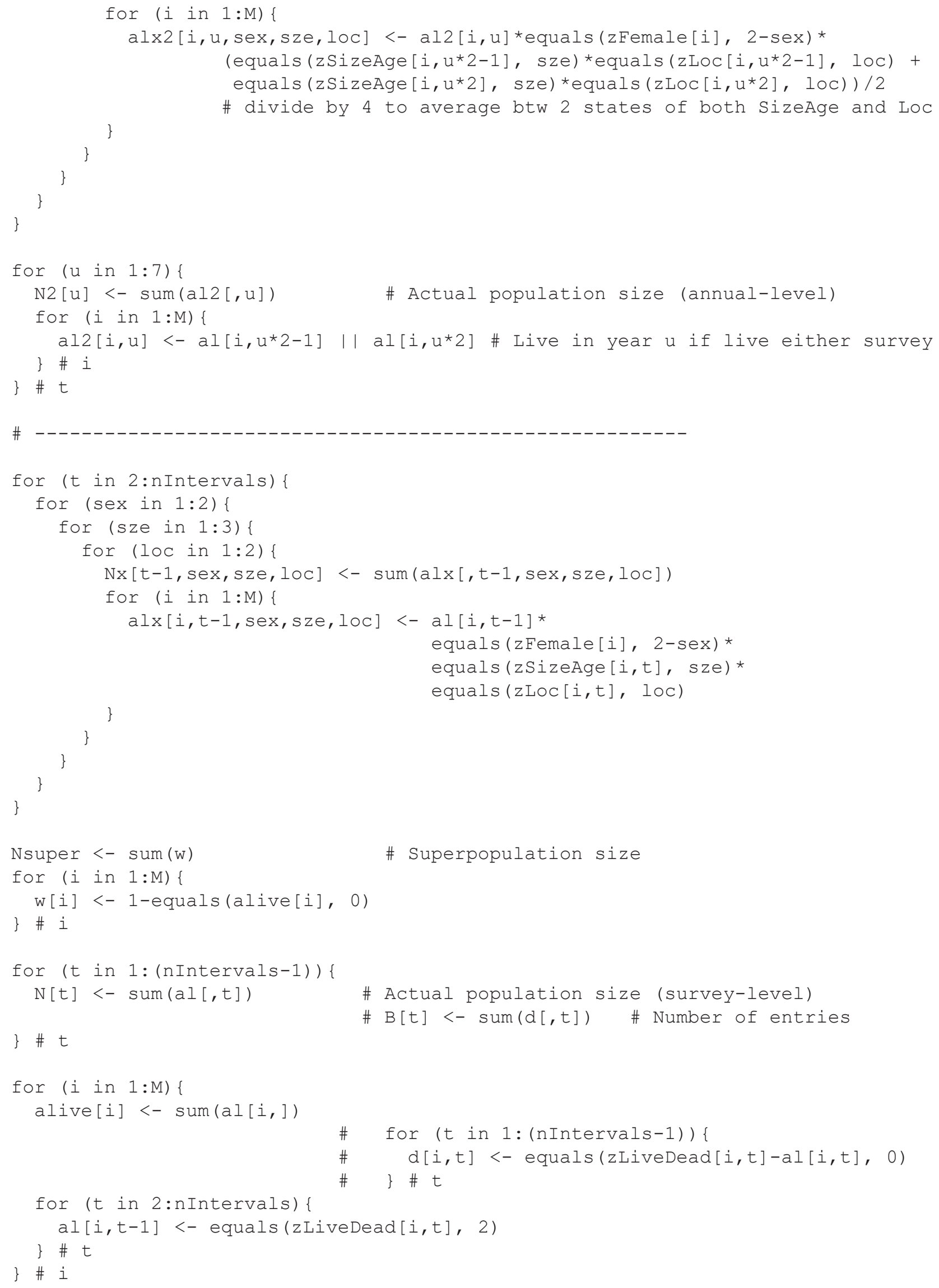




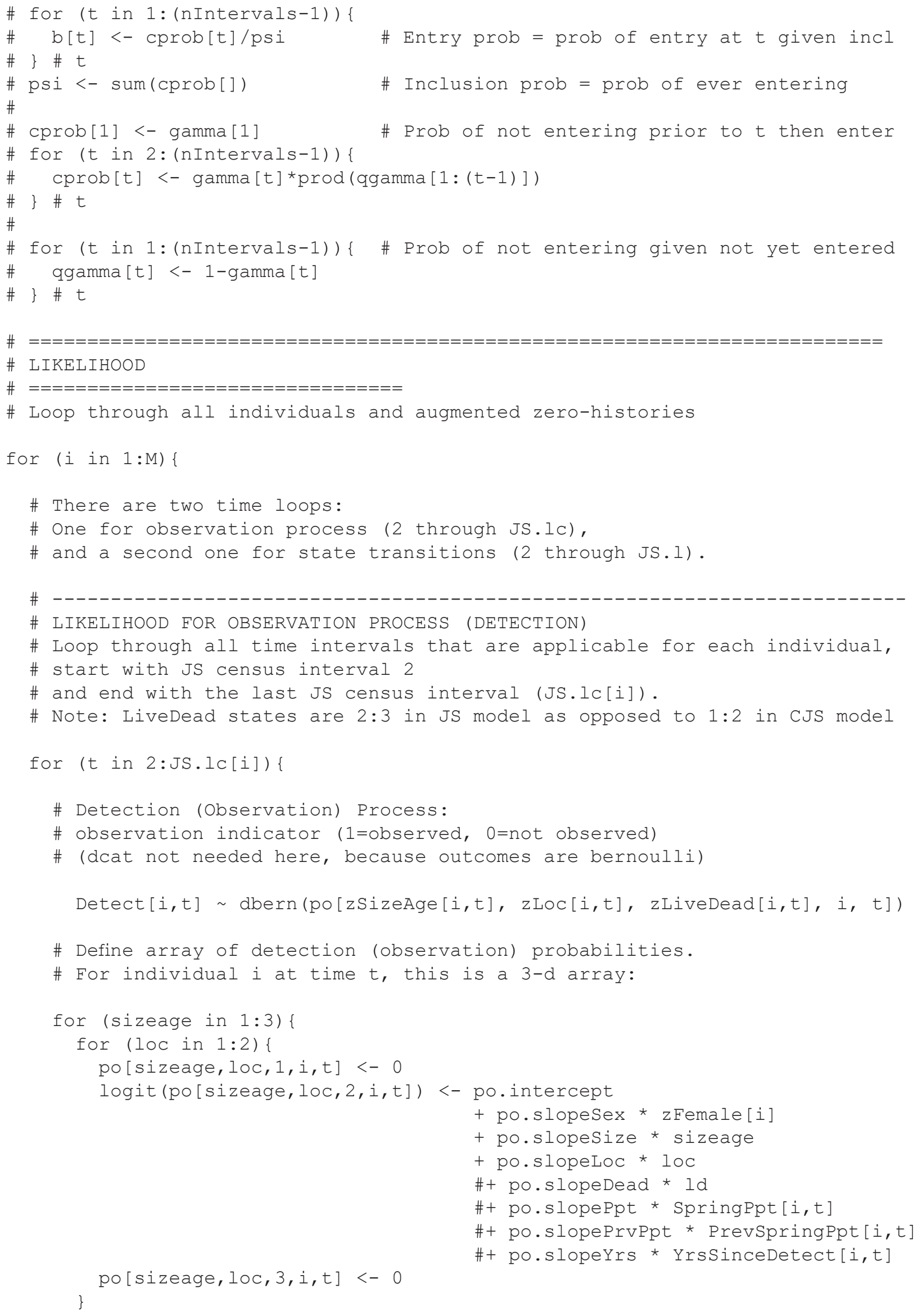




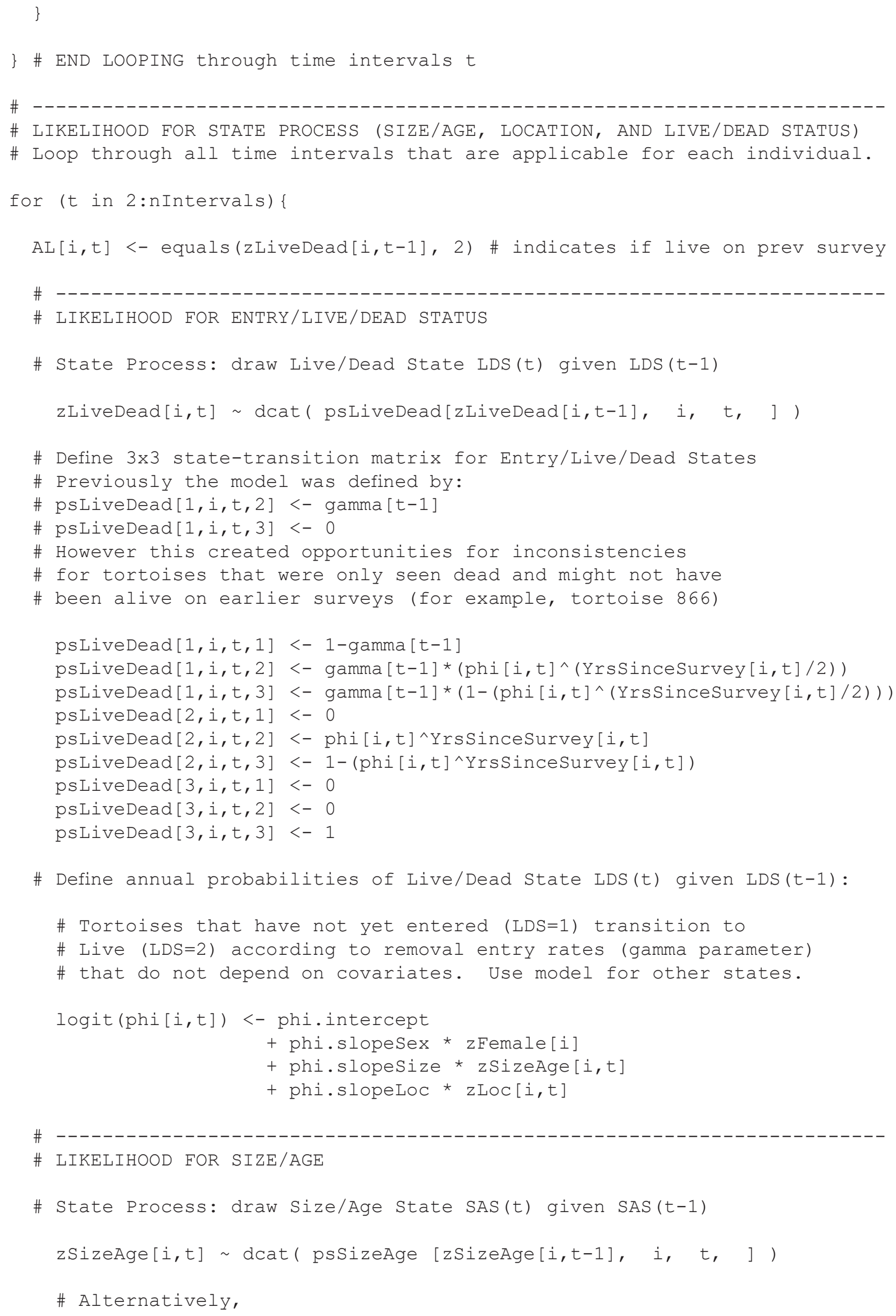




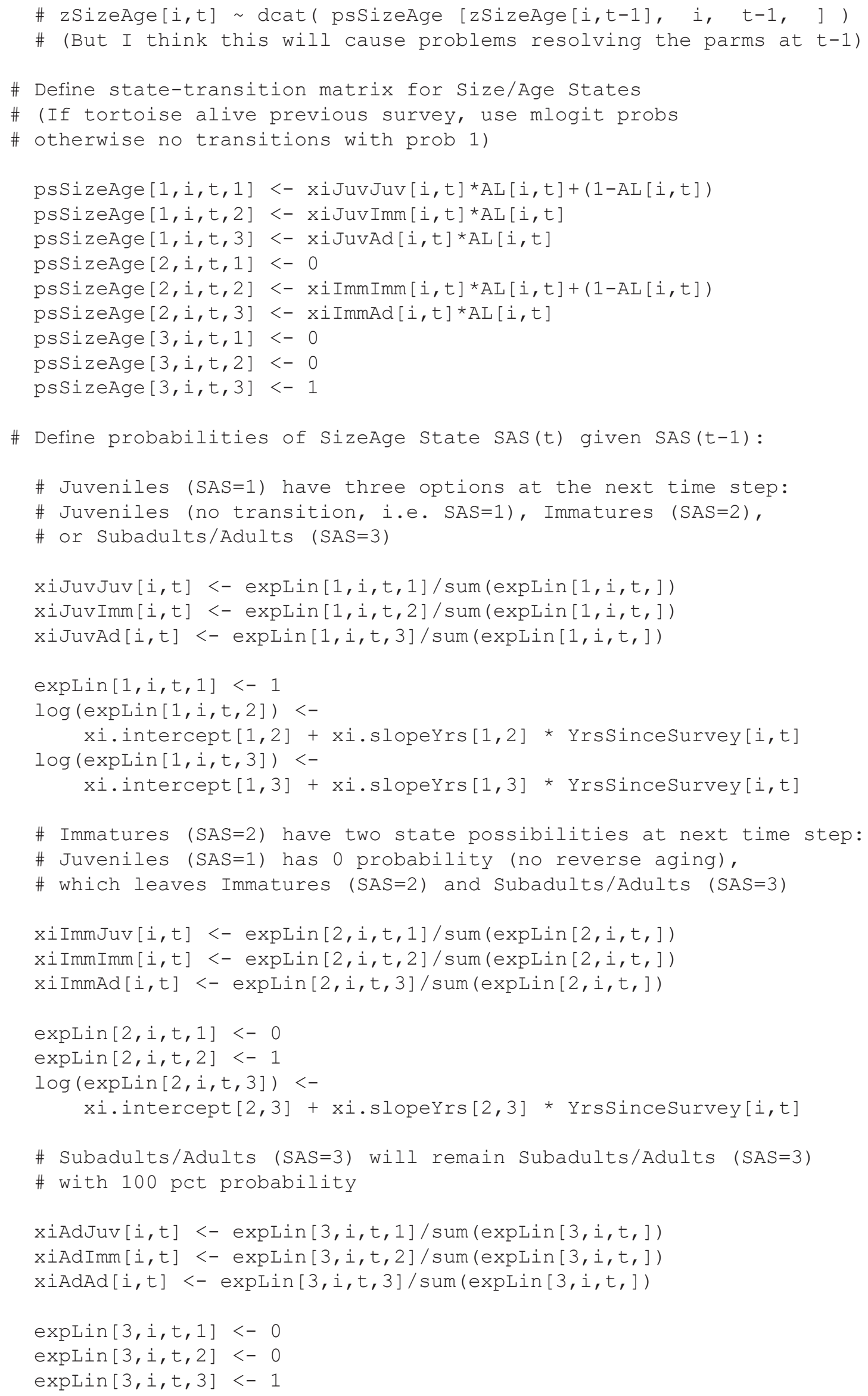




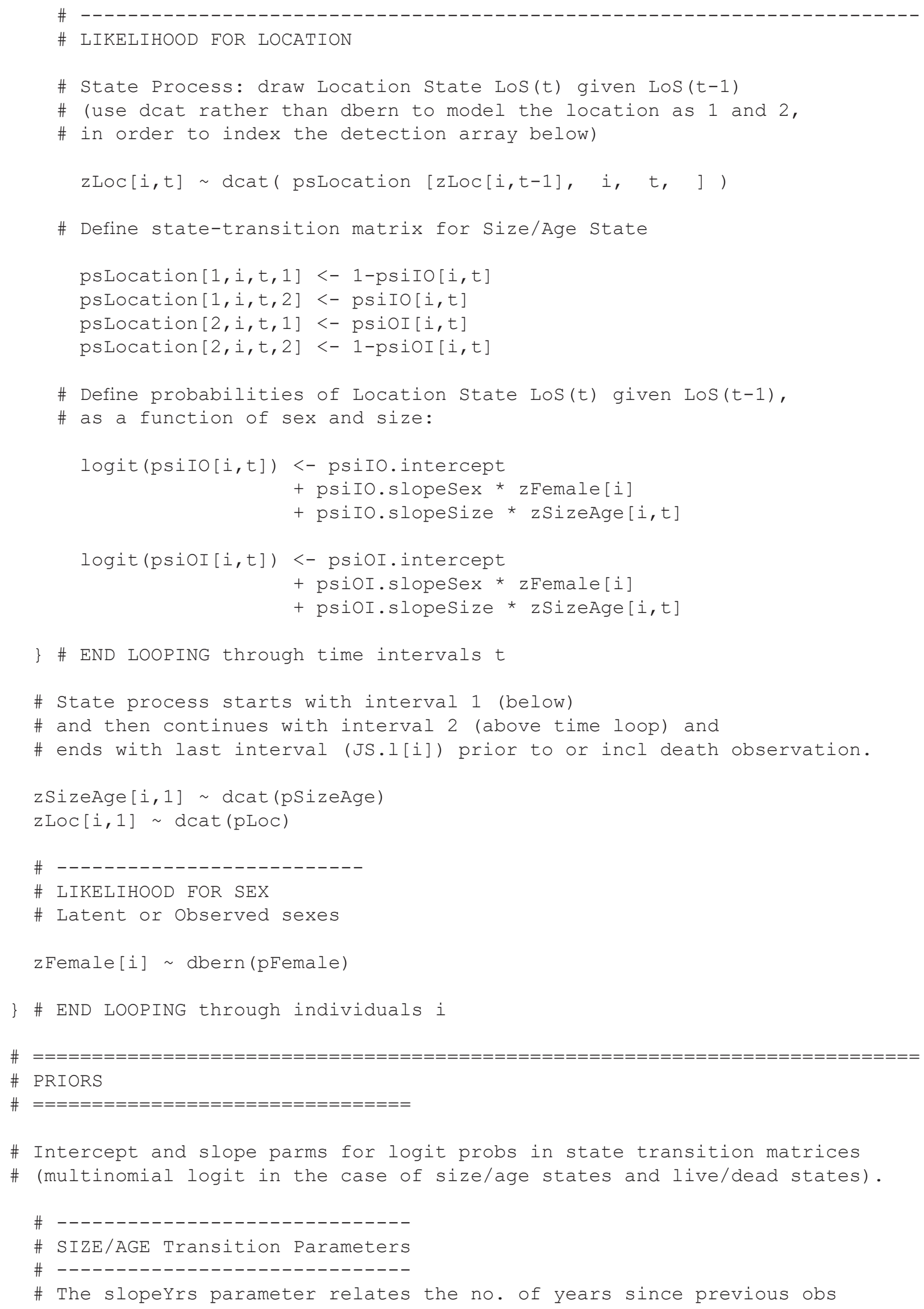


\# (YrsSincesurvey) to xi,

\# the prob that a size/age transition occurs

\# between the previous and current time step.

\# There are 3 size/age groups (3x3 transition matrix).

\# These constraints limit the number of parameters,

\# 1) the unit sum constraint

\# (probabilities of all states at the next time step must sum to 1)

\# 2) larger tortoises cannot transition to a smaller state

\# parameters for the logit probabilities of...

\# ...size/age state process: juvenile->immature

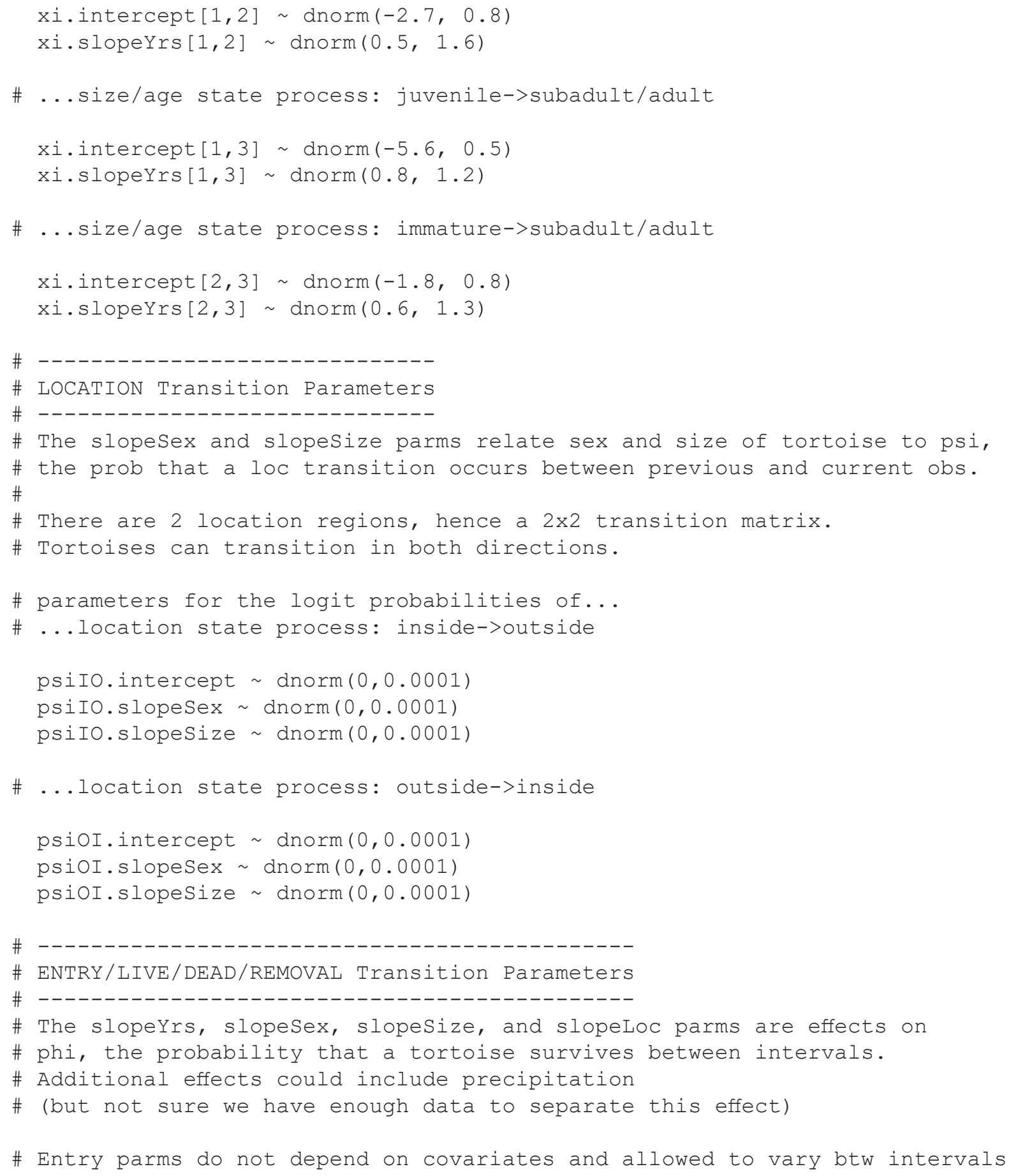




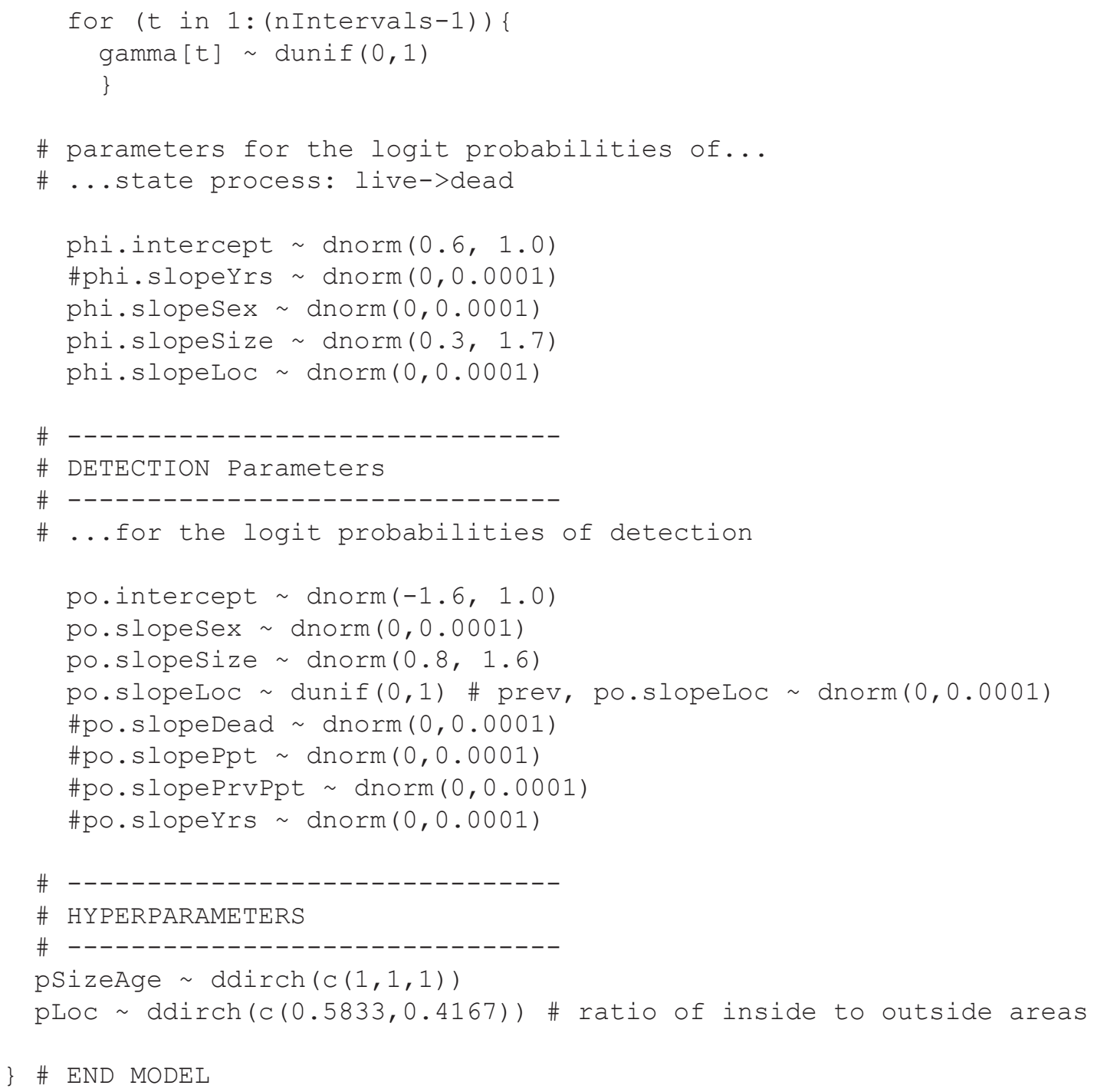



For more information concerning the research in this report, contact the

Director, Western Ecological Research Center

U.S. Geological Survey

3020 State University Drive East

Sacramento, California 95819

https://www.usgs.gov/centers/werc

Publishing support provided by the U.S. Geological Survey

Science Publishing Network, Sacramento and Tacoma Publishing

Service Centers 
